André Lawson Pedral Sampaio

\title{
On the Decision-Hazard Approach for the Stochastic Dual Dynamic Programming Applied to Hydrothermal Operation Planning
}

Dissertation presented to the Programa de Pós-Graduação em Engenharia Elétrica of PUC-Rio in partial fulfillment of the requirements for the degree of Mestre em Engenharia Elétrica

Advisor : Prof. Alexandre Street de Aguiar Co-Advisor: $\quad$ Prof. Davi Michel Valladão 


\section{André Lawson Pedral Sampaio}

\section{On the Decision-Hazard Approach for the Stochastic Dual Dynamic Programming Applied to Hydrothermal Operation Planning}

Dissertation presented to the Programa de Pós-Graduação em Engenharia Elétrica of PUC-Rio in partial fulfillment of the requirements for the degree of Mestre em Engenharia Elétrica. Approved by the undersigned Examination Committee.

Prof. Alexandre Street de Aguiar

Advisor

Departmento de Engenharia Elétrica - PUC-Rio

Prof. Davi Michel Valladão

Co-Advisor

Departmento de Engenharia Industrial - PUC-Rio

Dr. Bernardo Vieira Bezerra

PSR Consultoria

Dr. André Luiz Diniz Souto Lima

CEPEL

Prof. Márcio da Silveira Carvalho

Vice Dean of Graduate Studies

Centro Técnico Científico - PUC-Rio

Rio de Janeiro, December 19th, 2017 
All rights reserved.

\section{André Lawson Pedral Sampaio}

Graduated in Electrical Engineering at Federal University of Rio de Janeiro in 2011. In 2015 he started the master course at Pontifical Catholic University of Rio de Janeiro at the Electrical Engineering Department. During this period, he joined the research group of the Laboratory of Applied Mathematical Programming and Statistics (LAMPS), where he worked as a researcher in the area of hydrothermal power systems operation planning.

Bibliographic data

Sampaio, André Lawson Pedral

On the Decision-Hazard Approach for the Stochastic Dual Dynamic Programming Applied to Hydrothermal Operation Planning / André Lawson Pedral Sampaio; advisor: Alexandre Street de Aguiar; co-advisor: Davi Michel Valladão. — 2017. 76 f: il. color ; $30 \mathrm{~cm}$

Dissertação (mestrado) - Pontifícia Universidade Católica do Rio de Janeiro, Departmento de Engenharia Elétrica, 2017.

Inclui bibliografia.

1. Engenharia Elétrica - Teses. 2. Stochastic Dual Dynamic Programming. 3. Time inconsistency. 4. Hydrothermal Operation Planning. 5. Hazard-decision. 6. Decision-hazard. I. Aguiar, Alexandre Street de. II. Valladão, Davi Michel. III. Pontifícia Universidade Católica do Rio de Janeiro. Departamento de Engenharia Elétrica. IV. Título. 


\section{Acknowledgments}

First of all, I would like to thank my parents for all the support and strength they gave me along this path.

Thank to my advisors Prof. Alexandre Street and Prof. Davi Valladão for all the knowledge and support throughout this work.

Thank to all my colleagues at the Laboratory of Applied Mathematics and Statistics (LAMPS): Alexandre Velloso, Arthur Brigatto, Bruno Fânzeres, Dimas Ramos, Henrique Helfer, Marcelo Ruas, Mario Souto, and Raphael Saavedra. The great atmosphere at the laboratory was essential to handle all the pressure that involves research activities.

Lastly, I would like to thank CNPq for the financial support which allowed this work to be done. 


\section{Abstract}

Sampaio, André Lawson Pedral; Aguiar, Alexandre Street de(Advisor); Valladão, Davi Michel (Co-advisor). On the Decision-Hazard Approach for the Stochastic Dual Dynamic Programming Applied to Hydrothermal Operation Planning. Rio de Janeiro, 2017. 76p. Dissertação de Mestrado - Departmento de Engenharia Elétrica, Pontifícia Universidade Católica do Rio de Janeiro.

Stochastic Dual Dynamic Programming (SDDP) is currently one of the most employed methods for hydrothermal planning. All previous works on this subject are based on a hazard-decision approach, whereas reality is more closely related to a decision-hazard process. This dissonance between planning and implementation is a source of time-inconsistency, as future planned decisions under the same conditions may not be put into practice. If on the one hand the hazard-decision modeling framework allows a scenario-decomposable efficient solution methodology, on the other hand the decision-hazard structure provides a more robust (pessimistic) solution as it does not rely on anticipativity assumptions. In this work, we measure the inconsistency-gap related to the current methodology and propose an alternative approach for hydrothermal planning that utilizes an informationrevelation structure and decision process based on a decision-hazard framework, thereby approximating the planning model to realistic operational actions. Instead of relying on non-anticipativity constraints, which would prevent the scenario decomposition of each two-stage stochastic subproblem, the proposed methodology considers first-stage decisions as state variables to be optimized through the SDDP procedure. In this framework, the complexity and time required to find a solution is considerably reduced yet ensuring the decision-hazard decision structure and non-anticipativity of the first-stage decisions. Results based on the Brazilian power system indicate that this inconsistency may considerably increase generation of more expensive thermal units, leading to spikes in energy market spot prices and an increase in overall operational costs. Therefore, the proposed decision-hazard approach and augmented-state solution methodology constitute timely and relevant contributions to both industry practices and state of the art literature on the subject of hydrothermal operation planning under uncertainty.

\section{Keywords}

Stochastic Dual Dynamic Programming; Time inconsistency; Hydrothermal Operation Planning; Hazard-decision; Decision-hazard. 


\section{Resumo}

Sampaio, André Lawson Pedral; Aguiar, Alexandre Street de; Valladão, Davi Michel. Uma Abordagem Decisão-Acaso para a Programação Dinâmica Dual Estocástica Aplicada ao Planejamento da Operação Hidrotérmica. Rio de Janeiro, 2017. 76p. Dissertação de Mestrado — Departmento de Engenharia Elétrica, Pontifícia Universidade Católica do Rio de Janeiro.

A Programação Dinâmica Dual Estocástica (PDDE) constitui um dos métodos mais utilizados no planejamento hidrotérmico. Trabalhos anteriores neste campo se baseiam numa abordagem tipo acaso-decisão, enquanto a realidade está mais próxima de um processo tipo decisão-acaso. Tal dissonância entre planejamento e implementação gera um problema de inconsistência temporal, pois decisões futuras planejadas podem não ser colocadas em prática sob as mesmas condições. Se por um lado a modelagem acaso-decisão permite uma metodologia de solução cenário-decomponível eficiente, por outro, a estrutura decisão-acaso proporciona uma solução mais robusta (pessimista), já que desconsidera a antecipatividade. Neste trabalho, mensura-se o gap de inconsistência relativo à metodolo-gia atual, assim como se propõe uma abordagem alternativa para o planejamento hidrotérmico que utiliza uma estrutura de revelação de incertezas e um processo decisório tipo decisão-acaso, aproximando o modelo de planejamento da realidade operativa. Ao invés de empregar restrições de nãoantecipatividade, o que impossibilitaria a decomposição por cenário de cada subproblema estocástico de dois estágios, a metodologia proposta considera decisões de primeiro estágio como variáveis de estado a serem otimizadas via PDDE. Assim, reduz-se consideravelmente a complexidade e tempo necessário para se obter uma solução, garantindo ainda a estrutura decisória tipo decisão-acaso e não-antecipatividade das decisões de primeiro estágio. Resultados baseados no SIN indicam que tal inconsistência pode levar a um aumento considerável da geração de termelétricas mais caras, causando maior volatilidade nos preços de curto prazo e aumento no custo total de operação. Desta forma, a solução metodológica proposta, baseada na abordagem decisão-acaso via espaço de estado aumentado, constitui contribuição relevante e oportuna tanto para práticas na indústria quanto para o estado-da-arte da literatura utilizada para o planejamento da operação hidrotérmica sob incerteza.

\section{Palavras-chave}

Programação Dinâmica Dual Estocástica; Inconsistência temporal; Planejamento da operação hidrotérmica; Acaso-decisão; Decisão-acaso. 


\section{Contents}

1. Introduction . . . . . . . . . . . . . . . . . . . 10

1.1 Objective and contributions . . . . . . . . . . . . . . . . . . . 14

1.2 Organization of this work . . . . . . . . . . . . 16

2. The Brazilian Power System . . . . . . . . . . . . . . . . . . . . . . . 17

3. Stochastic Dual Dynamic Programming Applied to Hydrothermal Power System Operation . . . . . . . . . . . . . . . . . . . . . . . . . . . . 22

3.1 Hazard-decision . . . . . . . . . . . . . . . . . 22

3.1.1 Illustrative example . . . . . . . . . . . . . . 27

3.2 Time-inconsistency due to perfect information simplification . . . . 31

3.2 .1 Illustrative example . . . . . . . . . . . . . . 32

4. Proposed Model: Decision-Hazard . . . . . . . . . . . . . . . . . . . 35

4.1 Two-stage decision-hazard approach . . . . . . . . . . . . 35

4.1.1 Illustrative example . . . . . . . . . . . . . . . . 40

4.2 Augmented-state decomposable decision-hazard approach . . . . . 40

5. Case Study . . . . . . . . . . . . . . . . . . . . . . . . . . . . . . . 45

5.1 Policies definition . . . . . . . . . . . . . . . 45

5.2 Time-inconsistency gap and the consistency benefit . . . . . . . 46

5.3 Expected value of one-step ahead information . . . . . . . . . . . 47

5.4 Price of energy . . . . . . . . . . . . . . . . . . . . . . . 48

5.5 Results analysis . . . . . . . . . . . . . . . . . 48

6. Conclusions ......................... . . 61

6.1 Nextsteps . . . . . . . . . . . . . . . . . 62

Bibliography . . . . . . . . . . . . . . . . . . . 64

$\begin{array}{ll}\text { Appendix } & 70\end{array}$

A. Data For Case Studies From Chapter 5 . . . . . . . . . . . . . . . . . 71 


\section{List of Figures}

1.1 Scenario prediction dispersion for the SE subsystem . . . . . . . . 13

2.1 Brazilian transmission system . . . . . . . . . . . 17

2.2 Brazilian power system matrix source . . . . . . . . . . 18

2.3 Energy generation by source - September 2017 . . . . . . . . . . . 18

2.4 Brazilian hydro plants schematic diagram . . . . . . . . . . . . 19

2.5 The operator's dilemma . . . . . . . . . . . . . . . 20

3.1 Hazard-decision decision structure . . . . . . . . . . . . . . 24

3.2 Water inflow scenario tree . . . . . . . . . . . . . 27

3.3 Thermal units dispatch . . . . . . . . . . . . . . 33

4.1 Decision-hazard decision structure . . . . . . . . . . . 36

4.2 Thermal units dispatch . . . . . . . . . . . . . . . . . . . 39

5.1 Thermal dispatch for planning and inconsistent policies . . . . . . 51

5.2 Spot prices for planning and inconsistent policies . . . . . . . . 52

5.3 Spot prices for planning and inconsistent policies (cont.) . . . . . . 53

5.4 Inconsistency gap and consistency benefit . . . . . . . . . . . . . 54

5.5 Thermal dispatch for inconsistent and consistent policies . . . . . . 55

5.6 Spot prices for inconsistent and consistent policies . . . . . . . . 56

5.7 Spot prices for inconsistent and consistent policies (cont.) . . . . . . 57

5.8 Energy storage at the reservoirs . . . . . . . . . . . . 58

5.9 Energy storage at the reservoirs (cont.) . . . . . . . . . . . . 59 


\section{List of Tables}

3.1 Thermal Generators Data . . . . . . . . . . . . . . . 27

3.2 Hydro Generator Data $\left(m^{3}\right) \ldots \ldots . \ldots . \ldots 28$

5.1 Hydro unit data . . . . . . . . . . . . . . . . . . . . . . 49

5.3 Second-stage generator data . . . . . . . . . . . . . . . . . 49

5.2 First-stage generator data . . . . . . . . . . . . . . . 49

5.4 Elapsed time $(\mathrm{sec}) \ldots \ldots \ldots$. . . . . . . . . . 60

A.1 Transmission line data for case studies from Chapter 5 . . . . . 71

A.2 Thermal generators data for case studies from Chapter 5 . . . . 71

A.3 Demand data for case studies from Chapter 5 (MWmonth) . . . . . 74 


\section{1}

\section{Introduction}

A planning process is a set of actions carried out to define the best recourse allocation policy, given certain restrictions and a planning horizon. In the context of the Brazilian hydrothermal power system, operation planning determines thermal units energy dispatch for a given period based on demand prediction, a decision that is made under uncertainty of the water inflow of the period for which it shall be implemented. The objective is to minimize cost of energy based on water inflow scenarios [1], which is made by balancing the available water stored in the hydroelectrical reservoirs and the energy provided by the different power plants that constitute the National Interconnected Power System (NIPS, or SIN in Portuguese). A recent study investigated the impacts on operation costs due to ignoring water inflow scenario uncertainty on hydrothermal power systems [2], a subject that is also examined in the present work.

Optimal planning of real life hydrothermal power systems is a multistage stochastic dynamic programming problem, for which the Stochastic Dual Dynamic Programming (SDDP) solution method is typically employed [3]. Solving this sort of problem is a complex task, given the number of variables to be determined at each stage and the planning horizon. The SDDP algorithm provides a methodology that allows overcoming the so-called curse of dimensionality and permits to treat such problems in a reasonable manner. Since its introduction, it has been subject of many works in order to improve the technique and introduce new features, such as risk aversion, for which Conditional Value-at-Risk (CVaR) [4] has been utilized in a considerable range of applications [5-9], and time dependence of water inflow, by employing a periodic autoregressive model $(\operatorname{PAR}(\mathrm{p}))[1,10,11]$. However, in spite of providing a more precise translation of reality, the incorporation of a $\operatorname{PAR}(\mathrm{p})$ model may increase solution variability, as shown in [12].

Even though the SDDP technique avoided the curse of dimensionality, operation of hydrothermal power systems are still highly complex, and relaxation of the real problem is commonly employed in long/medium-term studies. Many of the system constraints ignored during the first phase are then taken into account when optimizing for the short-term dispatch. In Brazil, some of the introduced restrictions are the representation of electrical network transmission losses [13], modeling of hydro generation plants as a function of turbined outflow, spillage and head in the reser- 
voir [14], $n-k$ security criteria [15, 16], individual reservoir representation [17], renewable resources intermittent generation, and demand uncertainty [18]. Centralized hydrothermal energy dispatch models have also been studied with great attention. Some of these studies include limitations on the gas network [19], $\mathrm{CO}_{2}$ emission constraints [20], river level and routing restrictions [17], and transmission constraints with non-linear formulation [21]. In general, apart from the main subject referred in each of the mentioned works, other important aspects of the problem are usually disregarded, consequently it is difficult to find a work that properly addresses all of them.

Another sort of relaxation employed is related to the information revelation process. Within the SDDP technique, due to computational and conceptual reasons, the information revelation process utilizes a hazard-decision structure, i.e., thermal generation decisions are determined assuming perfect knowledge of the water inflow over the current period. This approximation process induces time-inconsistent decisions [22-24], which results in a hidden overcost, not foreseen neither by the planner or operator, the so-called inconsistency-gap, as proposed in [22] and detailed in [25]. The reason for this overcost may be easily seen from Jensen's inequality, as we consider the convexity of the cost function.

Differently from the planning process, actual decisions are made in real time all along the period, by observing water inflow and reviewing the planned actions based on the new set of information revealed over time. Since water inflow presents low variance on an hourly basis, it is a reasonable approximation to assume that the decision process is made under perfect information. Although, even on operation planning implementation for the shortest term possible, the day ahead operation, energy dispatch of thermal units is still a first-stage decision, obtained based on unit commitment models. Hydro generation, for its turn, is a recourse decision in the short-term schedule, determined in order to correctly respond to energy demand. Therefore, for systems highly dependent on hydro reservoirs, all deviation of the original plan due to error on scenario assumption is usually compensated by the hydro units. These deviations are of a different nature from automatic generation control (AGC), since it is originated on a prediction error of water inflow, while AGC constitutes a spinning reserve and is properly allocated during operation planning to ensure system's reliability within the considered scenario.

The necessity of addressing the energy dispatch problem within an hourly basis in Brazil has been under discussion for many years, with a first version of the 
DESSEM software presented as early as 2002 [26]. In practice, however, up to the present time such model has not yet been incorporated to the operation planning procedure. An overview of the current process is provided in Chapter 2.

Due to computational reasons, on the planning process, calculated for a medium/long term horizon, energy dispatch of hydro and thermal units is determined on a monthly or weekly basis, based on an approximation of the short-term process. From the perspective above, as we extend the time step, water inflow variability increases as well. Assuming that the information will be known beforehand within a weekly or monthly time frame is the same to say that it is possible to correctly predict water inflow in a given period, which is a very optimistic view of the process. It is much more realistic, however, to acknowledge our limitation on that matter and to emulate a daily process than placing the decision after the scenario is revealed, modifying the real scenario-revelation structure. In other words, it is more accurate to determine the monthly dispatch based on a typical day or typical week than to assume perfect information of water inflow. Since for the shortterm model baseload suppliers are considered first-stage decisions, while hydro and fast-response units are considered second-stage, when approximating the monthly dispatch to the average decision, it is better to proceed in the same fashion. This effect grows in importance with the adoption of renewable sources, as it augments uncertainty on the short-term and increases the difficulty on determining first-stage decisions for daily operation, which demands its correct representation in terms of costs and viability within the long-term operation planning.

Deviations between planned decisions and the actual hydro generation, after the information has been revealed, are directly related to water inflow variability. Therefore, for cases that present low variability, a hazard-decision approach may be considered a good proxy of the process. But what is the magnitude of the error related to scenario uncertainty within the planning process?

In order to exemplify it, we take the monthly water inflow observed from 1991 to 2015 for the SE subsystem of the NIPS. Figure 1.1 illustrates the scenario prediction dispersion based on water inflow of December 2014 and an autoregressive of order 1, as utilized in this work. The expected value of water inflow based on this sample is $60.9 \mathrm{GWmonth}$, with a standard deviation equal to $14.8 \mathrm{GWmonth}$, which gives a coefficient of variation $\left(c_{v}\right)$ of $24 \%$. To put in perspective, the energy demand in the SE subsystem in January 2015 was 41.4 GWmonth ( [27]) and the stored water at the end of the month was equal to $34.6 \mathrm{GWmonth}$ ( [28]). Hence, the 


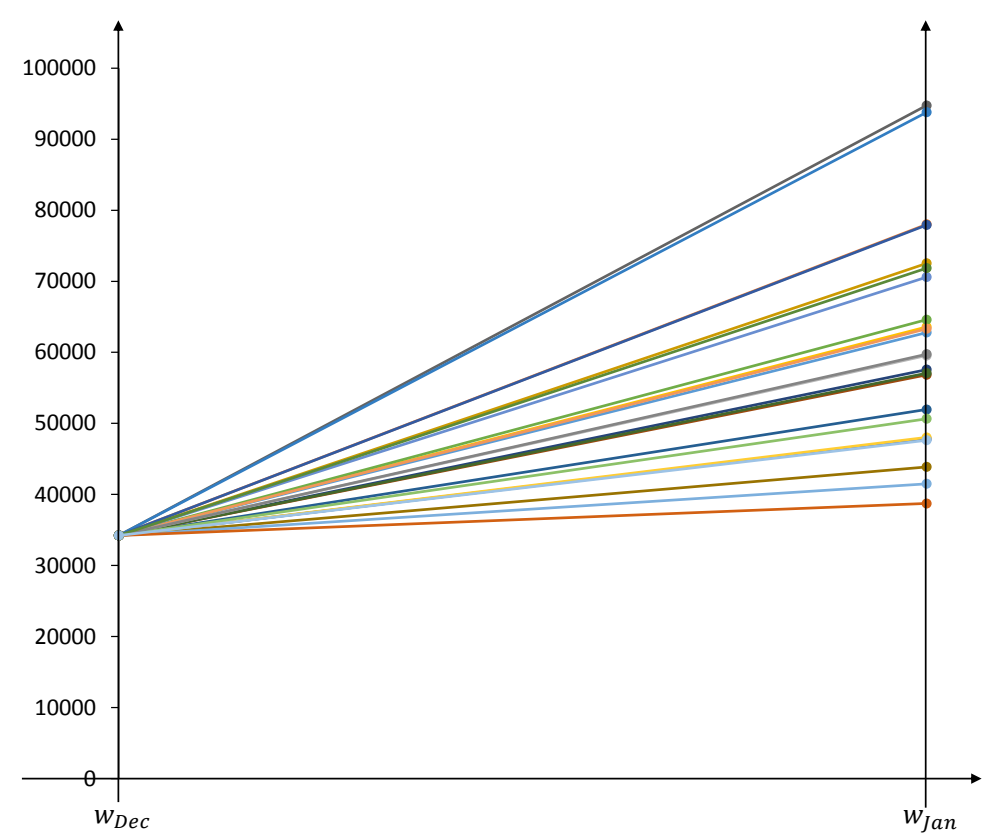

Fig. 1.1: Scenario prediction dispersion for the SE subsystem

standard deviation accounts for $36 \%$ of the demand and $43 \%$ of the observed stored water at that time, as shown by equations (1-1)-(1-3). Within the hazard-decision approach, since perfect scenario information is adopted, decisions are determined ignoring this uncertainty.

$$
\begin{aligned}
c_{v}(t \mid t-1)=\frac{\sigma\left(w_{t} \mid w_{t-1}\right)}{E\left(w_{t} \mid w_{t-1}\right)} & =24 \% \\
\frac{\sigma\left(w_{t} \mid w_{t-1}\right)}{\text { Demand }_{t}} & =36 \% \\
\frac{\sigma\left(w_{t} \mid w_{t-1}\right)}{\text { Vlume }_{t}} & =43 \%
\end{aligned}
$$

In most of the cases, real life operation of a hydrothermal system does not allow a wait-and-see methodology. Due to energetic restrictions (given either by technical or economic reasons), many of the thermal plants require a considerable amount of time to be available for energy supply. Nuclear and coal-fired plants, for instance, may take several days to start up and shut down, being considered baseload suppliers. Also, in spite of being peaking power plants due to their fast response to demand, because of contractual reasons many of the gas-fired units must be informed of their energy dispatch in advance, so as to purchase the required 
amount of fuel for a given operation. In Brazil, for instance, liquified natural gas (LNG) fired units must be notified of their planned dispatch 60 days prior to the operation. In order to more accurately reflect the implementation procedure, in the planning process, we argue that energy dispatch of such units should be considered first-stage decisions, leaving hydro generation and other thermal units as recourse decisions.

For the study presented on Chapter 5, three different policies were established. The first one represents the standard solution for hydrothermal systems operation and utilizes a hazard-decision model (planning policy). For the second one (inconsistent policy), first-stage decisions are determined based on the expected water inflow, the same methodology utilized in [2]. The remaining policy (consistent policy) is obtained following a decision-hazard structure [29,30], for which the employed methodology is the same utilized to determine the dispatch of LNG fueled units in Brazil [31].

Another topic under ongoing discussion is related to the algorithm convergence. Analysis on the subject were made in [32-35] and many stopping criteria have been explored since then ( $[12,36])$, but consent is far from being reached. In this work the convergence criteria adopted follows the methodology utilized in [25] and [37], which considers stabilization of lower and upper bounds.

\subsection{Objective and contributions}

The objective of this work is to propose a model for the hydrothermal operation planning that utilizes an information-revelation structure and decision process based on a decision-hazard framework, thereby approximating the planning model to more realistic operational actions. From this perspective, our main contributions are:

1. Bring to attention the time-inconsistency problem related to the informationrevelation structure simplification of the decision process utilized on hydrothermal planning models. Currently, the SDDP technique utilizes a hazard-decision structure, which is an optimistic view of a decision process. In this case, decisions taken during a given period assume perfect information of the uncertainty factors (water inflow), i.e., decisions are determined for each scenario. In this work we argue that the real decision process involves first-stage decisions (under uncertainty of the water inflow scenario of 
the current period) and recourse second-stage decisions (under perfect information). First-stage decisions are the energy dispatch of gas and baseload thermal plants (coal and nuclear), whereas second-stage are the remaining thermal plants and hydro generators. The importance of satisfactory representation of uncertainties during the planning phase augments as the installed capacity of renewable sources and distributed generation increases.

2. Estimate the impact of this source of inconsistency between planning and operation based on the time-inconsistency GAP, energy market spot prices and thermal units generation. As we demonstrate, one of the collateral effects of using a hazard-decision approximation during the planning phase is an increase on the energy dispatch of more expensive thermal units, along with spikes in energy market spot prices and an increase in overall operational costs.

To fulfill the objectives above, in this work we utilize a multistage model that incorporates the decision-hazard decision process for each stage. The mathematical model currently employed considers that, at each period, decisions may be determined for each scenario, therefore, the optimization problem of each stage, which computes the expected value of the operation from that stage onward, is scenariodecomposable. This approach does not consider the decision-hazard alternative. The implemented model, instead, incorporates the non-anticipativity restriction associated with first-stage decision variables, coupling the problems related to each scenario of the current period. Thus, the operation subproblem based on a decisionhazard framework is a two-stage stochastic model.

Direct application of a decision-hazard SDDP model equipped with nonanticipativity constraints is challenging, since it demands the solution of a two-stage model under uncertainty for each scenario and stage. The methodology utilized in this work conditions the SDDP operation subproblem to the firs-stage decisions. This is achieved by incorporating first-stage decisions to the state of the system, turning the model into a non-anticipative and scenario-decomposable problem. Our approach is based on a similar reformulation idea used on LNG pre-dispatch during the short-term operation planning in Brazil, briefly explained in Chapter 2. Within this framework, first-stage decisions are determined in the previous stage and transmitted to the subsequent problem through state parameters. Therefore, by augmenting the state, this technique aims to provide a hazard-decision solution methodology to a decision-hazard problem. 


\subsection{Organization of this work}

The remainder of this work is organized as follows. Chapter 2 presents the Brazilian power system and contextualizes the present work. In Chapter 3, a comparison is drawn between the hazard-decision and decision-hazard approaches to hydrothermal operation planning and their implications to the SDDP algorithm, bringing to attention the time-inconsistency GAP due to ignoring non-anticipativity constraints. Chapter 4 presents the proposed decision-hazard framework and the augmented-state solution methodology. In Chapter 5, a case study based on the Brazilian power system is presented and the results analyzed. Chapter 6 concludes this work with its final statements and potential future works. 


\section{2}

\section{The Brazilian Power System}

The Brazilian National Integrated Power System (NIPS) is one of the world's largest power systems both in generation installed capacity and transmission lines extension. The NIPS comprises most part of the national territory, with the exception of a few isolated regions in the Amazon area. Country regions are divided into four subsystems, namely Southeast/Center-West (SE/CO), South (S), Northeast $(\mathrm{NE})$, and North $(\mathrm{N})$, and energy prices may vary between them due to electrical restrictions. Long extension of transmission lines connect the subsystems, allowing energy exchange between all regions and granting the possibility to explore their complimentary water inflow. By 2016, the total extension of transmission lines in the country was $134.765 \mathrm{~km}$, with a prediction to reach $154.748 \mathrm{~km}$ in 2021 ( [38]). Figure 2.1 [39] shows the transmission lines map as in 2017.

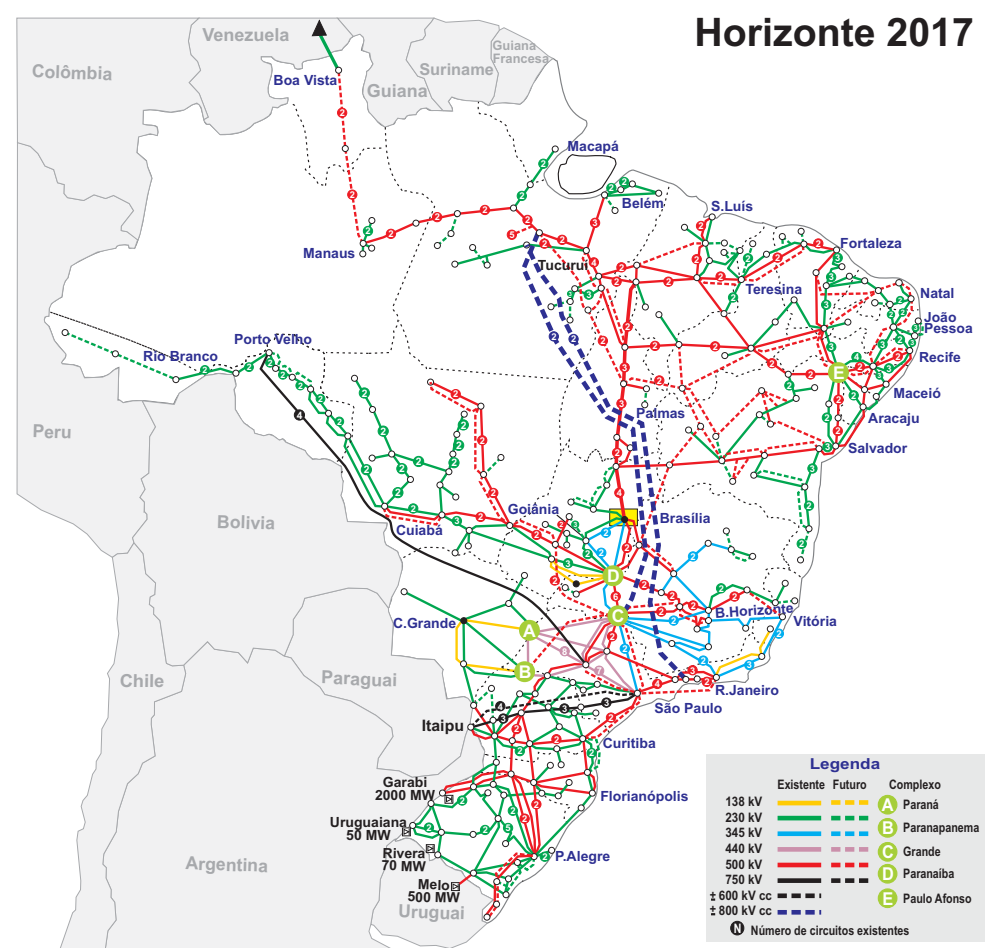

Fig. 2.1: Brazilian transmission system

Hydroelectric power plants constitute the major source of energy, with a total installed capacity of $101.6 \mathrm{GW}$ in 2016 , which corresponds to $72 \%$ of the country's total. Other power sources, such as gas fired thermal plants, usually located 


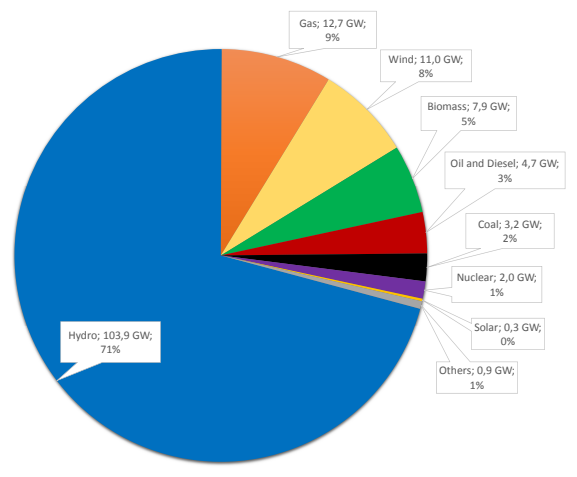

(a) Year 2016

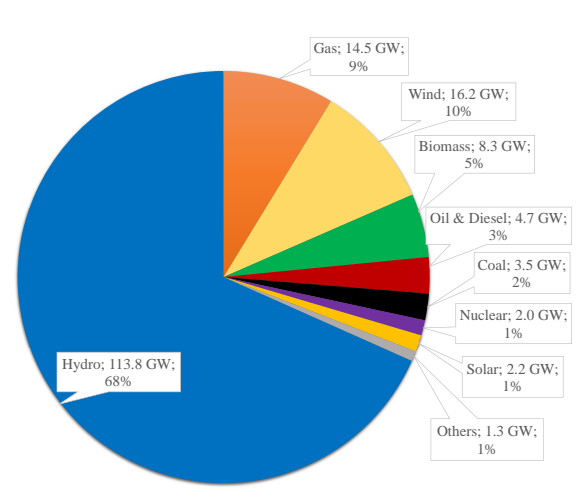

(b) Year 2021

Fig. 2.2: Brazilian power system matrix source

closer to major load centers, play an important role on electrical energy generation to fulfill national demand. More recently, the country experienced an expansion of renewable energy, particularly wind power, and expects to see this contribution increase in the upcoming years. Figure $2.2[38,40]$ depicts the Brazilian energy matrix source by installed capacity in September 2017 and the scheduled evolution for 2021. In spite of its proportional reduction, by 2021 hydroelectric power is expected to answer for $68 \%$ of total system's capacity.

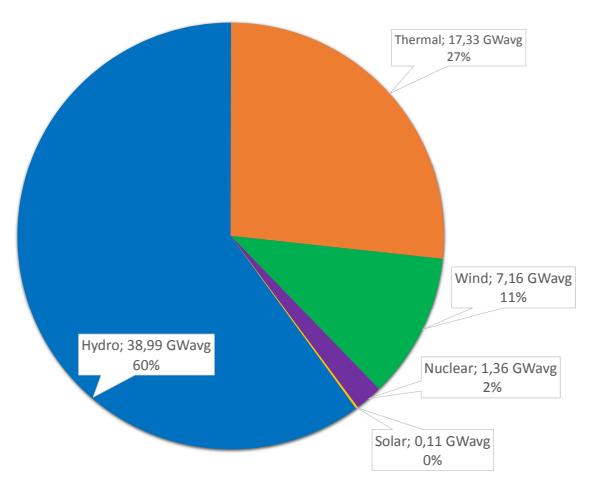

Fig. 2.3: Energy generation by source - September 2017

As expected, energy generation by source does not correspond to their equivalent installed capacity. Figure 2.3 [41] illustrates the observed generation distribution in September 2017 as an example. It is easily seen that wind generation responds to an energy share superior to its proportional installed capacity. However, if we take a closer look and analyze the NE subsystem, where most of the 


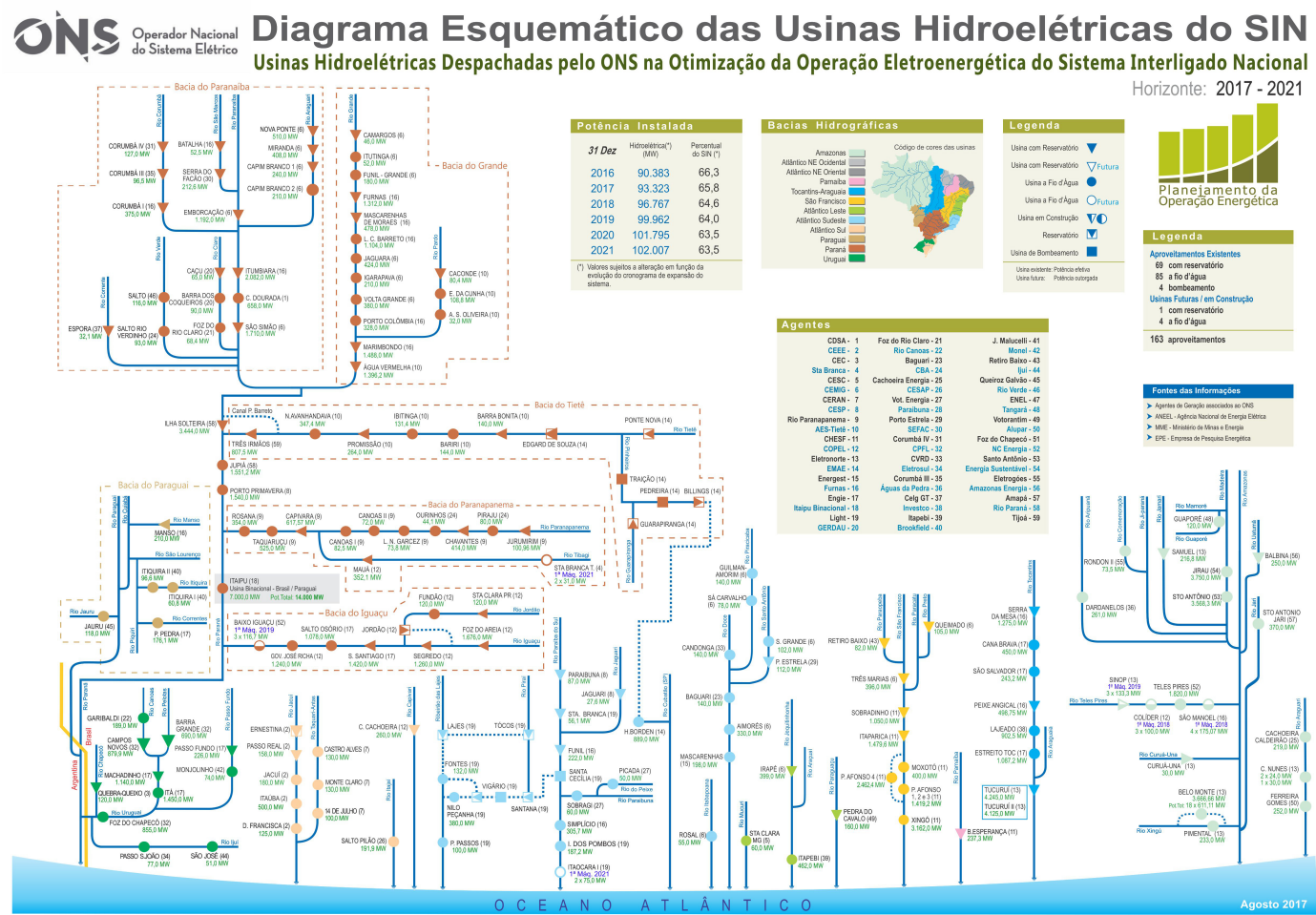

Fig. 2.4: Brazilian hydro plants schematic diagram

wind generators are installed, we notice that this particular source responded to approximately $55 \%$ of the total generation of the subsystem.

Hydroelectric plants are distributed in sixteen hydro basins throughout the country and classified according to their reservoir capacity, which may range from run-of-river plants to the $54.4 \mathrm{~km}^{3}$ Serra da Mesa reservoir. Many of these plants are in a cascade configuration, resulting in a highly complex topology, as shown in Figure 2.4 [42].

Operation of the power system is determined by an ISO, the National System Operator (ONS), based on results obtained from different softwares developed by the Electric Power Research Center (CEPEL). With a view to guarantee that the required energy to meet demand is provided at minimum cost, ensuring operation security and system's reliability, the ISO is responsible for managing the available energy sources. Operation management is separated into two main stages: planning and implementation, for which the former is also divided into long/medium-term and short-term planning [43].

At all stages of this process, the ISO faces a similar question: should it use the stored water in the reservoir for energy generation now or save it for the future? 


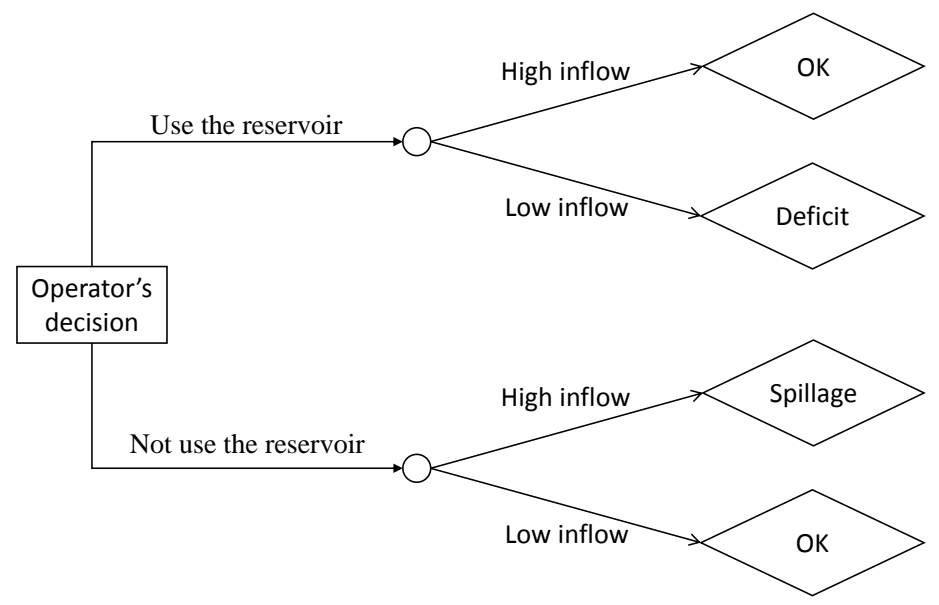

Fig. 2.5: The operator's dilemma

Since the impact of such decision for the system, taken in the present, will only be known in the future, answering that question may become quite a challenge. This is the so-called operator's dilemma, illustrated at Figure 2.5. In real life applications, one must also consider that water inflow at each period is subjected to high uncertainty, making the problem even more complex. In order to come up with an answer to that question, the ISO relies on computational models that optimizes the decision at each stage of the problem, and the methodology adopted is the Stochastic Dual Dynamic Program (SDDP), which belongs to the Sampling Based Benders Decomposition Algorithms class and will be discussed in Chapter 3.

The first stage of the operation process in Brazil is the long- to medium-term planning. At this stage, the implemented model aims to solve the hydrothermal generation problem at minimum risk-adjusted cost for a 5 to 10 years horizon with monthly discretization, which is done by executing the NEWAVE software. Since problem complexity is determined by the number of periods and uncertainty scenarios considered, in order to keep it computationally tractable, many of the system details are approximated or neglected at this point, as they may be reviewed later. This approximations include aggregating the storage capacity into four equivalent water reservoirs $[44,45]$, each of which located in one of the subsystems. At the end of this step, the ISO is provided with the expected cost of the operation and a chain of linear programming models indexed to the period. All along the process, inflow scenarios are obtained considering a periodic autoregressive model (PAR(p)) [10,11], 
in order to incorporate intertemporal effects.

Next, this chain of linear programming models is coupled into a more detailed model to determine short-term planning. This stage is done by means of the DECOMP software, for which the considered horizon is reduced to 12 months, with weekly discretization for the first month and monthly discretization for the remaining period. Reducing the horizon, as it also reduces problem complexity, allows the implementation of a more realistic configuration, with the incorporation of restrictions neglected at first, including individual representation of hydro plants and reservoirs. At this stage, due to contractual reasons, thermal generation for liquified natural gas (LNG) fueled units are determined in anticipation of scenario revelation and informed of their energy dispatch 60 days in advance.

Currently, this is the final stage before real-time operation. Beginning in January 2019, with the adoption of hourly prices, daily schedule will be determined by the DESSEM software. As before, other restrictions are incorporated to the problem at this stage, such as Kirchhoff's Second Law (for DC circuits) and ramp generation limits for the different units of the NIPS, while unit commitment, electrical network losses, among other restrictions, are yet under validation.

Throughout the whole procedure to determine the hydrothermal dispatch, as presented above, several simplifications are adopted. Many of them may be perfectly justified at early stages, the question is whether they lead to time-inconsistent decisions or not, and what is the impact to the system due to ignoring certain restrictions. As mentioned in Chapter 1, scenario anticipation provides a substantial gain on computational performance and it has been used for hydrothermal operations since the introduction of SDDP, however, energy dispatch is determined based on an optimistic view of reality, which may lead to an inconsistency GAP. In the next chapters, the impact related to the scenario anticipation methodology considered in the Brazilian power system is investigated, and an alternative approach is proposed in order to better address it. 


\section{Stochastic Dual Dynamic Programming Ap- plied to Hydrothermal Power System Opera- tion}

Stochastic Dual Dynamic Program (SDDP) currently represents the stateof-the-art solution method regarding multistage linear stochastic problems, and is widely employed in planning studies of hydrothermal power systems, along with many other applications. Based on the assessment of the recourse function, the methodology consists of successively approximating from below the expected costto-go function to a piecewise linear function until attaining the convergence criterion. By sampling the set of possible scenarios $\Omega_{t}$ at each period $t$, a series of forward-backward iterations are executed in order to build the approximated function. In the forward step, the function is evaluated and trial states are determined. Next, based on the newly obtained system state of each period $t$, the backward step is performed to establish a Benders cut and include it to the set of cuts of the model related to $t-1$.

The ultimate goal of the algorithm is to obtain the expected value of the total operational cost. At the end of this iteration process, its lower bound is obtained, along with a chain of linear programming models indexed to the period $t$ that determines the energy policy for the complete horizon $T$. To estimate its upper bound a Monte Carlo simulation is carried out, by means of the forward step of the algorithm.

This work does not intend to investigate the aspects of SDDP convergence, being more focused on the premises of energy planning policies. For analysis on the subject we refer to [32-34]. Likewise, more detailed discussions of the SDDP algorithm may be found in $[5,35]$.

\subsection{Hazard-decision}

As mentioned in Chapter 1, medium/long-term operation planning of countries relying on ISOs is usually implemented based on a hazard-decision framework $[3,5,12,35,36]$, i.e. operative decisions are made under perfect information of 
the occurred water inflow scenario. The main objective of the hydrothermal planning is to minimize the total expected cost of system operation for the given horizon, and the problem to be optimized is given by (3-1)-(3-5).

$$
\mathcal{Q}_{t}\left(v_{t-1}\right)=\frac{\min }{\left\{\begin{array}{c}
g_{t, \omega}, u_{t, \omega}, v_{t, \omega}, \\
s_{t, \omega}, f_{t, \omega}, \theta_{t, \omega}
\end{array}\right\}_{\omega \in \Omega_{t}} p_{\omega}\left[c_{t}^{\mathrm{T}} g_{t, \omega}+\mathcal{Q}_{t+1}\left(v_{t, \omega}\right)\right]}
$$

subject to

$$
\begin{aligned}
& A f_{t, \omega}+B g_{t, \omega}+P u_{t, \omega}=D_{t} \\
& v_{t, \omega}=v_{t-1}-H\left(u_{t, \omega}+s_{t, \omega}\right)+w_{t, \omega} \\
& f_{t, \omega}=S \theta_{t, \omega} \\
& \left(g_{t, \omega}, u_{t, \omega}, v_{t, \omega}, s_{t, \omega}, f_{t, \omega}, \theta_{t, \omega}\right) \in \mathcal{X}_{t}
\end{aligned}
$$

For each stage $t$ in $T$ and scenario $\omega$ in $\Omega_{t}$, the decision vector is comprised of thermal generation, $g_{t, \omega}$; hydro generation, $u_{t, \omega}$; water storage level at the end of the stage, $v_{t, \omega}$; water spillage, $s_{t, \omega}$; power flow in transmission lines, $f_{t, \omega}$; and bus angle, $\theta_{t, \omega}$. Demand at each period $t$ is represented by $D_{t}$ and water inflow by $w_{t, \omega}$. Additionally, the expected future cost after the end of the considered horizon, $\mathcal{Q}_{T+1}(\cdot)$ is fixed and equal to zero. For the sake of simplicity, we define $y_{t, \omega}$ as the vector that encompasses the aforementioned decision variables, i.e.,

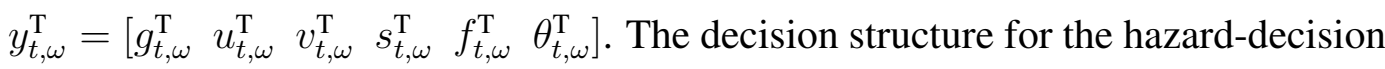
approach is depicted in Figure 3.1.

In the objective function (3-1), $c_{t}$ is the thermal generation row-cost vector. Nodal power imbalance constraints are translated by equation (3-2), in which $A$ represents the network incidence matrix, $B$ accounts for the thermal generators bus location matrix, and $P$ for the bus location matrix for hydro generators, also taking into account the average productivity transformation from water to energy. Expression (3-3) guarantees water balance between stages, where $H$ (consisted of $+1,0$, -1 elements) translates the system topology regarding hydro generators. Kircchoff's second law is taken into account through expression (3-4), in which the product of (transposed) incidence matrices and susceptance is represented by matrix $S$. Constraint (3-5) imposes lower and upper limits of the decision variables to form the feasible set $\mathcal{X}_{t}$.

Within the hazard-decision approach, decisions are determined individually 


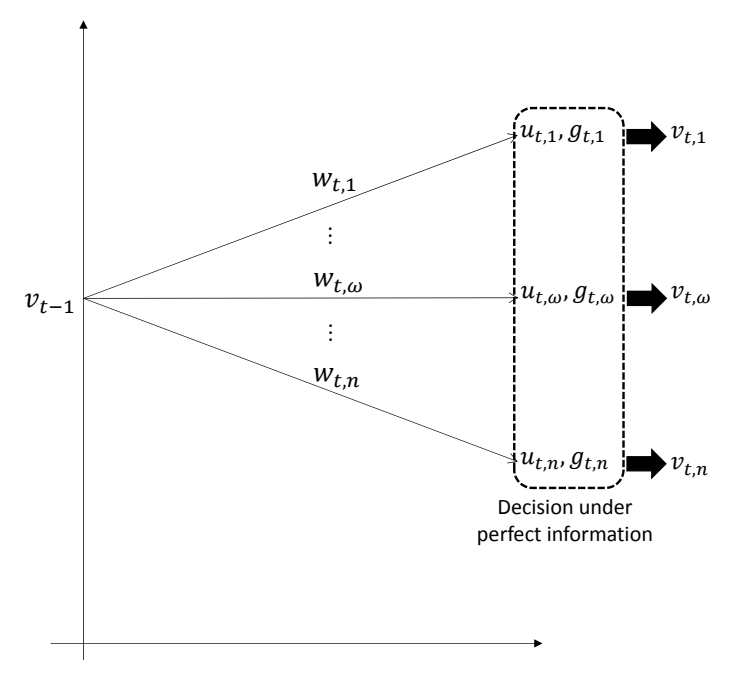

Fig. 3.1: Hazard-decision decision structure

upon the observed scenario, thereby allowing the objective function to be rewritten as follows.

$$
\begin{aligned}
& \mathcal{Q}_{t}\left(v_{t-1}\right)=\sum_{\omega \in \Omega_{t}} p_{\omega}\left[\min _{y_{t, \omega}} c_{t}^{\mathrm{T}} g_{t, \omega}+\mathcal{Q}_{t+1}\left(v_{t, \omega}\right)\right] \\
& \mathcal{Q}_{t}\left(v_{t-1}\right)=\sum_{\omega \in \Omega_{t}} p_{\omega}\left[Q_{t}\left(v_{t-1}, w_{t, \omega}\right)\right]
\end{aligned}
$$

Based on equation (3-7), we conclude that, within a hazard-decision framework, for a given initial state $v_{t-1}$ it is possible to solve the problem individually for each water inflow scenario subproblem $Q_{t}\left(v_{t-1}, w_{t, \omega}\right)$ and then compute the expected value.

Having defined the problem to be solved, we must now determine the future cost function approximation methodology. The SDDP technique consists of iteratively constructing an inferior approximation, which is made by employing Benders cuts obtained at trial points. Hence, $\mathcal{Q}_{t+1}\left(v_{t, \omega}\right)$ is replaced in the objective function for the auxiliary variable $\alpha_{t+1}$, which at iteration $m$ is defined by the following set of constraints:

$$
\alpha_{t+1} \geq \tilde{\mathcal{Q}}_{t+1}^{(k)}\left(v_{t}^{(k)}\right)+\tilde{\pi}_{t+1}^{(k)}{ }^{\mathrm{T}}\left(v_{t, \omega}-v_{t}^{(k)}\right) \quad \forall k \leq m
$$


Where $v_{t}^{(k)}$ is the final volume trial state at period $t$ iteration $k, \tilde{\mathcal{Q}}_{t+1}^{(k)}(\cdot)$ is the inferior approximation of the expected minimum cost function at period $t+1$ after $k$ iterations, and $\tilde{\pi}_{t+1}^{(k)}$ translates the expected value of the dual variable $\pi$ of constraint (3-3) at $t+1$, iteration $k$. Thus,

$$
\tilde{\pi}_{t+1}^{(k)}=\sum_{\omega \in \Omega_{t+1}} p_{\omega} \pi_{t+1, \omega}^{(k)}
$$

And the hazard-decision linear program becomes:

$$
\begin{aligned}
& \tilde{Q}_{t}^{(m)}\left(v_{t-1}^{(m)}, w_{t, \omega}\right)=\min _{\alpha_{t+1}, y_{t, \omega}} c_{t}^{\mathrm{T}} g_{t, \omega}+\alpha_{t+1} \\
& \text { subject to } \\
& A f_{t, \omega}+B g_{t, \omega}+P u_{t, \omega}=D_{t} \quad:\left(\tau_{t}\right) \\
& v_{t, \omega}=v_{t-1}^{(m)}-H\left(u_{t, \omega}+s_{t, \omega}\right)+w_{t, \omega} \quad:\left(\pi_{t, \omega}^{(m)}\right) \\
& f_{t, \omega}=S \theta_{t, \omega} \\
& \alpha_{t+1} \geq \tilde{\mathcal{Q}}_{t+1}^{(k)}\left(v_{t}^{(k)}\right)+\tilde{\pi}_{t+1}^{(k)}{ }^{\mathrm{T}}\left(v_{t, \omega}-v_{t}^{(k)}\right) \quad \forall k \leq m \\
& \left(g_{t, \omega}, u_{t, \omega}, v_{t, \omega}, s_{t, \omega}, f_{t, \omega}, \theta_{t, \omega}\right) \in \mathcal{X}_{t}
\end{aligned}
$$

The adopted convergence criteria in this work follows the methodology utilized in [25] and [37], which considers stabilization both for lower and upper bounds. Within this technique, the algorithm initially runs a large number of forward-backward iterations (in this case, 1000). An evaluation step is then performed, for which a simulation for a large number of scenarios is carried out (in this case, 1000). Next, a few additional forward-backward iterations are executed (in this case, 100) and a new evaluation step performed. Convergence criteria is met if lower bound increase between stages lies within an $1 \%$ tolerance and a $t$-test to check the significance of the difference between the average of both samples does not reject the null hypothesis. If one of the conditions is not satisfied, 100 more iterations are carried out and the evaluation process repeated.

After convergence is satisfied, a final Monte Carlo simulation is carried out for a larger number of scenarios (in this case, 3000). Algorithm 1 summarizes the SDDP approach for determining the minimal cost of the hydrothermal operation problem within a hazard-decision framework. 


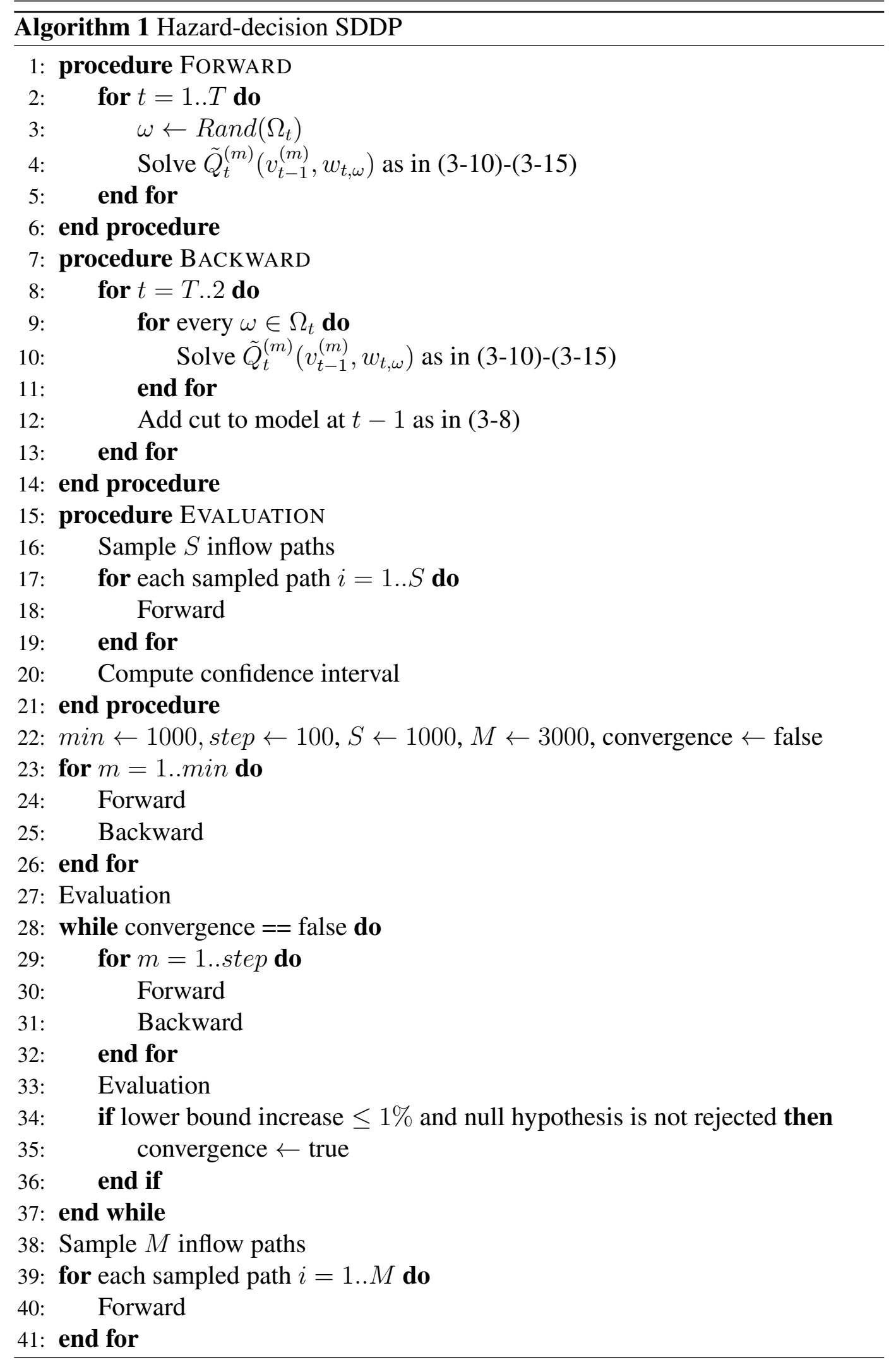




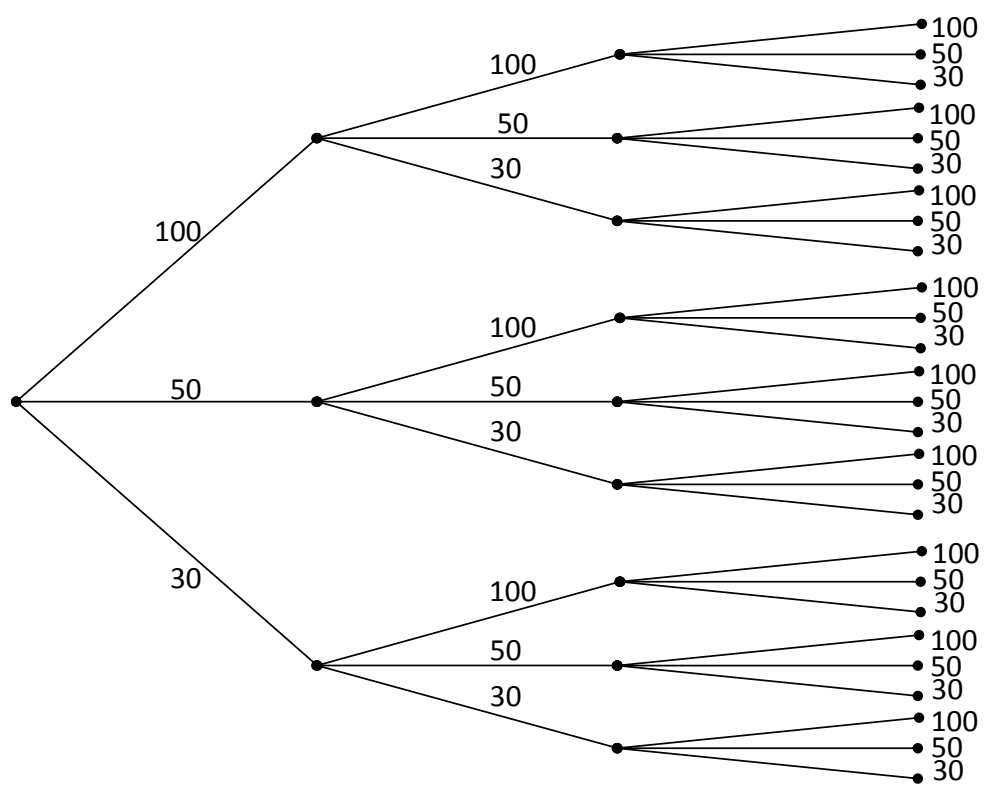

Fig. 3.2: Water inflow scenario tree

\subsubsection{Illustrative example}

In this section we take a simple example to illustrate the functionality of the SDDP algorithm based on a hazard-decision approach. The considered system is constituted by a single bus counting on one hydro generator and two thermal generators, being one cheap and the other expensive, to attend a constant demand of $100 \mathrm{MWh}$ within a planning horizon equal to $T=3$. Water inflow scenarios for $t=1 . . T$ are given by the set $\Omega_{t}=\{100,50,30\}$, all with the same probability, and illustrated in the scenario tree of Figure 3.2. Hydro production coefficient is equal to $1 \mathrm{MWh} / \mathrm{m}^{3}$ and the starting volume at the reservoir is $100 \mathrm{~m}^{3}$. Table 3.1 summarizes the data for thermal generators and Table 3.2 for the hydro unit.

Tab. 3.1: Thermal Generators Data

\begin{tabular}{cccc}
\hline $\begin{array}{c}\text { Thermal } \\
\text { Unit }\end{array}$ & $\begin{array}{c}c \\
(\mathrm{R} \$ \mathbf{M W h})\end{array}$ & $\begin{array}{c}\bar{G} \\
(\mathrm{MW})\end{array}$ & $\begin{array}{c}\underline{G} \\
(\mathrm{MW})\end{array}$ \\
\hline$G_{1}$ & 20 & 20 & 0 \\
$G_{2}$ & 100 & 100 & 0 \\
\hline
\end{tabular}


Tab. 3.2: Hydro Generator Data $\left(\mathrm{m}^{3}\right)$

\begin{tabular}{cccc}
\hline Hydro Unit & $\bar{V}$ & $\bar{U}$ & $v_{0}$ \\
\hline$H$ & 150 & 105 & 100 \\
\hline
\end{tabular}

For the given power system, at any $t$, the linear programming problem to be solved then becomes as follows:

$$
\begin{aligned}
\tilde{Q}_{t}^{(m)} & \left(v_{t-1}^{(m)}, w_{t, \omega}\right)=\min _{\substack{\alpha_{t+1, g_{1, t}, g_{2, t}} u_{t}, v_{t}, s_{t}\\
}} 20 g_{1, t}+100 g_{2, t}+\alpha_{t+1} \\
& \text { subject to } \\
& g_{1, t}+g_{2, t}+u_{t}=100 \\
& v_{t}=v_{t-1}^{(m)}-u_{t}-s_{t}+w_{t} \quad:\left(\pi_{t}\right) \\
& 0 \leq g_{1, t} \leq 20 \\
& 0 \leq g_{2, t} \leq 100 \\
& 0 \leq v_{t} \leq 150 \\
& \alpha_{t+1} \geq \tilde{\mathcal{Q}}_{t+1}^{(k)}\left(v_{t}^{(k)}\right)+\tilde{\pi}_{t+1}^{(k)}{ }^{\mathrm{T}}\left(v_{t, \omega}-v_{t}^{(k)}\right) \quad \forall k \leq m
\end{aligned}
$$

At the first iteration $(m=1)$, supposing scenario $w_{1}=30$ is sampled, we have:

$$
\begin{aligned}
& \widetilde{Q}_{1}^{(1)}(100,30)=\min _{\substack{\alpha_{2}, g_{1,1}, g_{2,1} \\
u_{1}, v_{1},,_{1}}} 20 g_{1,1}+100 g_{2,1}+\alpha_{2} \\
& \quad \text { subject to } \\
& g_{1,1}+g_{2,1}+u_{1}=100 \\
& v_{1}=100-u_{1}-s_{1}+30:\left(\pi_{1}\right) \\
& 0 \leq g_{1,1} \leq 20 \\
& 0 \leq g_{2,1} \leq 100 \\
& 0 \leq v_{1} \leq 150 \\
& \alpha_{2} \geq 0
\end{aligned}
$$

Optimizing for (3-23)-(3-29) provides the solution $u_{1}=100 \mathrm{MW}, g_{1,1}=$ $g_{2,1}=0 \mathrm{MW}$, which gives the final volume at the reservoir $v_{1}=30 \mathrm{~m}^{3}$. This is 
the initial volume at $t=2$. Then, taking for example $w_{2}=50$ as the randomized scenario for the next period, we have:

$$
\tilde{Q}_{2}^{(1)}(30,50)=\min _{\substack{\alpha_{3}, g_{1,2}, g_{2,2} \\ u_{2},,_{2}, s_{2}}} 20 g_{1,2}+100 g_{2,2}+\alpha_{3}
$$

subject to

$$
\begin{aligned}
& g_{1,2}+g_{2,2}+u_{2}=100 \\
& v_{2}=30-u_{2}-s_{2}+50 \quad:\left(\pi_{2}\right) \\
& 0 \leq g_{1,2} \leq 20 \\
& 0 \leq g_{2,2} \leq 100 \\
& 0 \leq v_{2} \leq 150 \\
& \alpha_{3} \geq 0
\end{aligned}
$$

This time, since there is not enough water to fulfill the demand, the solution to problem (3-30)-(3-36) is $u_{2}=80 \mathrm{MW}, g_{1,2}=20 \mathrm{MW}, g_{2,2}=0 \mathrm{MW}$, and the reservoir is depleted $\left(v_{2}=0 \mathrm{~m}^{3}\right)$, with a total cost of $\$ 400$. Advancing to $t=3$, supposing $w_{3}=100$, the linear program becomes:

$$
\begin{aligned}
& \widetilde{Q}_{3}^{(1)}(0,100)=\min _{\substack{\alpha_{4}, g_{1}, 3, g_{2,3} \\
u_{3}, v_{3}, s_{3}}} 20 g_{1,3}+100 g_{2,3}+\alpha_{4} \\
& \quad \text { subject to } \\
& g_{1,3}+g_{2,3}+u_{3}=100 \\
& v_{3}=0-u_{3}-s_{3}+100 \quad:\left(\pi_{3}\right) \\
& 0 \leq g_{1,3} \leq 20 \\
& 0 \leq g_{2,3} \leq 100 \\
& 0 \leq v_{3} \leq 150 \\
& \alpha_{4} \geq 0 .
\end{aligned}
$$

Due to water inflow given by the sampled scenario, there is enough water in the reservoir to meet the demand. Hence, the solution is $u_{3}=100 \mathrm{MW}, g_{1,3}=$ $g_{2,3}=0 \mathrm{MW}$, and the reservoir is once again depleted.

Giving continuity to the SDDP, the algorithm advances to the backward procedure. At this step, at each period $t$, every scenario is evaluated in order to define 
the cut to be added at $t-1$. Scenario $w_{3}=100$ is the same problem given by (3-37)-(3-43) solved above, which gives a total cost of $\$ 0$. Thus, $Q_{3}^{1}(0,100)=0$ and the dual variable solution is $\pi_{3}=0$.

Solving for the second scenario $w_{3}=50$, we have:

$$
\tilde{Q}_{3}^{(1)}(0,50)=\min _{\substack{\alpha_{4}, g_{1,3}, g_{2,3} \\ u_{3}, v_{3}, s_{3}}} 20 g_{1,3}+100 g_{2,3}+\alpha_{4}
$$

subject to

$$
\begin{aligned}
& g_{1,3}+g_{2,3}+u_{3}=100 \\
& v_{3}=0-u_{3}-s_{3}+50 \quad:\left(\pi_{3}\right) \\
& 0 \leq g_{1,3} \leq 20 \\
& 0 \leq g_{2,3} \leq 100 \\
& 0 \leq v_{3} \leq 150 \\
& \alpha_{4} \geq 0
\end{aligned}
$$

Which gives the solution $u_{3}=50 \mathrm{MW}, g_{1,3}=20 \mathrm{MW}, g_{2,3}=30 \mathrm{MW}$, depleting the reservoir. This time $Q_{3}^{(1)}(0,50)=3400$ and the dual variable solution is $\pi_{3}=-100$.

Finally, for the third scenario $w_{3}=30$, the problem becomes:

$$
\begin{aligned}
& \tilde{Q}_{3}^{(1)}(0,30)=\min _{\substack{\alpha_{4}, g_{1,3}, g_{2,3} \\
u_{3}, v_{3}, s_{3}}} 20 g_{1,3}+100 g_{2,3}+\alpha_{4} \\
& \quad \text { subject to }
\end{aligned}
$$

$$
\begin{aligned}
& g_{1,3}+g_{2,3}+u_{3}=100 \\
& v_{3}=0-u_{3}-s_{3}+30 \quad:\left(\pi_{3}\right) \\
& 0 \leq g_{1,3} \leq 20 \\
& 0 \leq g_{2,3} \leq 100 \\
& 0 \leq v_{3} \leq 150 \\
& \alpha_{4} \geq 0
\end{aligned}
$$

And the solution is $u_{3}=30 \mathrm{MW}, g_{1,3}=20 \mathrm{MW}, g_{2,3}=50 \mathrm{MW}$, for a total cost of $Q_{3}^{(1)}(0,50)=5400$ and dual variable solution $\pi_{3}=-100$.

Having solved for all scenarios of $t=3$, the algorithm obtains the Benders 
cut that will be used to approximate the recourse function at $t=2$, which is given by:

$$
\alpha_{3} \geq \frac{0+3400+5400}{3}+\frac{0-100-100}{3}\left(v_{2}-0\right)=2933.33-66.67 v_{2}
$$

The backward step then moves on to $t=2$, which now counts with one extra restriction, given by the newly obtained cut. For the first scenario, $w_{2}=100$, the problem now becomes:

$$
\tilde{Q}_{2}^{(1)}(30,100)=\min _{\substack{\alpha_{3}, g_{1,2}, g_{2,2} \\ u_{2}, v_{2}, s_{2}}} 20 g_{1,2}+100 g_{2,2}+\alpha_{3}
$$

subject to

$$
\begin{aligned}
& g_{1,2}+g_{2,2}+u_{2}=100 \\
& v_{2}=30-u_{2}-s_{2}+100 \quad:\left(\pi_{2}\right) \\
& 0 \leq g_{1,2} \leq 20 \\
& 0 \leq g_{2,2} \leq 100 \\
& 0 \leq v_{2} \leq 150 \\
& \alpha_{3} \geq 2933.33-66.67 v_{2} .
\end{aligned}
$$

Solving to optimality, we obtain $u_{2}=86 \mathrm{MW}, g_{1,2}=14 \mathrm{MW}$ and $g_{2,2}=$ $0 \mathrm{MW}$. Notice that, in spite of counting with enough water to attend the immediate demand, only $86 \mathrm{MW}$ is generated by the hydroelectric, resulting in a final volume of $v_{2}=44 \mathrm{~m}^{3}$ and an immediate cost of $\$ 280$. This water is stored for future use and is a consequence of the introduction of restriction (3-65), which begins to translate the future cost function.

The backward procedure continues until reaching $t=1$, then moves on to the next iteration, and repeats it, introducing new cuts to the problems, while the convergence criteria is not met.

\subsection{Time-inconsistency due to perfect information simplification}

ISOs often adopt hazard-decision models for determining the operation planning of hydrothermal power systems. Such an approach may be explained due to 
problem complexity and, consequently, computational effort required to obtain an acceptable solution. As explained in Section 4.1, incorporation of non-anticipativity constraints may significantly increase the number of variables and restrictions of the problem, as it does not allow scenario decomposition. Nevertheless, it is important to keep in mind that assuming (unrealistic) perfect information of water inflow may lead to time-inconsistent decisions.

As explained in Chapter 1, due to energetic restrictions of technical or economic nature, baseload suppliers and gas-fired units must be informed in advance of their planned dispatch. Thus, the decision of how much energy each of these plants shall generate in a given period must be determined before the observation of water inflow. In other words, this is a stochastic two-stage decision problem, for which the energy dispatch of slow response suppliers and gas-fueled power plants is made under uncertainty, while the remaining thermal and hydro units constitute the second-stage adaptive decision set.

Indeed, after being provided with a cost-to-go function obtained based on a hazard-decision model, for the short-term operation a different approach must be adopted to determine first-stage units dispatch. In this work we apply a procedure that utilizes the expected value of water inflow scenarios to determine first-stage decision variables.

\subsubsection{Illustrative example}

In this section, the inconsistency due to the adoption of a hazard-decision model to determine hydrothermal operation is exemplified. Based on the same example utilized to illustrate the SDDP methodology in Section 3.1, the results obtained with an operation conducted within a hazard-decision framework is compared to the one resulted from the approach that determines first-stage decision variables utilizing the expected value of water inflow, for which the cheap thermal unit is considered a first-stage decision variable. This approach is closely related to the short-term operation employed in the Brazilian power system, as explained in Chapter 2, and was equally employed in [2].

After executing forward-backward iterations a sufficient number of times to attain convergence, as recorded in Algorithm 1, a final simulation is carried out for every possible inflow path of the scenario tree depicted in Figure 3.2. Energy dispatch for the thermal units obtained with each of the procedures described are compared in Figure 3.3. 


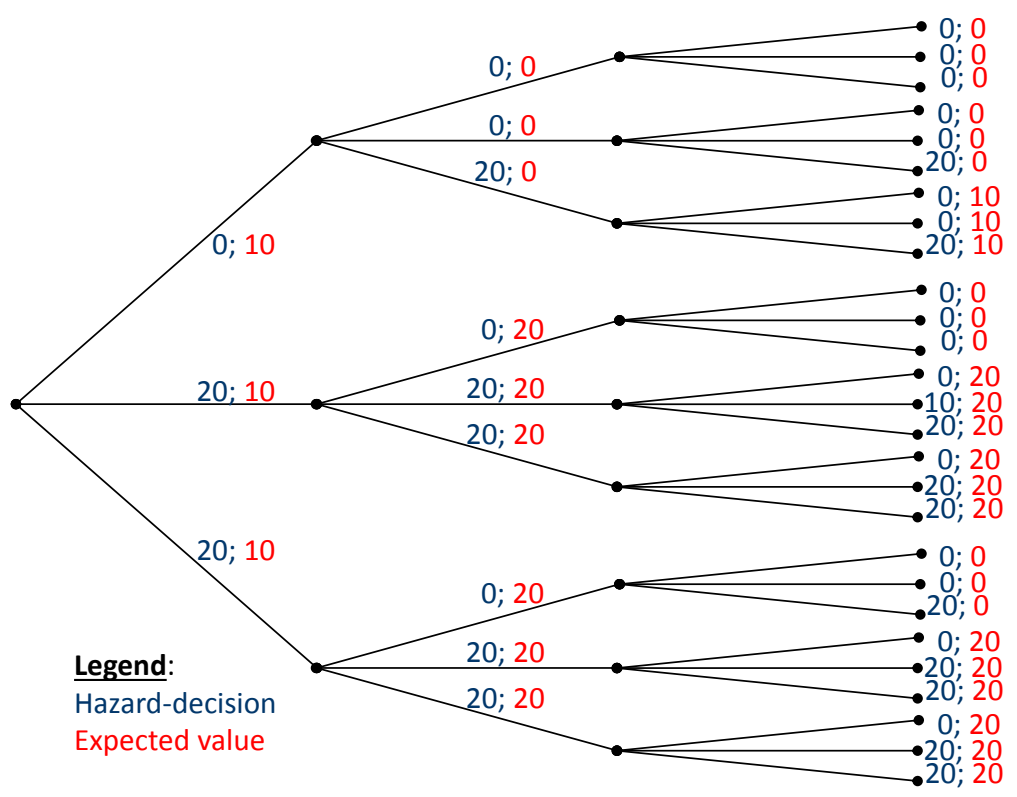

(a) Cheap thermal unit $\left(g_{1}\right)$

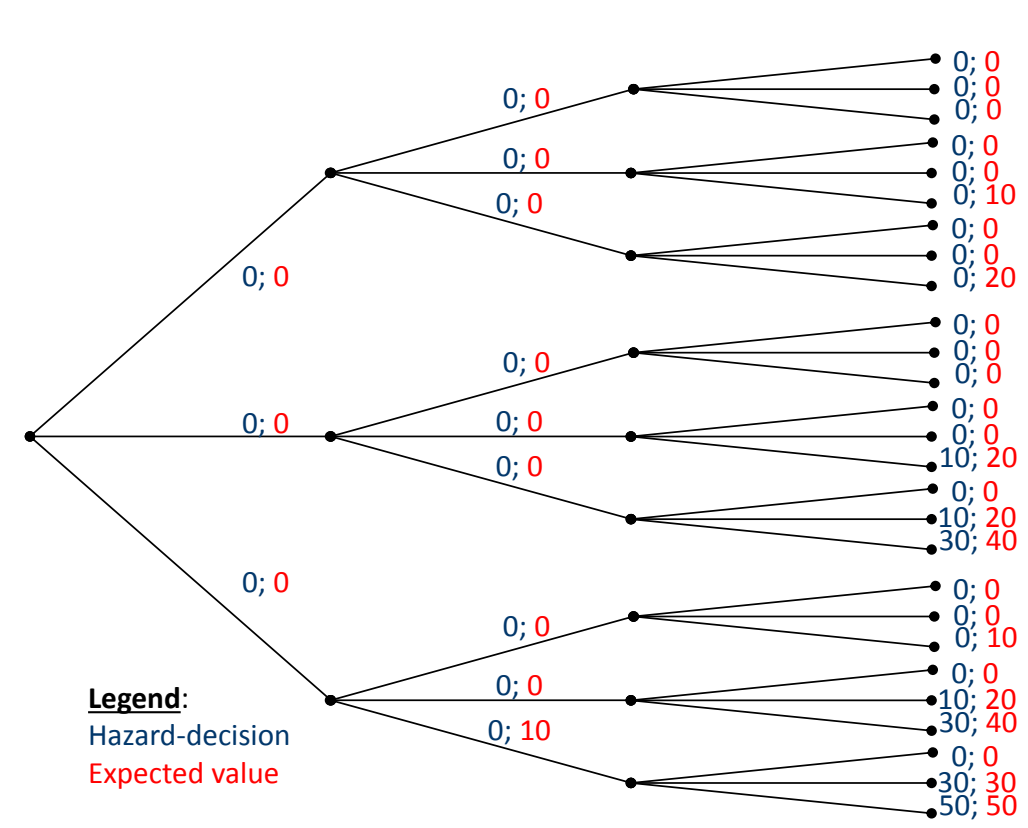

(b) Expensive thermal unit $\left(g_{2}\right)$

Fig. 3.3: Thermal units dispatch

Note that for the case where the expected value of water inflow is used to determine first-stage dispatch, the generation of $g_{1}$ is the same for every branch of the tree that comes out of a given node and how it differs from the hazard-decision 
approach. The difference presented between the two policies is an exemplification of time-inconsistency, since the hazard-decision approach is in accordance with the perfect-information structure assumed by the ISO at the planning stage.

By calculating the expected operational cost as in expression (3-66), we obtain a result equal to $\$ 1,274$ for the hazard-decision policy and $\$ 1,630$ for the expected value of inflow, an overcost of $27.9 \%$ due to suboptimal decisions.

$$
\text { Expected cost }=\frac{1}{M} \sum_{m=1}^{M} \sum_{t=1}^{T} c_{1} g_{1, m, t}+c_{2} g_{2, m, t}
$$




\section{4 \\ Proposed Model: Decision-Hazard}

In order to obtain a more consistent solution, in this chapter we analyze a model that does not consider approximations related to scenario anticipation. Differently from the hazard-decision approach, within a decision-hazard framework, for a given set of variables the decision process is made under scenario uncertainty. Hence, for these variables the decision must be made in anticipation of the information-revelation process. Figure 4.1 illustrates the decision structure for the decision-hazard approach.

\subsection{Two-stage decision-hazard approach}

The most straightforward method to adapt the original hazard-decision operation planning model consists of including non-anticipativity constraints associated with the first-stage variables. By introducing the decision variable $g_{t}^{o}$, representing the first-stage dispatch, and expression (4-5), we guarantee that, at period $t$, for every thermal generator $j$ in the first-stage generators set $J$, power generation must be the same for every scenario $\omega$ in $\Omega_{t}$.

Incorporating the necessary changes, the problem for determining the minimal expected cost for the hydrothermal operation within a decision-hazard framework becomes:

$$
\mathcal{Q}_{t}\left(v_{t-1}\right)=\min _{\left\{g_{t}^{o}, y_{t, \omega}\right\}_{\omega \in \Omega_{t}}} \sum_{\omega \in \Omega_{t}} p_{\omega}\left[c_{t}^{\mathrm{T}} g_{t, \omega}+\mathcal{Q}_{t+1}\left(v_{t, \omega}\right)\right]
$$

subject to

$$
\begin{array}{ll}
A f_{t, \omega}+B g_{t, \omega}+P u_{t, \omega}=D_{t} & \forall \omega \in \Omega_{t} \\
v_{t, \omega}=v_{t-1}-H\left(u_{t, \omega}+s_{t, \omega}\right)+w_{t, \omega} & \forall \omega \in \Omega_{t} \\
f_{t, \omega}=S \theta_{t, \omega} & \forall \omega \in \Omega_{t} \\
g_{j, t, \omega}=g_{j, t}^{o} & \forall \omega \in \Omega_{t}, \forall j \in J \\
\left(g_{t, \omega}, u_{t, \omega}, v_{t, \omega}, s_{t, \omega}, f_{t, \omega}, \theta_{t, \omega}\right) \in \mathcal{X}_{t} & \forall \omega \in \Omega_{t}
\end{array}
$$

Inclusion of non-anticipativity constraints, on the one hand provides a more 


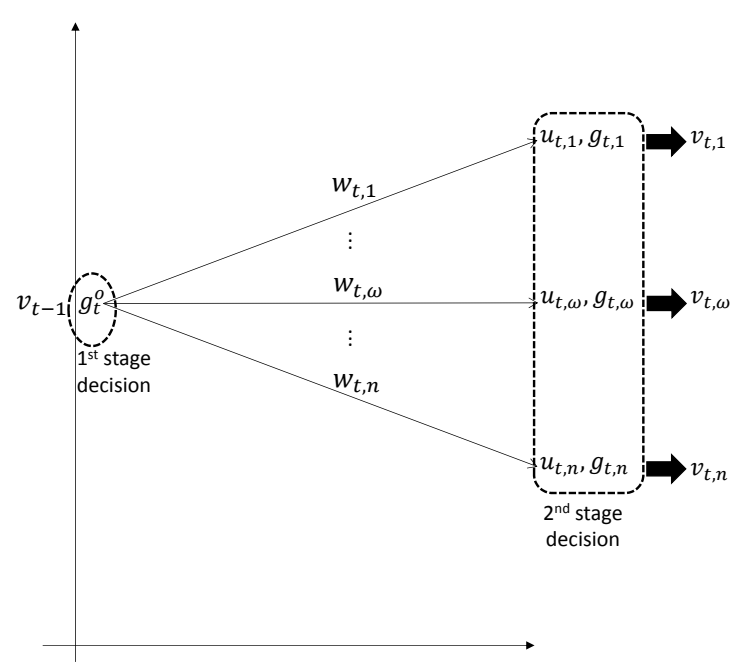

Fig. 4.1: Decision-hazard decision structure

precise solution, on the other hand, however, as it couples the subproblems related to each scenario of the current period, the problem is no longer scenario-decomposable and rewriting it as in (3-7) is not possible. Nonetheless, it is still possible to solve the decision-hazard problem using the SDDP methodology. To do so, we must then define the new Benders cuts that can successfully approximate the future cost function

By obtaining the dual of the problem above, since constraint (4-3) is indexed to the scenarios, its dual variable is determined by the sum of the duals for each scenario $\omega$ in $\Omega_{t}$. Thus,

$$
\pi_{t}=\sum_{\omega \in \Omega_{t}} \pi_{t, \omega}
$$

By analyzing the hazard-decision SDDP problem, we notice that at each backward iteration one single cut, based on the average future cost of the possible scenarios at $t$, is added to $t-1$, which, in turn, is valid for every single scenario of the problem in $t-1$. To treat this problem in a similar manner, we must then introduce one restriction for each scenario. Hence, one single cut is formed by a set of restrictions equal to the number of scenarios, and the set of constraints that define the auxiliary variable $\alpha_{t+1}$ in this case becomes 


$$
\alpha_{t+1, \omega} \geq \tilde{\mathcal{Q}}_{t+1}^{(k)}\left(v_{t}^{(k)}\right)+\tilde{\pi}_{t+1}^{(k)^{\mathrm{T}}}\left(v_{t, \omega}-v_{t}^{(k)}\right) \quad \forall \omega \in \Omega_{t}, \forall k \leq m
$$

And the linear programming model within the decision-hazard framework becomes as given by equations (4-9)-(4-15).

$$
\tilde{\mathcal{Q}}_{t}^{(m)}\left(v_{t-1}^{(m)}\right)=\min _{\left\{\alpha_{t+1, \omega}, g_{t}^{o}, y_{t, \omega}\right\}_{\omega \in \Omega_{t}}} \sum_{\omega \in \Omega_{t}} p_{\omega}\left[c_{t}^{\mathrm{T}} g_{t, \omega}+\alpha_{t+1, \omega}\right]
$$

subject to

$$
\begin{array}{ll}
A f_{t, \omega}+B g_{t, \omega}+P u_{t, \omega}=D_{t} & \forall \omega \in \Omega_{t}:\left(\tau_{t}\right) \\
v_{t, \omega}=v_{t-1}^{(m)}-H\left(u_{t, \omega}+s_{t, \omega}\right)+w_{t, \omega} & \forall \omega \in \Omega_{t}:\left(\pi_{t, \omega}^{(m)}\right) \\
f_{t, \omega}=S \theta_{t, \omega} & \forall \omega \in \Omega_{t} \\
g_{j, t, \omega}=g_{j, t}^{o} & \forall \omega \in \Omega_{t}, \forall j \in J \\
\alpha_{t+1, \omega} \geq \tilde{\mathcal{Q}}_{t+1}^{(k)}\left(v_{t}^{(k)}\right)+\tilde{\pi}_{t+1}^{(k)}{ }^{\mathrm{T}}\left(v_{t, \omega}-v_{t}^{(k)}\right) & \forall \omega \in \Omega_{t}, \forall k \leq m \\
\left(g_{t, \omega}, u_{t, \omega}, v_{t, \omega}, s_{t, \omega}, f_{t, \omega}, \theta_{t, \omega}\right) \in \mathcal{X}_{t} & \forall \omega \in \Omega_{t}
\end{array}
$$

Despite the more realistic solution provided by the decision-hazard approach, there is a plausible reason not to employ it: computational effort. As mentioned above, the introduction of non-anticipativity constraints transforms the problem into non-scenario-decomposable. Consequently, for every second-stage decision variable in this method, a number of variables equal to the number of scenarios is required. Moreover, apart from the number of restrictions that represent each cut, which is increased by a factor of $\left|\Omega_{t}\right|$ per iteration, the initial number of restrictions is equally multiplied by the number of scenarios.

From the SDDP perspective, differently from the hazard-decision approach, in the forward step, instead of solving the problem for one particular scenario chosen randomly, all scenarios are evaluated at once. Next, one single scenario is selected, which will then determine the final volume to be used as the initial state in the subsequent period. Analogously, in the backward step, instead of repeatedly solving the problem for one scenario at a time, every possible outcome of a given period is evaluated at a single call of the problem. Hence, since a solution cannot be obtained for one scenario individually, at each iteration $k$ of the algorithm, at period $t$ the problem solved in the forward stage is exactly the same of the one in 


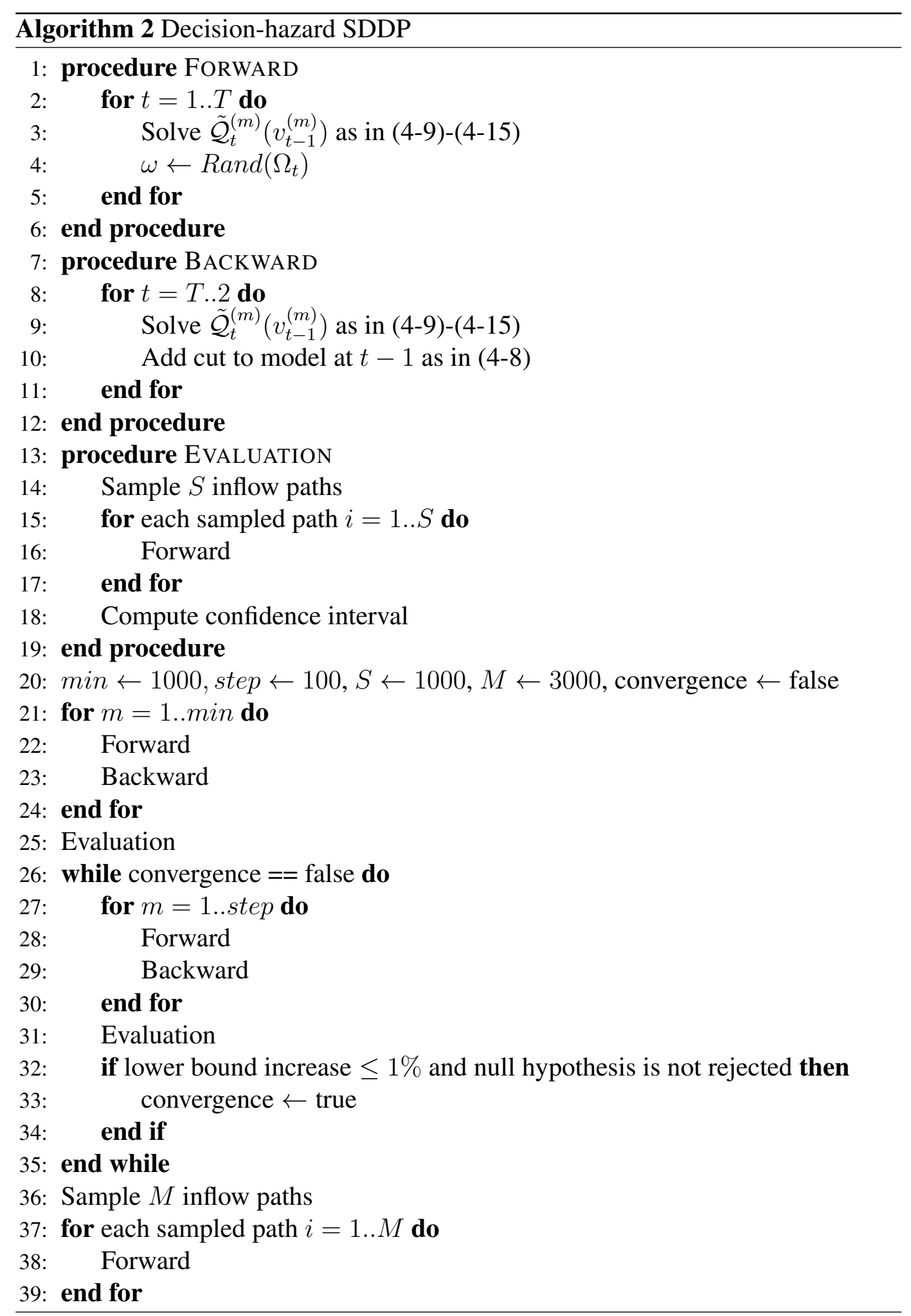

the backward step, apart from the cut obtained in $t+1$, formed by a set of $\left|\Omega_{t}\right|$ restrictions. Algorithm 2 summarizes the decision-hazard approach solution for the 
problem.

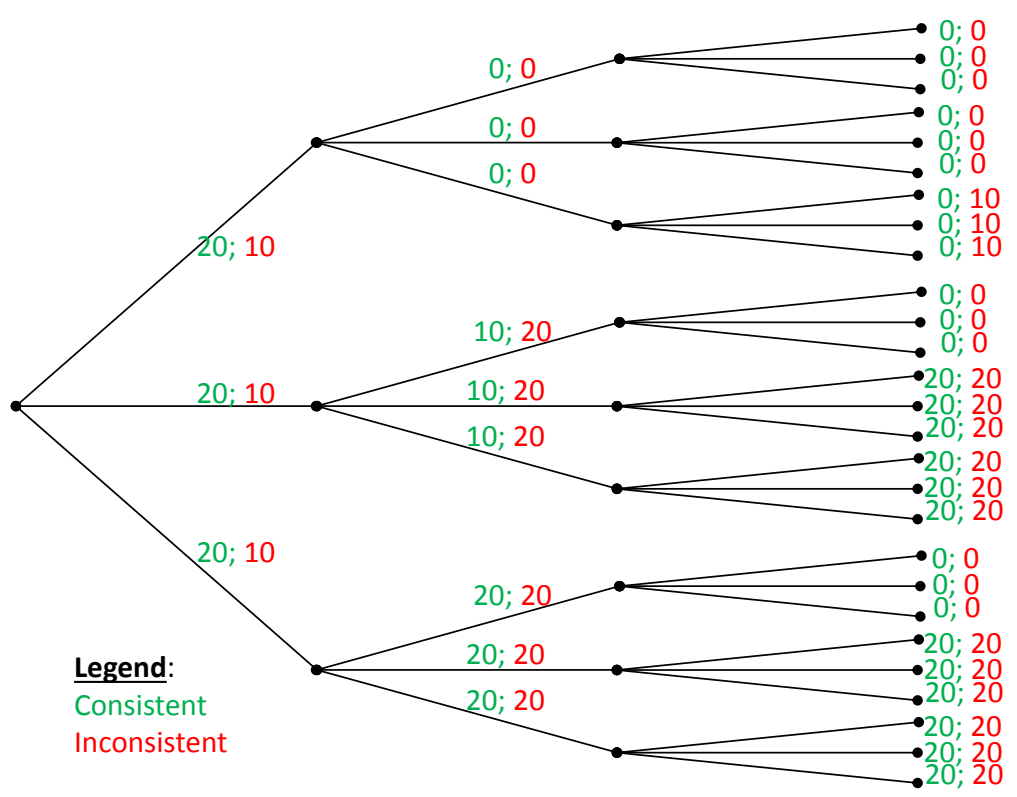

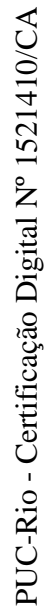

(a) Cheap thermal unit $\left(g_{1}\right)$

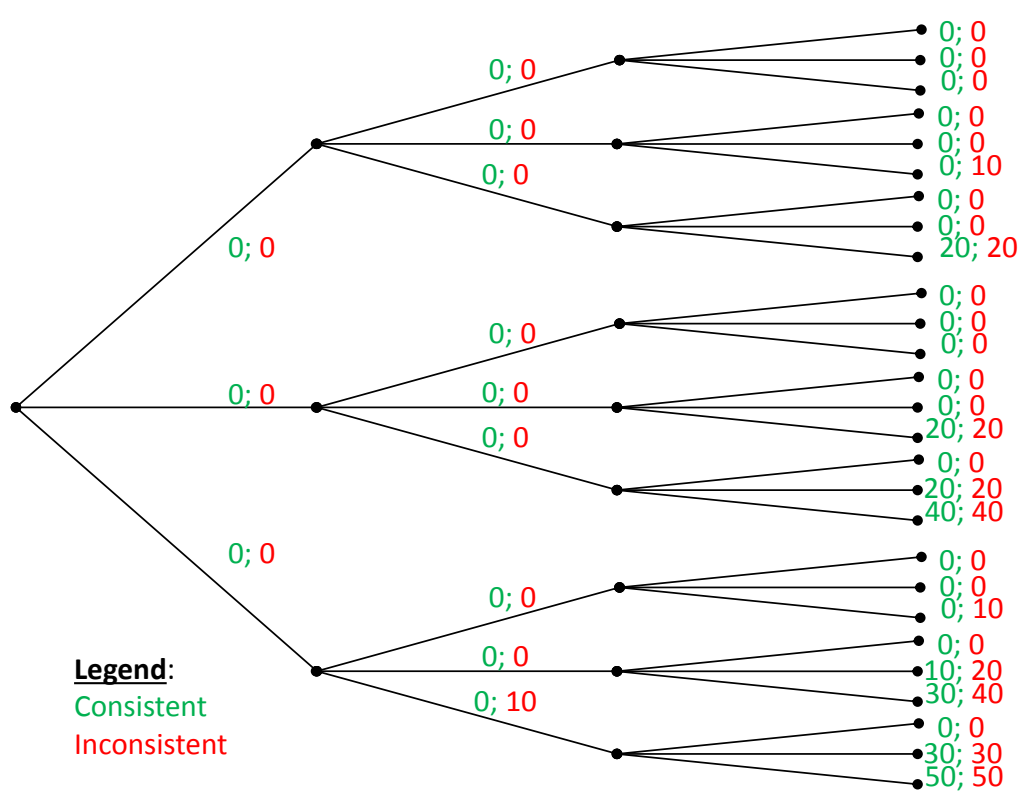

(b) Expensive thermal unit $\left(g_{2}\right)$

Fig. 4.2: Thermal units dispatch 


\subsubsection{Illustrative example}

We take the same example used in section 3.2 to illustrate the difference on the solution obtained with a decision-hazard consistent methodology. As before, the results obtained after convergence has been reached are presented for every possible inflow path of the scenario tree of Figure 3.2. Energy dispatch for each of the thermal units are shown in Figure 4.2, both for the consistent and inconsistent approaches.

In both cases, generation of $g_{1}$, the first-stage variable, is equal for every branch of the three that comes out of a given node. Notice, however, how the optimal solution for each policy differ one from another, due to the approximations employed in the inconsistent methodology. Even though, at $t=1$, thermal generation is superior within the consistent methodology, incurring a higher immediate cost, dispatch of the expensive thermal unit is limited to a minimum. As a result, the expected operational cost is $\$ 1,592$, inferior to that obtained based on the inconsistent approach, equal to $\$ 1,630$.

\subsection{Augmented-state decomposable decision-hazard approach}

It is clear that implementation of the decision-hazard model as presented considerably increases the time required to find an appropriate solution. Not only during the forward-backward recursion, but specially in the final simulation step that provides the upperbound of the problem, since the forward procedure of the algorithm is considerably affected.

However, an alternative approach that substantially reduces the number of variables and restrictions of the subproblem, yet providing similar results is possible. Instead of handling the immediate cost at each period as a two-stage problem, it is possible to incorporate the first-stage variables into the system's state and let the dispatch of these generators be an argument of the future cost function of the preceding period. Consequently, the decision vector at period $t$ includes not only the generation of the second-stage variables at $t$, but also of the first-stage variables at $t+1$. This is done by means of the decision variable $g_{t+1 \mid t}^{o}$, which stands for the first-stage generation at $t+1$ given the conditions at the end of period $t$, and guaranteed by expression (4-19). The adaptation results in the following: 


$$
\mathcal{Q}_{t}\left(v_{t-1}, g_{t \mid t-1}^{o}\right)=\min _{\left\{g_{t+1 \mid t}^{o}, y_{t, \omega}\right\}_{\omega \in \Omega_{t}}} \sum_{\omega \in \Omega_{t}} p_{\omega}\left[c_{t}^{\mathrm{T}} g_{t, \omega}+\mathcal{Q}_{t+1}\left(v_{t, \omega}, g_{t+1 \mid t}^{o}\right)\right]
$$

subject to

$$
\begin{aligned}
& A f_{t, \omega}+B g_{t, \omega}+P u_{t, \omega}=D_{t} \\
& v_{t, \omega}=v_{t-1}-H\left(u_{t, \omega}+s_{t, \omega}\right)+w_{t, \omega} \\
& g_{j, t, \omega}=g_{t+1 \mid t}^{o} \quad \forall j \in J \\
& f_{t, \omega}=S \theta_{t, \omega} \\
& \left(g_{t+1 \mid t}^{o}, g_{t, \omega}, u_{t, \omega}, v_{t, \omega}, s_{t, \omega}, f_{t, \omega}, \theta_{t, \omega}\right) \in \mathcal{X}_{t}
\end{aligned}
$$

By incorporating the first-stage decision variables into the system's state, we obtain once again a scenario-decomposable problem. Hence, we are able to rewrite the objective function as

$$
\begin{aligned}
& \mathcal{Q}_{t}\left(v_{t-1}, g_{t \mid t-1}^{o}\right)=\sum_{\omega \in \Omega_{t}} p_{\omega}\left[\min _{g_{t+1 \mid t}^{o}, y_{t, \omega}} c_{t}^{\mathrm{T}} g_{t, \omega}+\mathcal{Q}_{t+1}\left(v_{t, \omega}, g_{t+1 \mid t}^{o}\right)\right] \\
& \mathcal{Q}_{t}\left(v_{t-1}, g_{t \mid t-1}^{o}\right)=\sum_{\omega \in \Omega_{t}} p_{\omega}\left[Q_{t}\left(v_{t-1}, g_{t \mid t-1}^{o}, w_{t, \omega}\right)\right]
\end{aligned}
$$

From equation (4-23), similarly to the hazard-decision problem, within the augmented-state approach, for a given initial state $\left(v_{t-1}, g_{t \mid t-1}^{o}\right)$, defined by the initial volume in the hydro reservoirs and the dispatch for the first-stage generators set $J$, it is possible to solve each subproblem determined by the water inflow scenarios $w_{t, \omega}$ individually and then obtain the expected value. Therefore, the proposed methodology results in a decision-hazard structure problem that may be solved through a hazard-solution methodology.

As before, following the SDDP technique, an inferior approximation of the future expected cost $\mathcal{Q}_{t}\left(v_{t-1}, g_{t \mid t-1}^{o}\right)$ based on Benders cuts must be established. These cuts must take into account all state variables, which now include not only the dual of restriction (4-17), $\pi$, but also the dual of restrictions (4-19), $\gamma_{j}$. Thus, the auxiliary variable $\alpha_{t+1}$ becomes 
$\alpha_{t+1} \geq \tilde{\mathcal{Q}}_{t+1}^{(k)}\left(v_{t}^{(k)}, g_{t+1 \mid t}^{o(k)}\right)+\tilde{\pi}_{t+1}^{(k)^{\mathrm{T}}}\left(v_{t, \omega}-v_{t}^{(k)}\right)+\sum_{j \in J} \tilde{\gamma}_{j, t+1}^{(k)}{ }^{\mathrm{T}}\left(g_{j, t+1 \mid t}^{o}-g_{j, t+1 \mid t}^{o(k)}\right) \quad \forall k \leq m$

Analogously to (3-9), $\tilde{\pi}_{t+1}^{(k)}$ translates the expected value of the dual variable $\pi$ of constraint (4-18) at $t+1$, iteration $k$; and $\tilde{\gamma}_{j, t+1}^{(k)}$ translates the expected value of the dual variable $\gamma_{j}$ of constraint (4-19) for each $j \in J$, represented by expressions (4-25) and (4-26), respectively.

$$
\begin{aligned}
& \tilde{\pi}_{t+1}^{(m)}=\sum_{\omega \in \Omega_{t+1}} p_{\omega} \tilde{\pi}_{t+1, \omega}^{(m)} \\
& \tilde{\gamma}_{j, t+1}^{(m)}=\sum_{\omega \in \Omega_{t+1}} p_{\omega} \tilde{\gamma}_{j, t+1, \omega}^{(m)}
\end{aligned}
$$

As a result, the proposed augmented-state decision-hazard linear programming model becomes

$$
\tilde{Q}_{t}^{(m)}\left(v_{t-1}^{(m)}, g_{t \mid t-1}^{o(m)}, w_{t, \omega}\right)=\min _{\alpha_{t+1}, g_{t+1 \mid t}^{o}, y_{t, \omega}} c_{t}^{\mathrm{T}} g_{t, \omega}+\alpha_{t+1}
$$

subject to

$$
\begin{array}{ll}
A f_{t, \omega}+B g_{t, \omega}+P u_{t, \omega}=D_{t} & :\left(\tau_{t}\right) \\
v_{t, \omega}=v_{t-1}^{(m)}-H\left(u_{t, \omega}+s_{t, \omega}\right)+w_{t, \omega} & :\left(\pi_{t, \omega}^{(m)}\right) \\
g_{j, t, \omega}=g_{t+1 \mid t}^{o(m)} & \forall j \in J:\left(\gamma_{j, t, \omega}^{(m)}\right) \\
f_{t, \omega}=S \theta_{t, \omega} & \\
\alpha_{t+1} \geq \tilde{\mathcal{Q}}_{t+1}^{(k)}\left(v_{t}^{(k)}, g_{t+1 \mid t}^{o(k)}\right)+\tilde{\pi}_{t+1}^{(k)}{ }^{\mathrm{T}}\left(v_{t, \omega}-v_{t}^{(k)}\right)+ & \\
\sum_{j \in J} \tilde{\gamma}_{j, t+1}^{(k)}{ }^{\mathrm{T}}\left(g_{j, t+1 \mid t}^{o}-g_{j, t+1 \mid t}^{o(k)}\right) & \forall k \leq m \\
\left(g_{t+1 \mid t}^{o}, g_{t, \omega}, u_{t, \omega}, v_{t, \omega}, s_{t, \omega}, f_{t, \omega}, \theta_{t, \omega}\right) \in \mathcal{X}_{t} &
\end{array}
$$

At each iteration, similarly to the original hazard-decision model, at period $t$, one cut composed by only one restriction is included in the model of $t-1$. When compared to the hazard-decision model, however, this cut has its dimension increased in $|J|$, the number of first-stage generators. Furthermore, the number of 
variables, as well as the initial restrictions, is also augmented by $|J|$, due to the additional decision variable $g_{t \mid t-1}^{o}$ and constraint (4-30).

For $t=2 . . T$, first-stage variables $g_{j, t, \omega}$ have their values determined by means of constraint (4-30), obtained at $t-1$. Constraint (4-33), which defines the feasible set, is enough to guarantee that $g_{t+1 \mid t}^{o}$ will not lead the the model at $t+1$ to an unfeasible solution.

To determine $g_{t=1 \mid 0}^{o}$, the first-stage decision at $t=1$, however, a pre-dispatch model is necessary. Its objective function is constituted solely by the expected future-cost function, and its initial restrictions are the upper and lower generation limits of the first-stage generators, given by (4-35). This constraint is enough to define a feasible set at $t=0$ that does not lead the model at $t=1$ to an unfeasible solution. The pre-dispatch model within the SDDP approach is then:

$$
\tilde{Q}_{0}^{(m)}\left(g_{t=0}^{o(m)}\right)=\min _{\alpha_{1}, g_{t=1 \mid 0}^{o}} \alpha_{1}
$$

subject to

$$
\begin{aligned}
& g_{\text {min }}^{o} \leq g_{t=1 \mid 0}^{o} \leq g_{\max }^{o} \\
& \alpha_{1} \geq \tilde{\mathcal{Q}}_{1}^{(k)}\left(v_{0}, g_{t=1 \mid 0}^{o(k)}\right)+\sum_{j \in J} \tilde{\gamma}_{j, 1}^{(k)^{\mathrm{T}}}\left(g_{j, t=1 \mid 0}^{o}-g_{j, t=1 \mid 0}^{o(k)}\right) \quad \forall k \leq m
\end{aligned}
$$

Notice that in expression (4-36), since $v_{t}$ for $t=0$ is the initial state of the system, cuts of the pre-dispatch model do not depend on the variation of the volume at the reservoirs. Algorithm 3 summarizes the minimal cost dispatch problem within a decision-hazard framework using the augmented-state solution methodology.

The SDDP algorithm described in this section provides similar results to the one presented in section 4.1, but with considerable improvements on computational performance. For the illustrative example presented in the previous section, where the difference between upper and lower bounds is null, results are exactly the same. In Chapter 5, the proposed methodology is employed to estimate the impact due to ignoring non-anticipativity restrictions on hydrothermal power systems operation planning. 


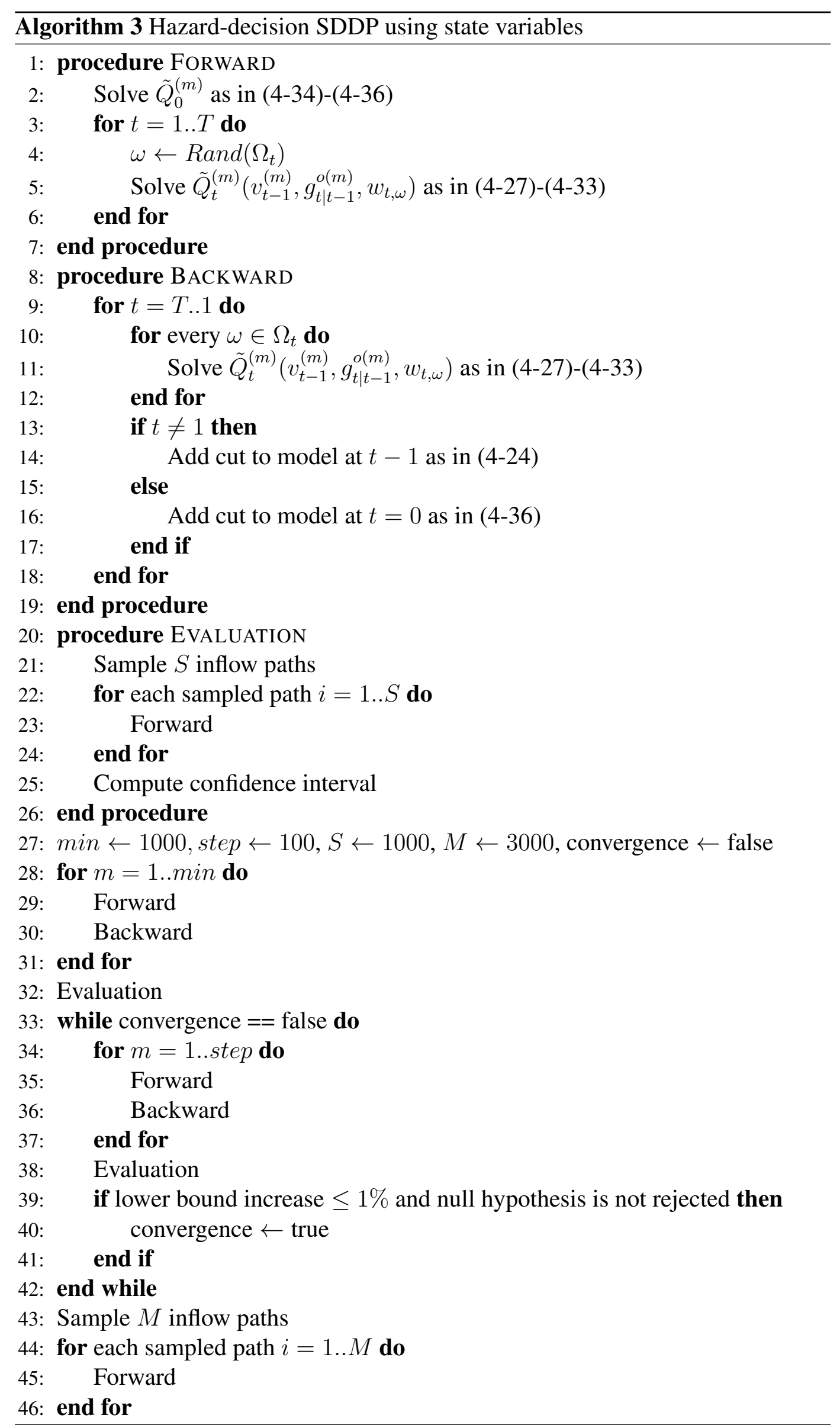




\section{5 \\ Case Study}

In this chapter we analyze the effects of adopting a decision-hazard model instead of a hazard-decision on the hydrothermal system operation planning. Based on the time inconsistency concept discussed in Chapter 3, the impact due to ignoring non-anticipativity restrictions is estimated for the Brazilian power system. To do so, it is necessary to define the parameters that will be employed to compare the different policies considered.

\subsection{Policies definition}

We begin by determining the dispatch policies from which the results are gathered. In this work, three different policies based on the models presented are utilized, each one of them defined as follows.

In the first policy, both the planning and simulation are implemented following a hazard-decision approach, as illustrated in Algorithm 1. This is the expected operation behavior from the ISO's perspective, and will hereinafter be referred to as planning policy.

Short-term operation, however, does not utilize the hazard-decision approach to determine the operation. In spite of being provided with a cost-to-go function obtained using the hazard-decision framework, the implementation put into effect is a two-stage decision method. In this work, for the second dispatch policy, firststage decision variables are determined based on the expected value of water inflow scenarios, the same methodology utilized in [2]. From the definition of timeconsistency in [22], a policy to be regarded as consistent must adopt on its calibration process a model that reflects the problem that will be actually going to be implemented in the future, an approach that does not correspond to the methodology described. Therefore, this policy will be referred to as inconsistent policy.

The third dispatch policy is the one obtained within the decision-hazard framework both on planning and implementation phases. Algorithms 2 and 3 correspond to this definition and provide similar results, only with differences on computational performance. Since this policy agrees with the time-consistency definition provided, it will be referred to as consistent policy.

It is important to emphasize that this is a reduced study based on the Brazilian 
power system and that reality is more complex than what is reflected here, with many other uncertainties ignored in this study. The objective is to illustrate how results could be affected if reality was to be implemented following a decisionhazard model, but planned based on a hazard-decision structure. In practice, this is a more complex process and the resulting gap should be greater.

\subsection{Time-inconsistency gap and the consistency benefit}

The methodology described for the inconsistent policy is an attempt to emulate a decision-hazard implementation, for it predetermines the energy dispatch for some of the generators before the information-revelation process. Given the convexity of the cost function, determined by the generators individual costs and capacities, this water inflow simplification may result in severe discrepancies when compared to a more precise methodology, easily seen from Jensen's inequality. Furthermore, within this policy, first-stage decisions are not only determined based on a non-realistic scenario, but it also utilizes a future-cost function obtained from a perfect information decision approach. Consequently, the attained solution may greatly differ both from the hazard-decision and decision-hazard models, potentially leading to suboptimal results.

With a view to measure the effect of the inconsistent policy, we will adopt the time-inconsistency gap introduced in [22] and extended in [25]. The inconsistency gap is estimated by computing the difference on total operational cost between implemented (inconsistent) and planning policies.

$$
G A P=\frac{1}{M} \sum_{i=1}^{M} \sum_{t=1}^{T} c_{t}^{\mathrm{T}} g_{t, i}^{\text {incon }}-\frac{1}{M} \sum_{i=1}^{M} \sum_{t=1}^{T} c_{t}^{\mathrm{T}} g_{t, i}^{\text {plan }}
$$

Where $g_{t, i}^{\text {incon }}$ and $g_{t, i}^{\text {plan }}$ represent the thermal generation decision variable at period $t$, simulation path $i$ obtained from the inconsistent and planning policies, respectively.

It is also possible to estimate the impact due to adopting a consistent policy instead of an inconsistent one. Based on the time-inconsistency gap, by computing the difference between inconsistent and consistent policies on the total operational cost we obtain the consistency benefit: 


$$
\text { Benefit }=\frac{1}{M} \sum_{i=1}^{M} \sum_{t=1}^{T} c_{t}^{\mathrm{T}} g_{t, i}^{\text {incon }}-\frac{1}{M} \sum_{i=1}^{M} \sum_{t=1}^{T} c_{t}^{\mathrm{T}} g_{t, i}^{\text {con }}
$$

Where, similarly to $(5-1), g_{t, i}^{c o n}$ is the thermal generation decision variable at period $t$, simulation path $i$ obtained from the consistent policy. The consistency benefit reflects the potential cost reduction induced by the adoption of a consistent policy. In order to avoid estimation error due to sampling, in the following study all policy simulations are executed based on the same inflow paths sample.

\subsection{Expected value of one-step ahead information}

Both the hazard-decision and decision-hazard approaches, by means of the algorithms presented on Section 3.1 and Chapter 4, provide an estimation of the expected cost of system operation, namely planning and consistent policy, respectively. The former translates a perfect information approach of the total operational cost, assuming that the operator always has perfect knowledge of the water inflow scenario beforehand, while the latter, in contrast, incorporates scenario uncertainty to the decision-making process. Hence, from expressions (3-1) and (4-16), by construction, we have:

$$
\frac{1}{M} \sum_{i=1}^{M} \sum_{t=1}^{T} c_{t}^{\mathrm{T}} g_{t, i}^{\text {plan }} \leq \frac{1}{M} \sum_{i=1}^{M} \sum_{t=1}^{T} c_{t}^{\mathrm{T}} g_{t, i}^{\text {con }}
$$

Thermal generation for the consistent policy $g_{t}^{\text {con }}$ includes both first- and second-stage decision variables. However, if the scenario is known beforehand, the first-stage dispatch $g_{t \mid t-1}^{o}$ is determined under perfect information and equality is attained. Hence, based on the concept of the expected value of perfect information (EVPI), we define the expected value of the one-step-ahead information (EVOSAI) as:

$$
E V O S A I=\frac{1}{M} \sum_{i=1}^{M} \sum_{t=1}^{T} c_{t}^{\mathrm{T}} g_{t, i}^{c o n}-\frac{1}{M} \sum_{i=1}^{M} \sum_{t=1}^{T} c_{t}^{\mathrm{T}} g_{t, i}^{\text {plan }}
$$


Which can be viewed as the value the ISO would be inclined to pay to gain access to perfect scenario information at each period $t$. EVOSAI can be equally determined by computing the difference between time-inconsistency gap and the consistency benefit, given by equations (5-1) and (5-2).

\subsection{Price of energy}

Another relevant aspect of electrical systems operation is the price of energy. How to determine the amount to be charged for each megawatt-hour is a matter of long discussion, particularly for system highly depending on hydroelectric power. Conditional upon local regulations, prices can be determined either by energy market mechanisms alone or according to explicit rules, the latter being the most common method for system relying on ISOs.

In general, prices are based on the marginal cost of energy for immediate delivery, commonly referred to as spot prices. As proposed by [46], for this study we adopt spot prices as the dual variable of power imbalance constraints, namely expressions (3-11) and (4-28) for hazard-decision and decision-hazard with augmented-state, respectively. For a given period, spot prices are fixed and determined individually for each of the buses that compose the system.

\subsection{Results analysis}

The case study presented in this work is based on the Brazilian power system, for which the inconsistent policy is closely related to the currently implemented method throughout the whole operation process determination. The objective here is to estimate the impact of adopting a decision-hazard approach for hydrothermal operation planning. To do so, we obtain the results for all three policies presented in Section 5.1 and compare the effects of each one of them on system's behavior, paying special attention to the operational cost and spot prices, as well as computational performance. All cases were run with Julia version 0.5.1 using an $\operatorname{Interl}(\mathrm{R})$ Xeon(R) CPU E5-2680 v3 @ 2.5GHz with 128GB of RAM memory.

The National Interconnected Power System (NIPS) is constituted of four distinct subsystems, namely, Southeast/Center-West (SE/CO), South (S), Northeast $(\mathrm{NE})$, and North $(\mathrm{N})$. In this version, hydro plants are aggregated into four different 
Tab. 5.1: Hydro unit data

\begin{tabular}{cccc}
\hline Subsystem & $u_{\max }(\mathrm{MWh})$ & $v_{\max }($ MWmonth $)$ & $v_{0}($ MWmonth $)$ \\
\hline SE/CO & 45829.1 & 200717.6 & 119428.8 \\
$\mathrm{~S}$ & 13381.8 & 19617.2 & 11535.1 \\
$\mathrm{NE}$ & 89780.9 & 51806.1 & 29548.2 \\
$\mathrm{~N}$ & 7740.2 & 12679.9 & 6649.4 \\
\hline
\end{tabular}

Tab. 5.3: Second-stage generator data

\begin{tabular}{cccc}
\hline Subsystem & Units & $G_{\max }(\mathrm{MWh})$ & $G_{\min }(\mathrm{MWh})$ \\
\hline $\mathrm{SE} / \mathrm{CO}$ & 13 & $2057(8.99 \%)$ & $430(1.88 \%)$ \\
$\mathrm{S}$ & 3 & $277(1.21 \%)$ & $34(0.15 \%)$ \\
$\mathrm{NE}$ & 30 & $2953(12.90 \%)$ & 0 \\
$\mathrm{~N}$ & 10 & $1000(4.37 \%)$ & $233(1.02 \%)$ \\
\hline Total & 56 & $6287(27.47 \%)$ & $697(3.05 \%)$ \\
\hline
\end{tabular}

reservoirs, each one of them located in one of the subsystems. The system is also constituted of 10 transmission lines and 111 thermal plants distributed throughout the subsystems, from which 55 are to be considered first-stage thermal units ( $2 \mathrm{nu}$ clear, 11 coal, and 42 gas-fired). Table 5.1 summarizes hydro units main details, while Tables 5.2 and 5.3 present thermal generators data, which are based on the Brazilian system data utilized in July 2017.

Tab. 5.2: First-stage generator data

\begin{tabular}{cccc}
\hline Subsystem & Units & $G_{\max }(\mathrm{MWh})$ & $G_{\min }(\mathrm{MWh})$ \\
\hline SE/CO & 24 & $8788(38.40 \%)$ & $1600(6.99 \%)$ \\
$\mathrm{S}$ & 10 & $2498(10.92 \%)$ & $738(3.22 \%)$ \\
$\mathrm{NE}$ & 8 & $2860(12.50 \%)$ & 0 \\
$\mathrm{~N}$ & 13 & $2451(10.71 \%)$ & 0 \\
\hline Total & 55 & $16597(72.53 \%)$ & $2338(10.21 \%)$ \\
\hline
\end{tabular}

The planning horizon considered in this study is 5 years long on a monthly basis and with a discount rate of $0.5 \%$ per month, i.e., approximately $6.2 \%$ per year. In order to avoid end effects ( [47]), the forward-backward iterations step is conducted considering a total period of 7 years. The simulation step is then carried out for the first 60 months only, based on a 3000 inflow paths sample. The 
inflow scenarios utilized in this study are based on monthly observations for the four equivalent reservoirs from 1991 to 2015, totalizing 25 observations per month. A periodic autoregressive model of order 1 was also utilized, so as to incorporate intertemporal effects of water inflow. The adopted convergence criteria in this work follows the methodology utilized in [25] and [37], which considers stabilization both for lower and upper bounds.

By comparing the results obtained with the planning and inconsistent policies it is possible to estimate the effects of time-inconsistency due to ignoring nonanticipativity restrictions during the planning phase. Figure 5.1 shows the difference on total energy dispatch for first- and second-stage thermal plants, given by their mean and the 5\% and $95 \%$ percentiles. For the inconsistent policy, since firststage decisions are determined based on the expected water inflow of the upcoming period, energy generation of these units, on average, are slightly lower than in the planning policy, as it lessens the impact of the most pessimistic scenarios. However, the opposite effect is observed for second-stage thermal units, as it is forced to absorb the difference in order to prevent shortages.

In Brazil, since most of the energy demand is met by hydros, energy prices augment with the beginning of the dry season, which occurs between the months of May and November. Such behavior is particularly remarkable in the NE, a subsystem for which spikes in spot prices is a well-known characteristic during the mentioned period. Hence, given the fact that cost of energy for first-stage thermal generators are in general lower, increase of second-stage energy dispatch causes a similar effect on spot prices. As shown in Figures 5.2 and 5.3, spikes on the marginal cost of energy correlate with periods of higher generation of thermal units and is considerably affected by second-stage thermal generation increase, resulting in higher spot prices for the inconsistent policy.

Increase of energy generation on more expensive thermal units also impact on operation cost. Based on the planning policy, which corresponds to the ISO's perspective, the expected operational cost for a 5 years period is MM\$12,467.7. Meanwhile, the inconsistent policy indicates an expected cost of MM\$13,960.4. Hence, the inconsistency gap related to the hazard-decision approach is equal to MM\$1,492.66, representing an increase of $11.97 \%$ over the original expected cost. The adoption of a consistent policy, however, provides an expected reduction of $\$ 738.14$, which is half of this overcost. Figure 5.4 illustrates the inconsistency gap and consistency benefit obtained within a $95 \%$ confidence interval. 


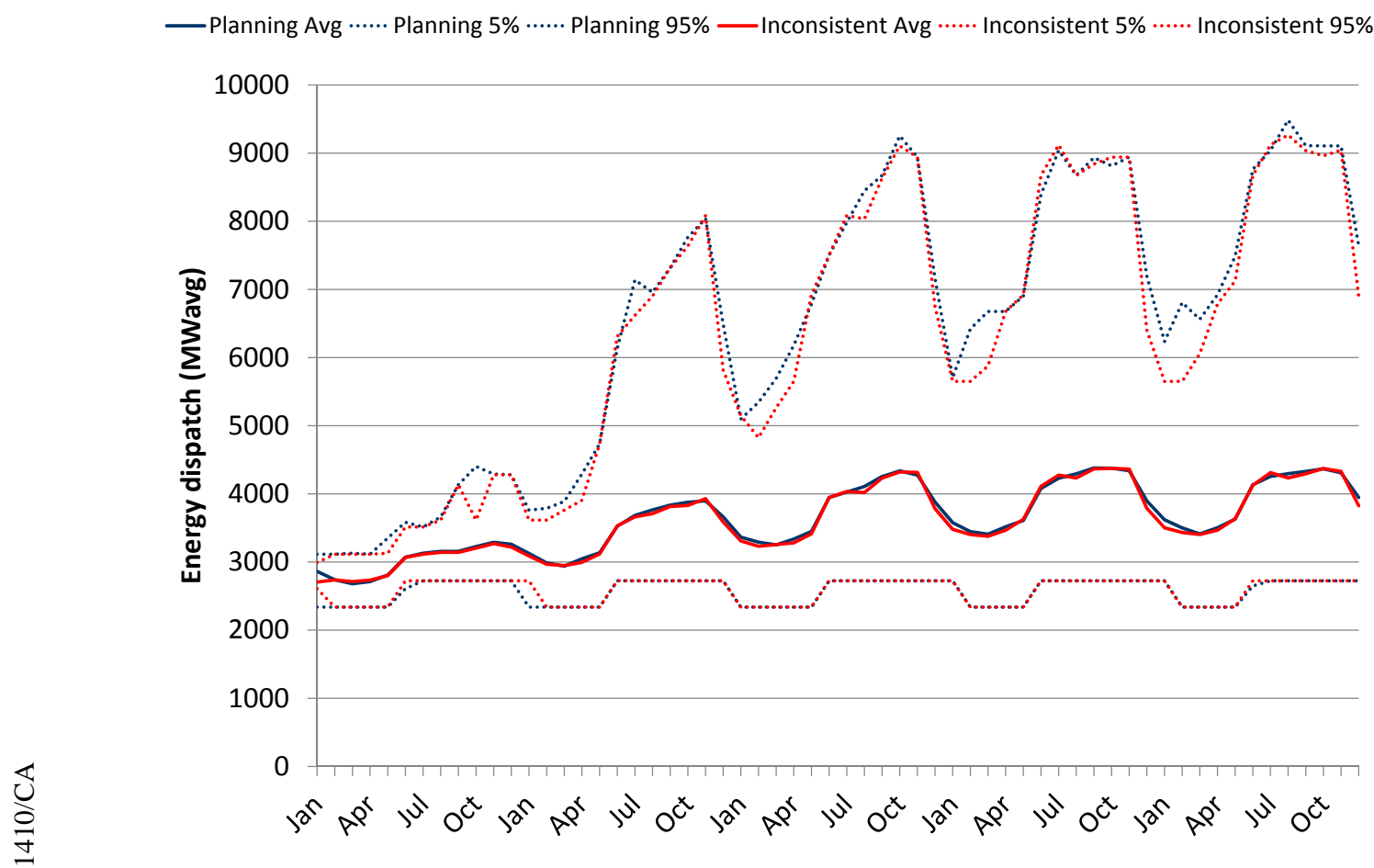

(a) First-stage

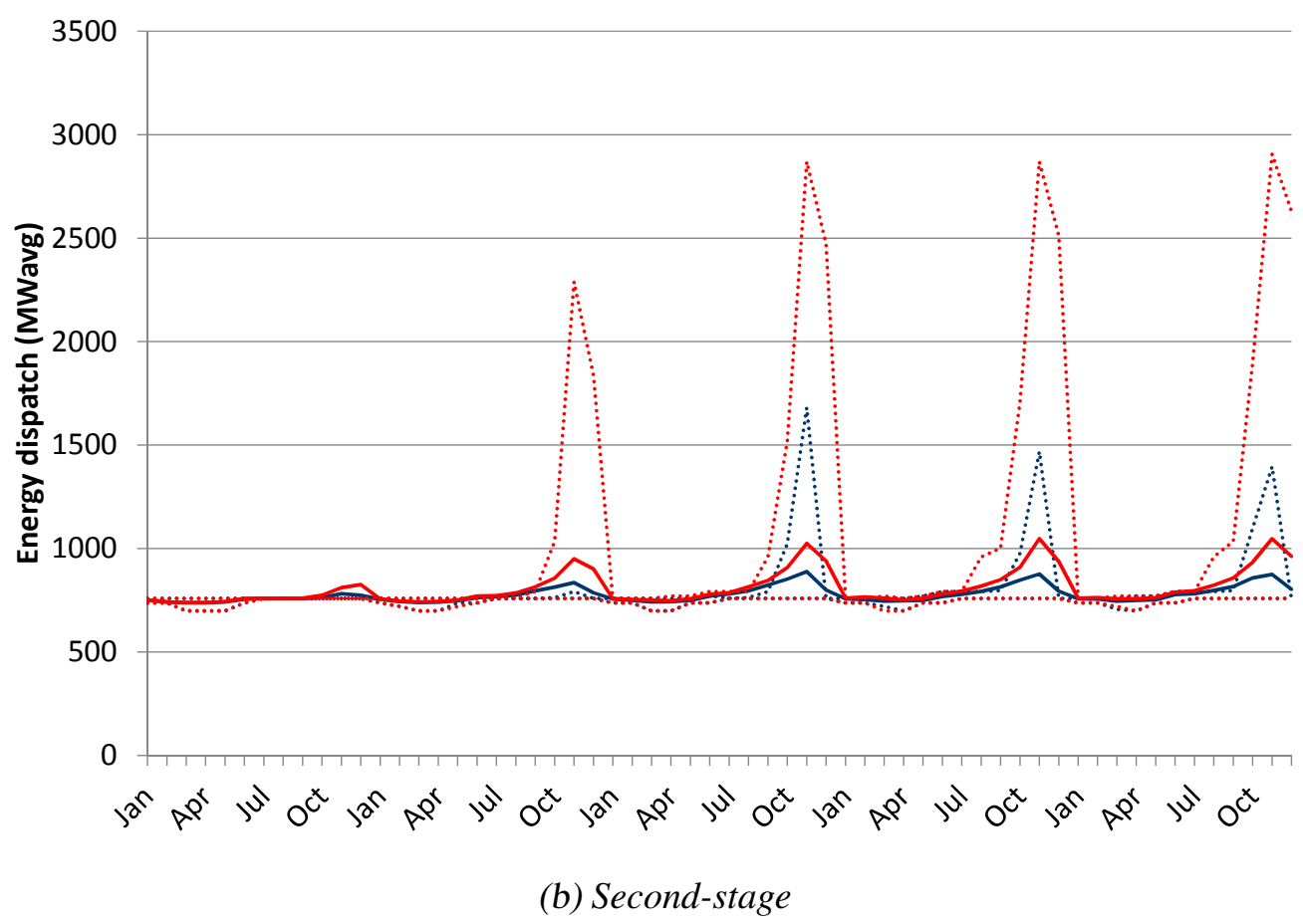

Fig. 5.1: Thermal dispatch for planning and inconsistent policies 


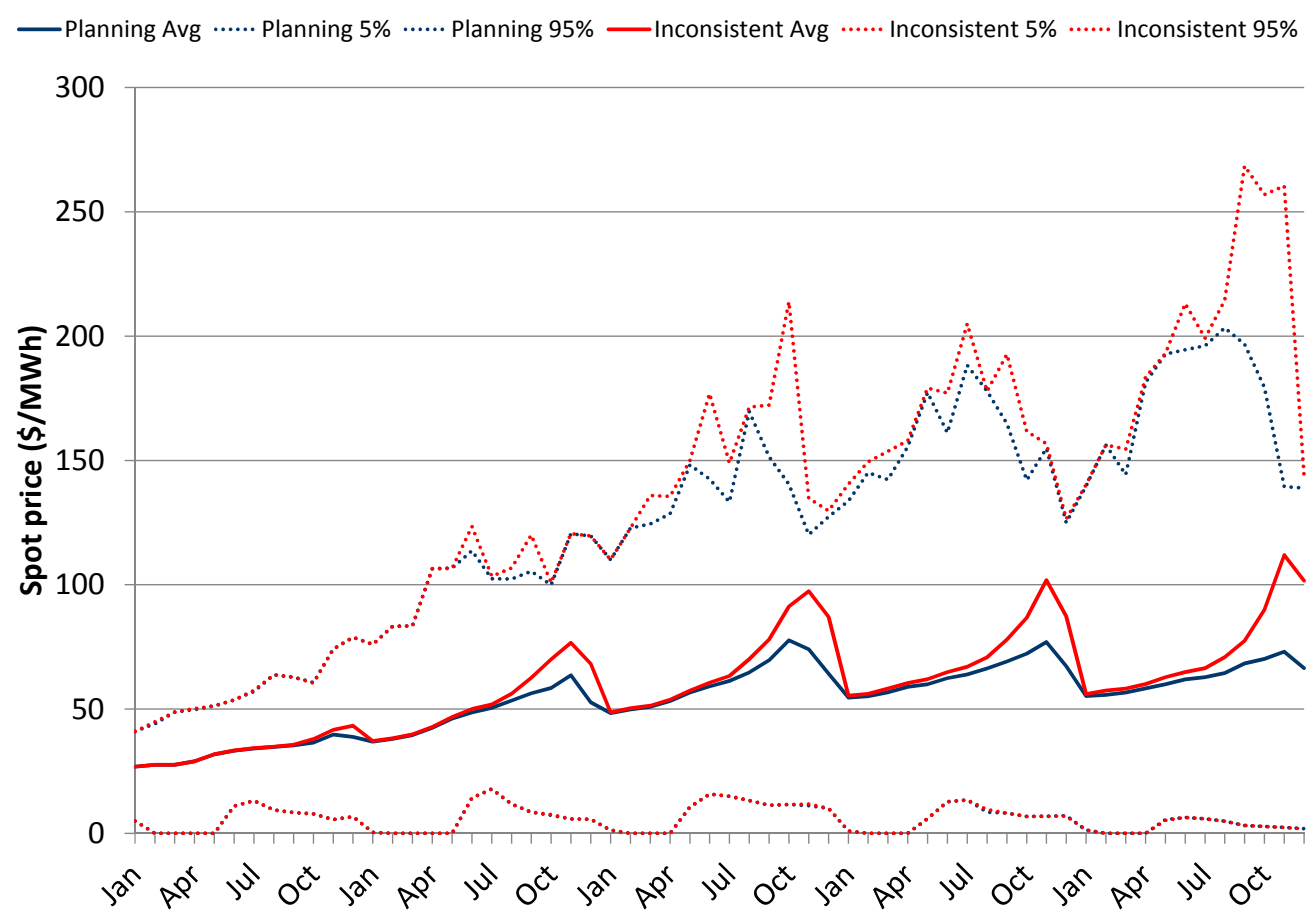

(a) Southeast Subsystem

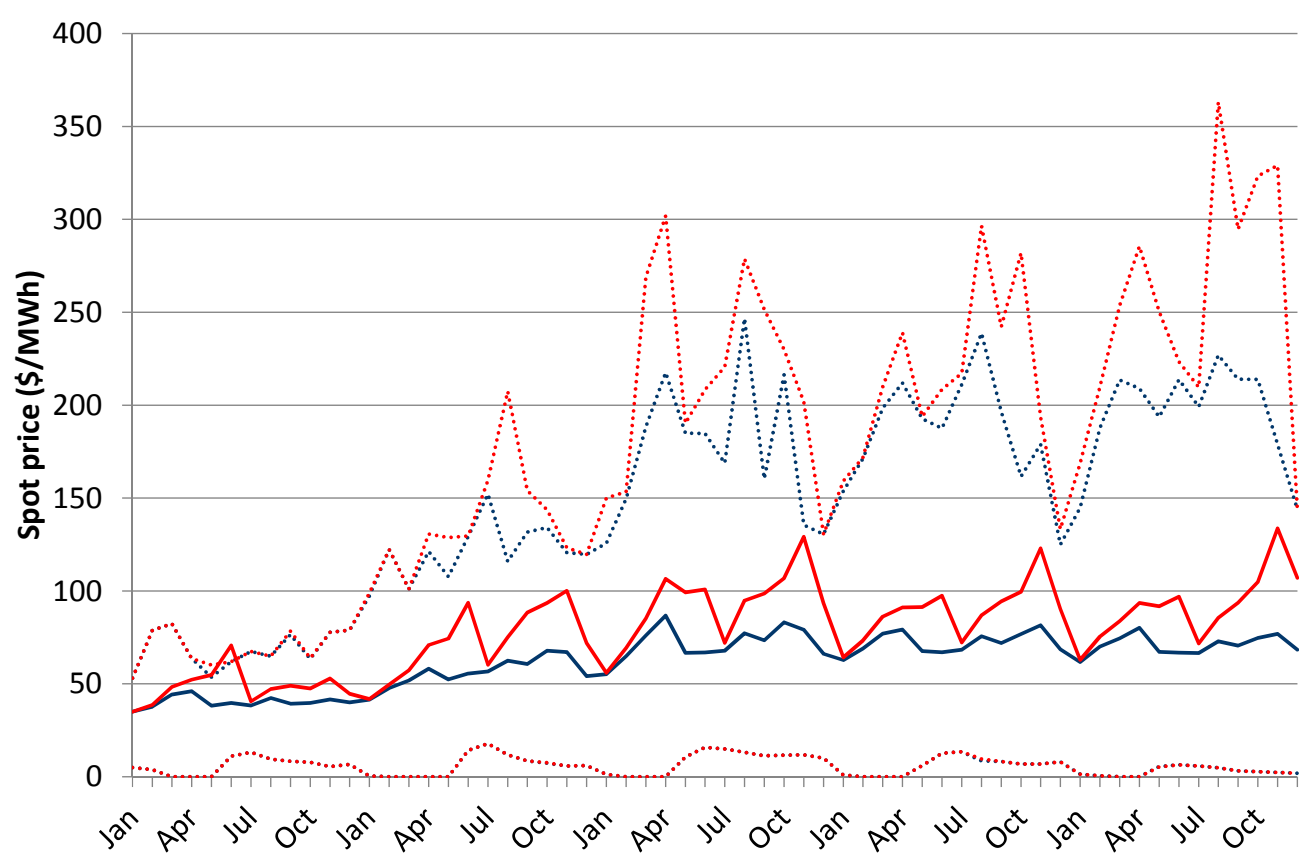

(b) South Subsystem

Fig. 5.2: Spot prices for planning and inconsistent policies 


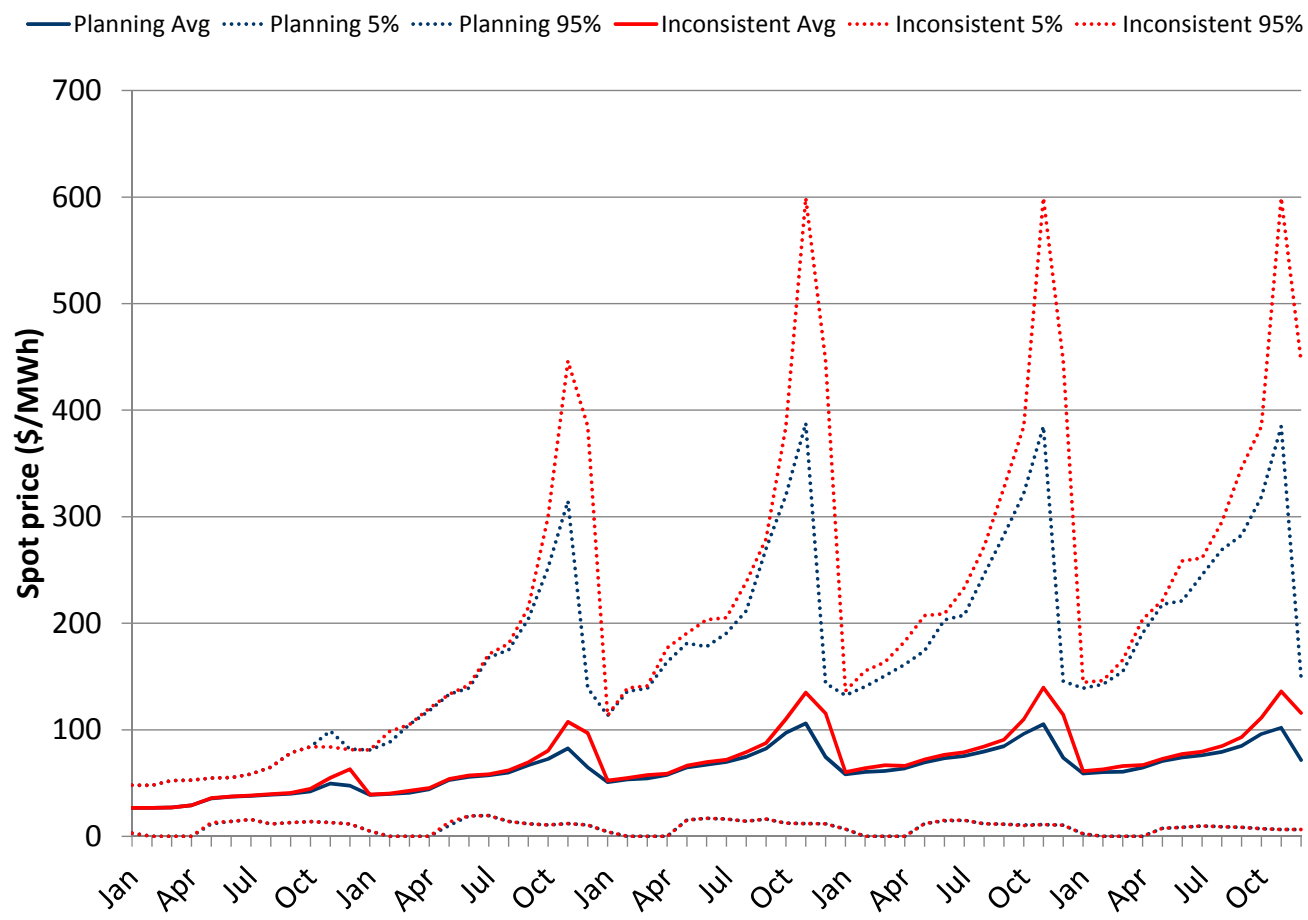

(a) Northeast Subsystem

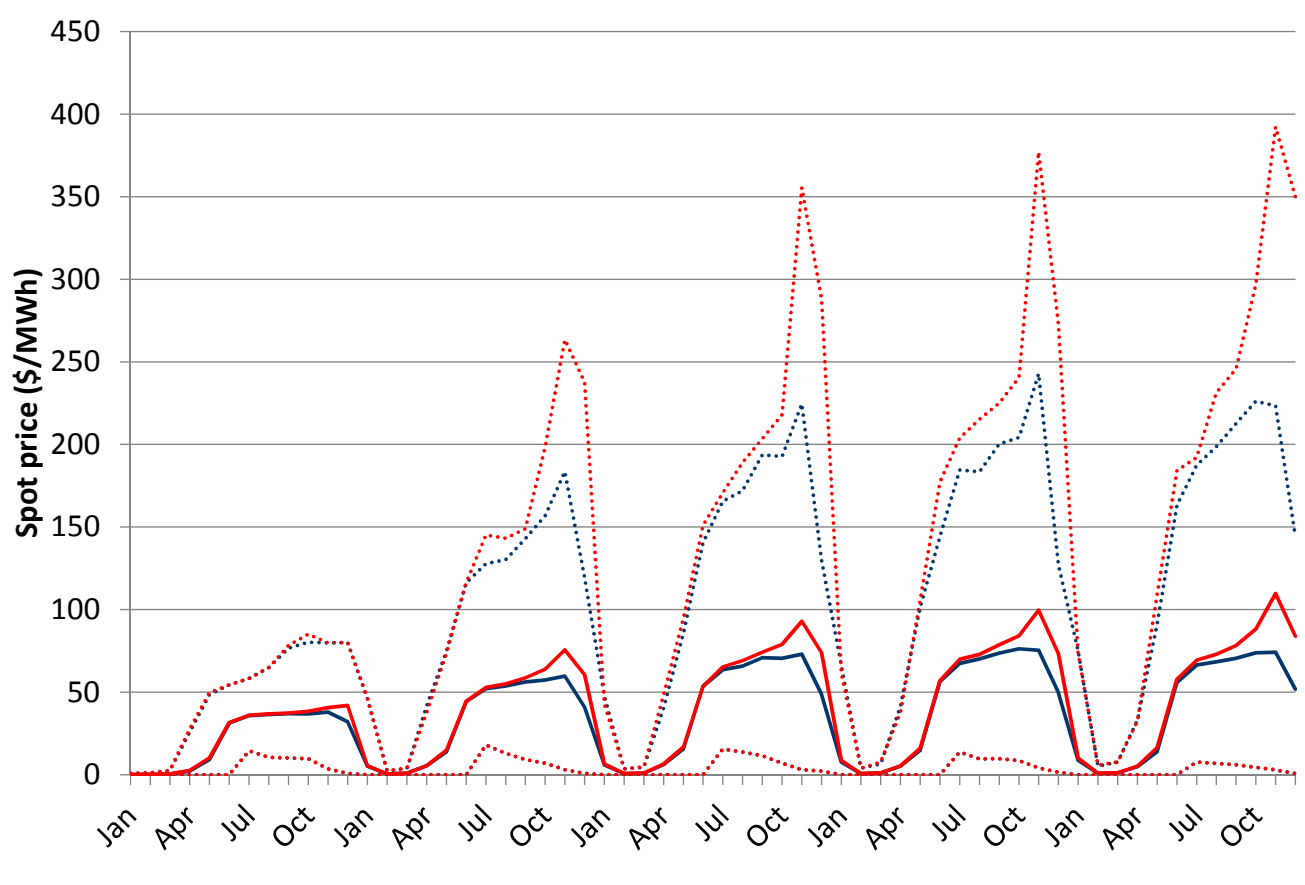

(b) North Subsystem

Fig. 5.3: Spot prices for planning and inconsistent policies (cont.) 


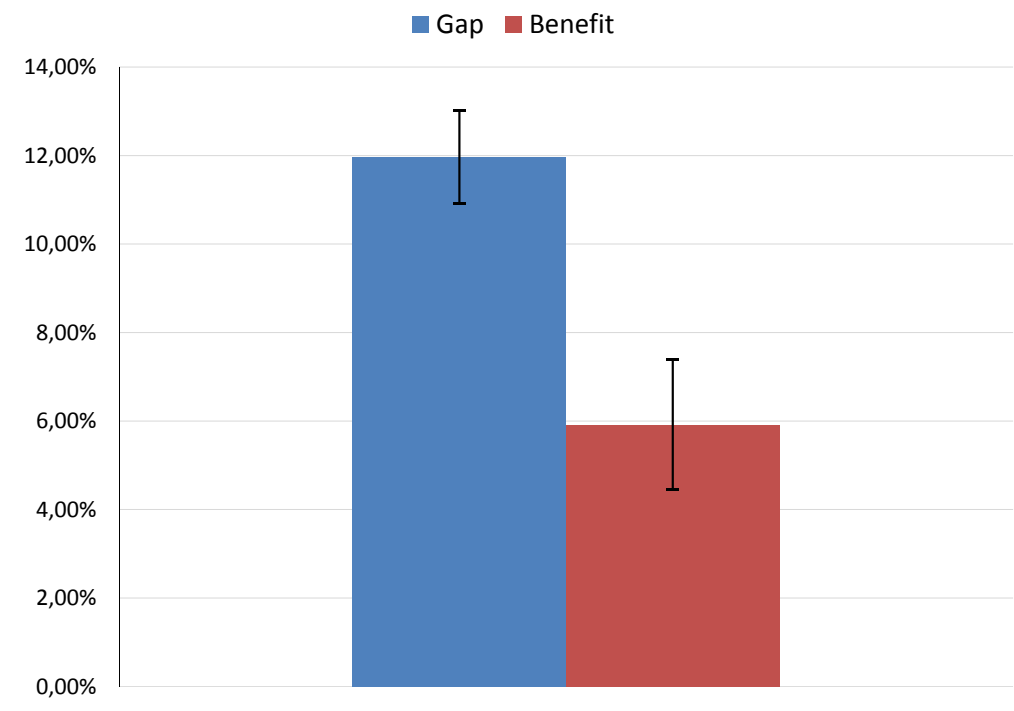

Fig. 5.4: Inconsistency gap and consistency benefit

The reason for this reduction may be explained by analyzing the system's operation when comparing the thermal dispatch resulted from the inconsistent and consistent policies. As shown in Figure 5.5, generation of first-stage thermal units tend to be higher for the latter, however, the spikes on energy dispatch of secondstage thermal plants observed previously are significantly reduced within this policy.

Again, since cost of energy of second-stage thermal generators is in general higher than first-stage units, the consistent policy presents much less pronounced spikes on energy prices with the beginning of the dry season. Moreover, the increase of first-stage energy generation results in lower variability of the marginal cost of energy throughout the whole simulated horizon. As before, such behavior is more easily seen on the NE subsystem.

Another relevant aspect of system's operation within the consistent policy is related to hydro reservoirs. Similarly to the behavior of spot prices, water volume in the reservoirs present lower variability in the consistent policy, and superior levels of storage for most of the considered period. Figures 5.8 and 5.9 depict the reservoirs situation.

The elapsed time of the different algorithms tested are summarized in Table 5.4. The $H D$ algorithm is the hazard-decision approach, equivalent to the planning policy, and corresponds to Algorithm 1; DH Two-stage is the decision-hazard implementation using non-aticipativity constraints, presented in Section 4.1 by means of Algorithm 2; DH Augmented-state is the proposed methodology presented in 


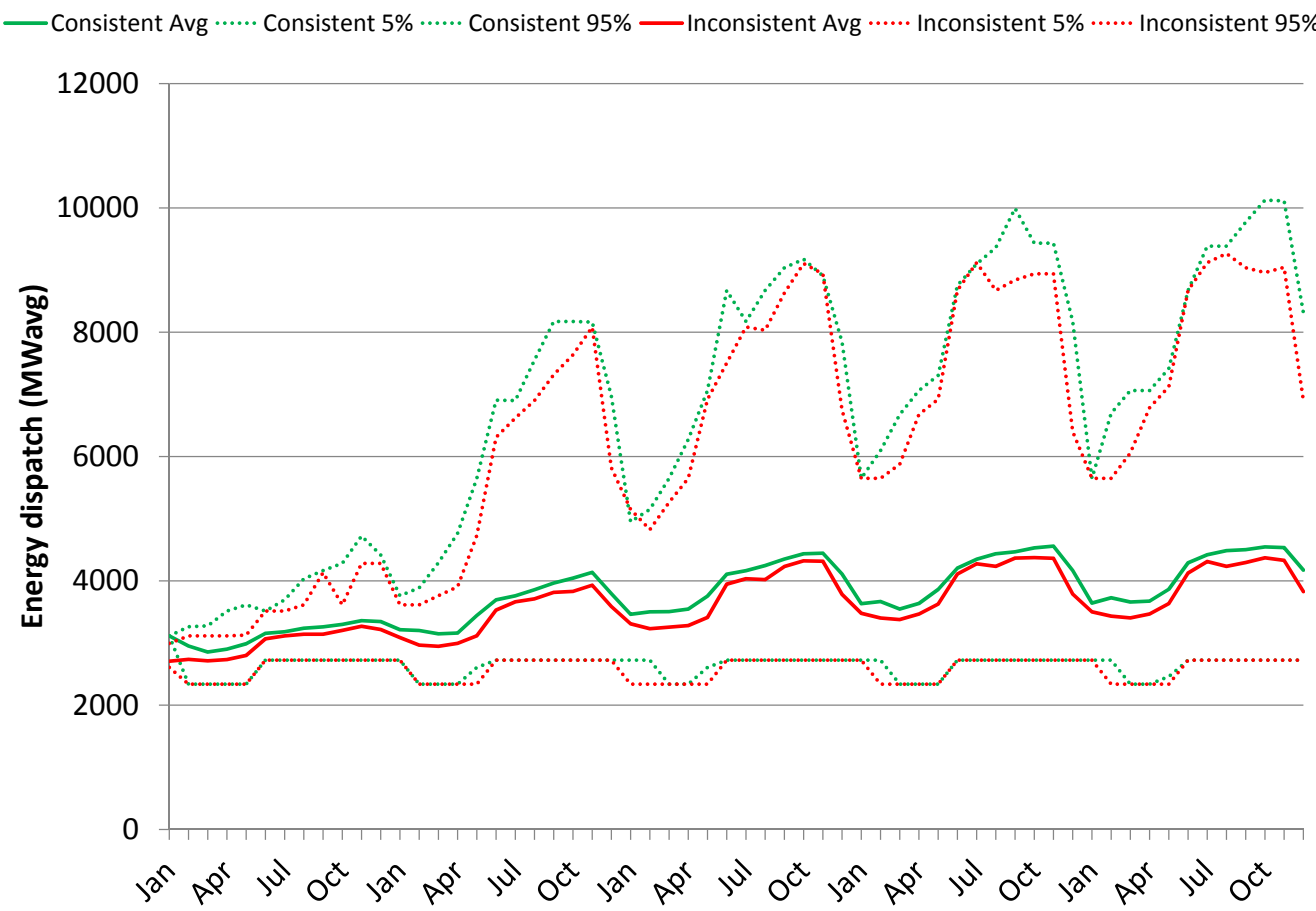

(a) First-stage

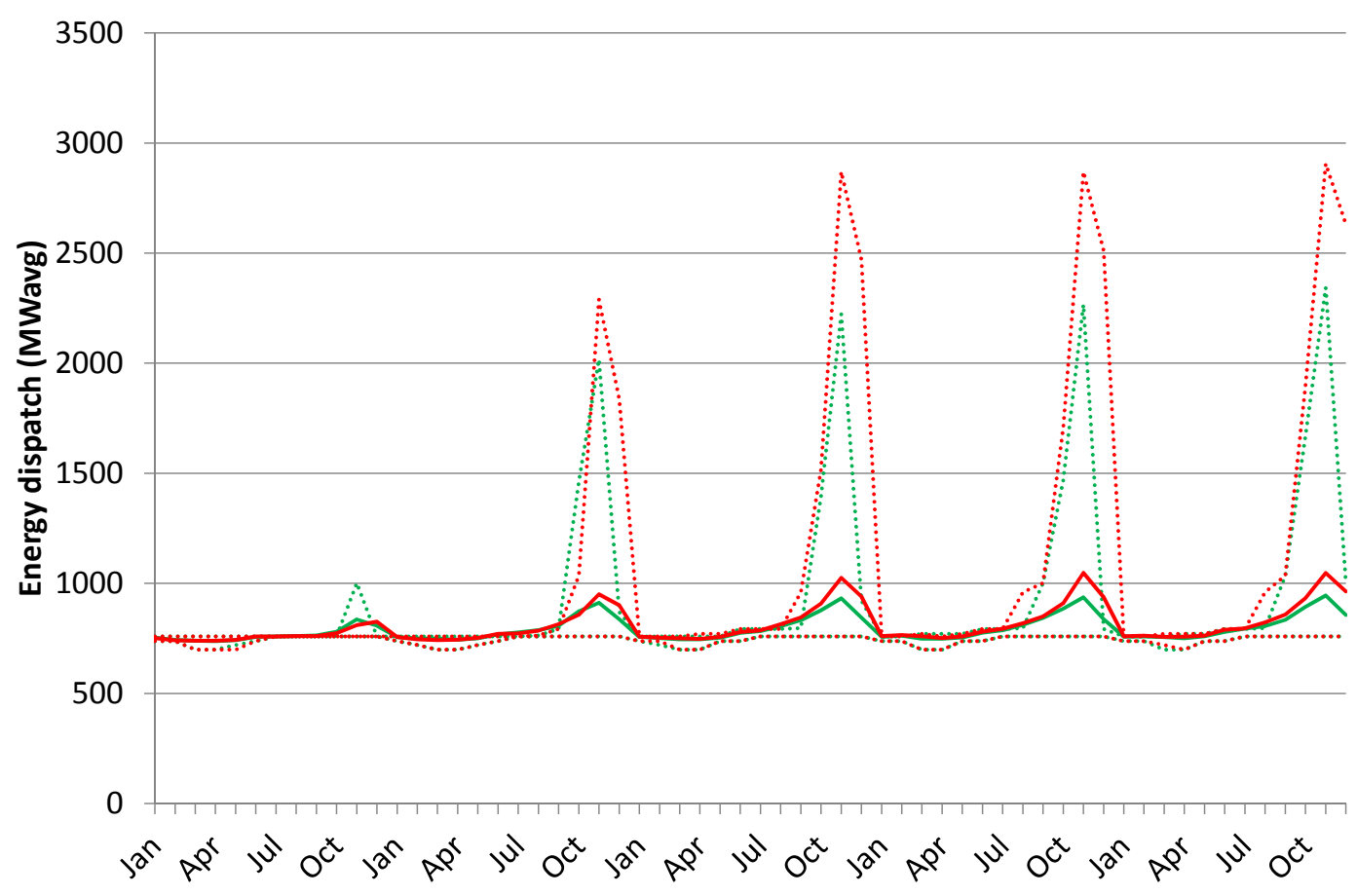

(b) Second-stage

Fig. 5.5: Thermal dispatch for inconsistent and consistent policies 


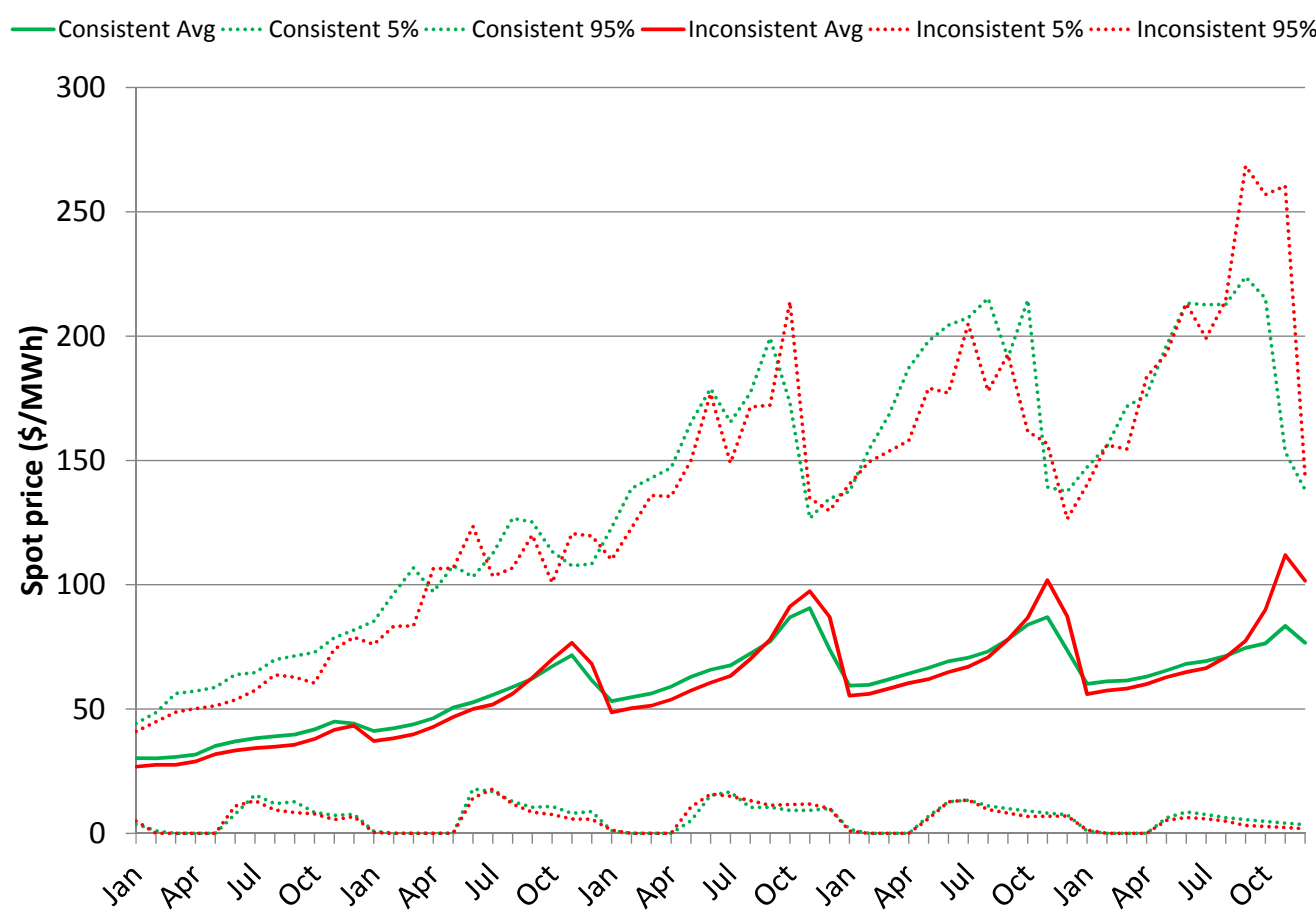

(a) Southeast Subsystem

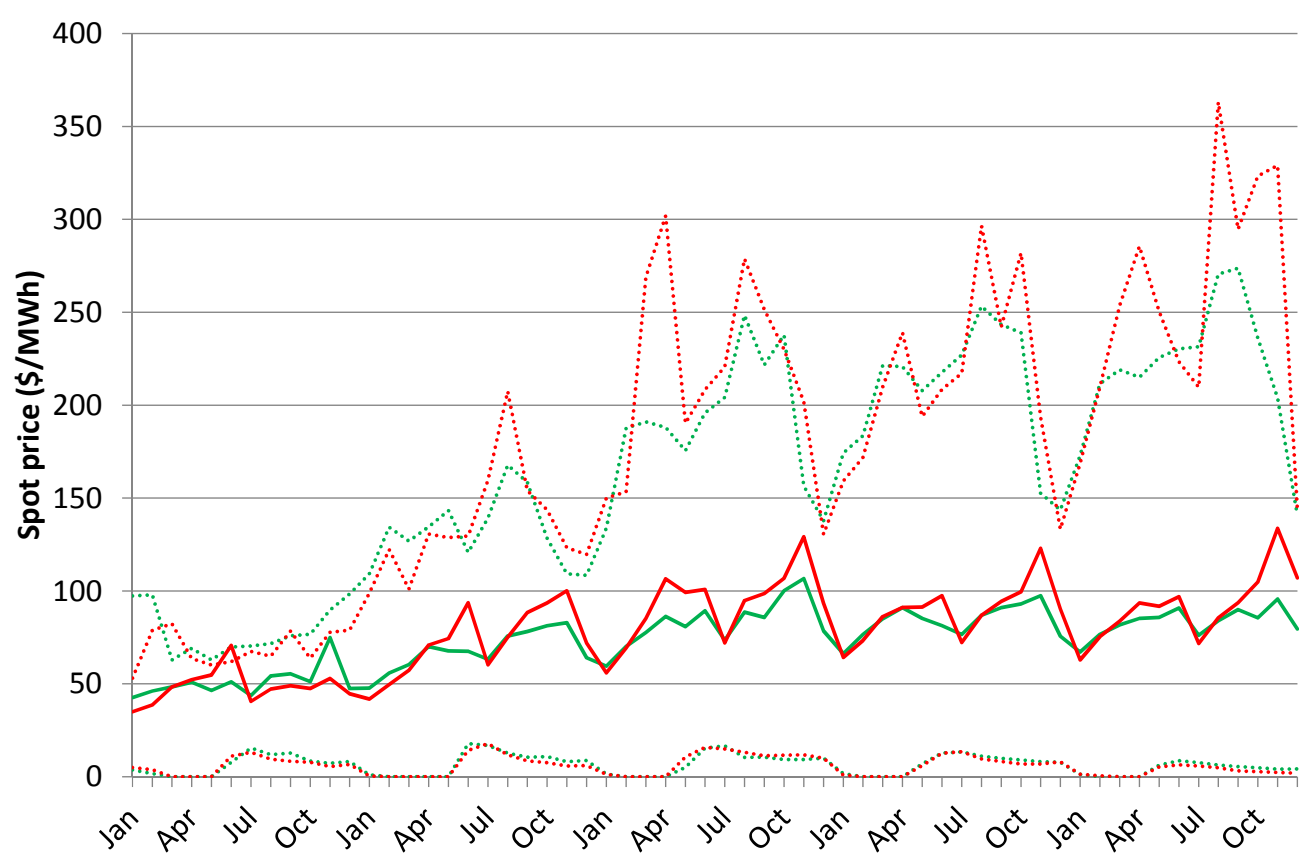

(b) South Subsystem

Fig. 5.6: Spot prices for inconsistent and consistent policies 


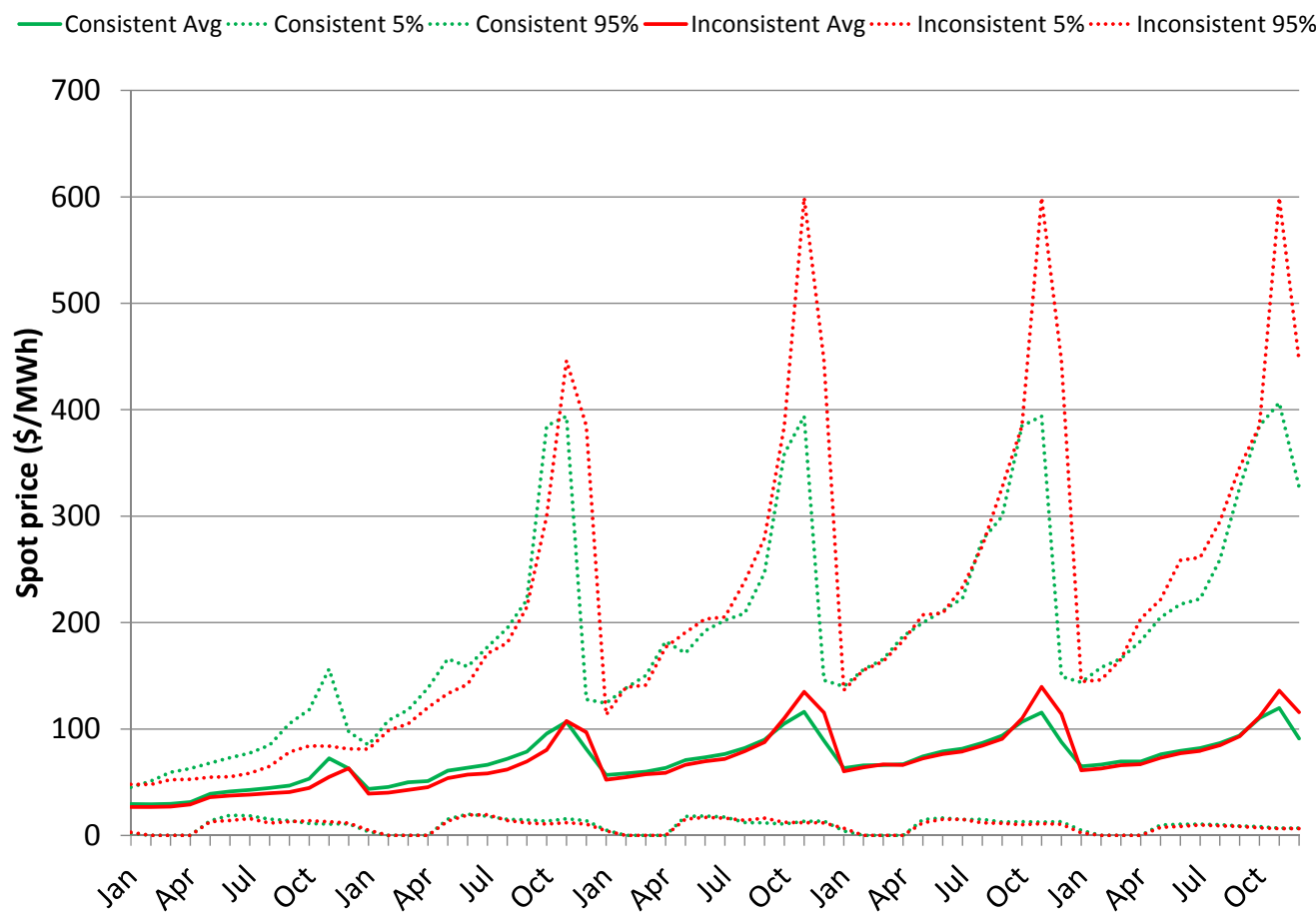

(a) Northeast Subsystem

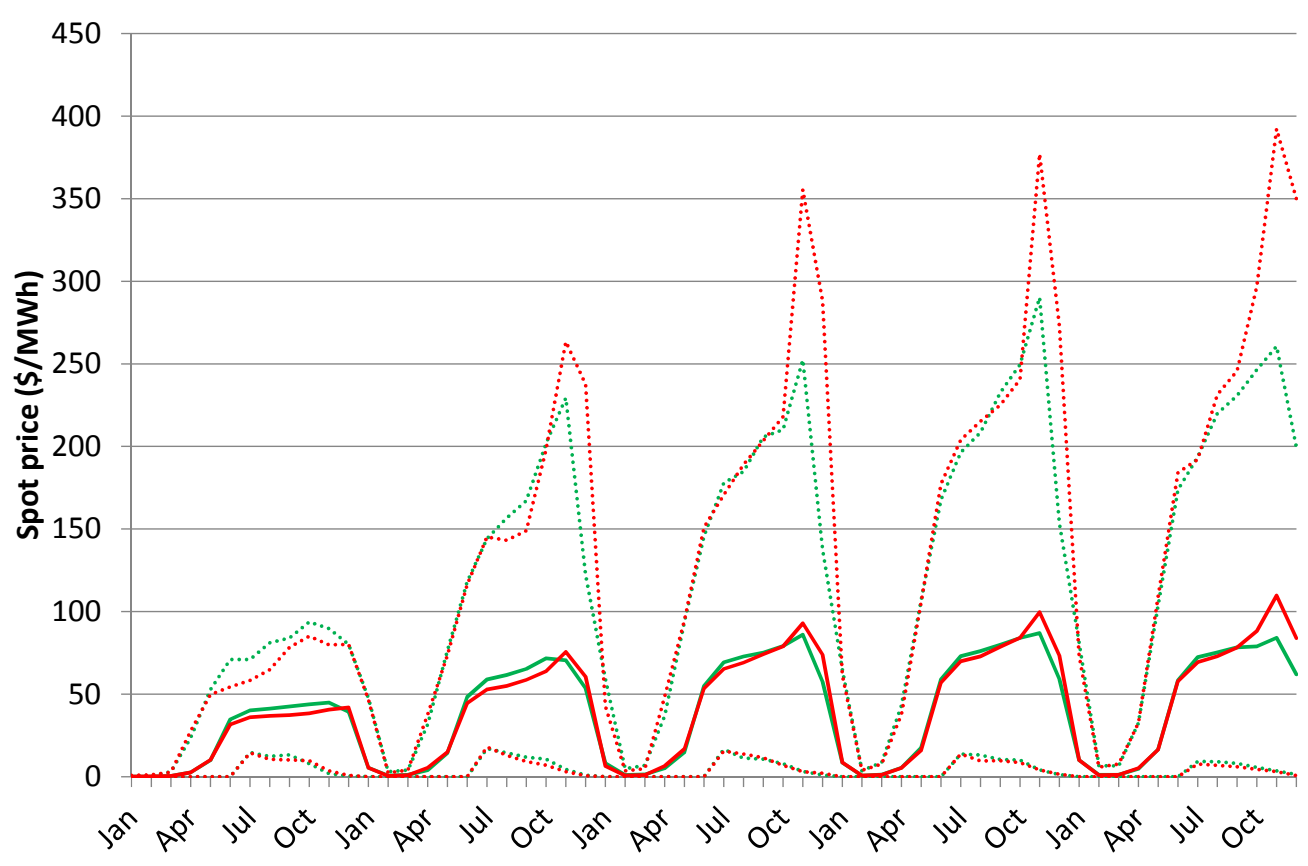

(b) North Subsystem

Fig. 5.7: Spot prices for inconsistent and consistent policies (cont.) 


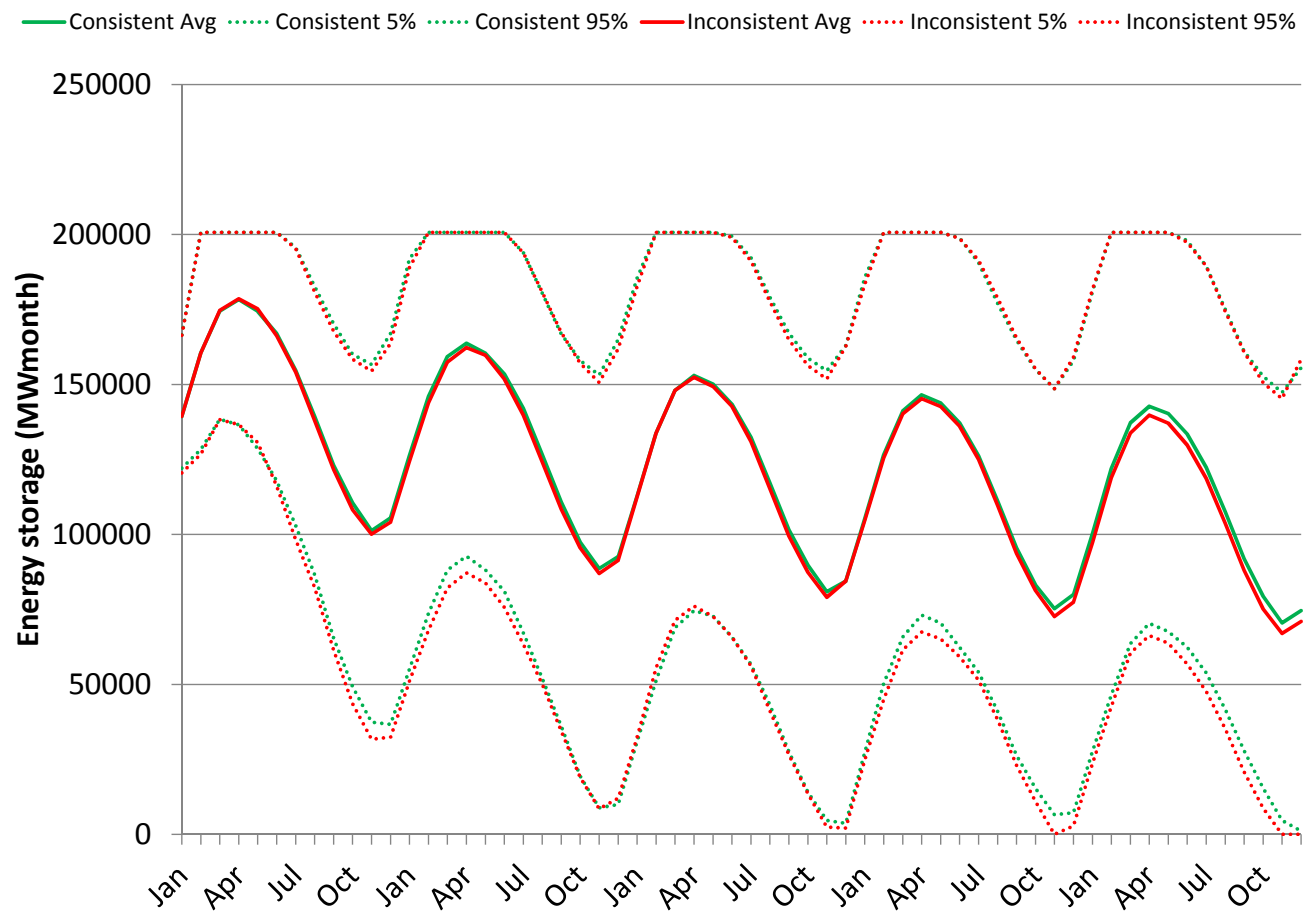

(a) Southeast Subsystem

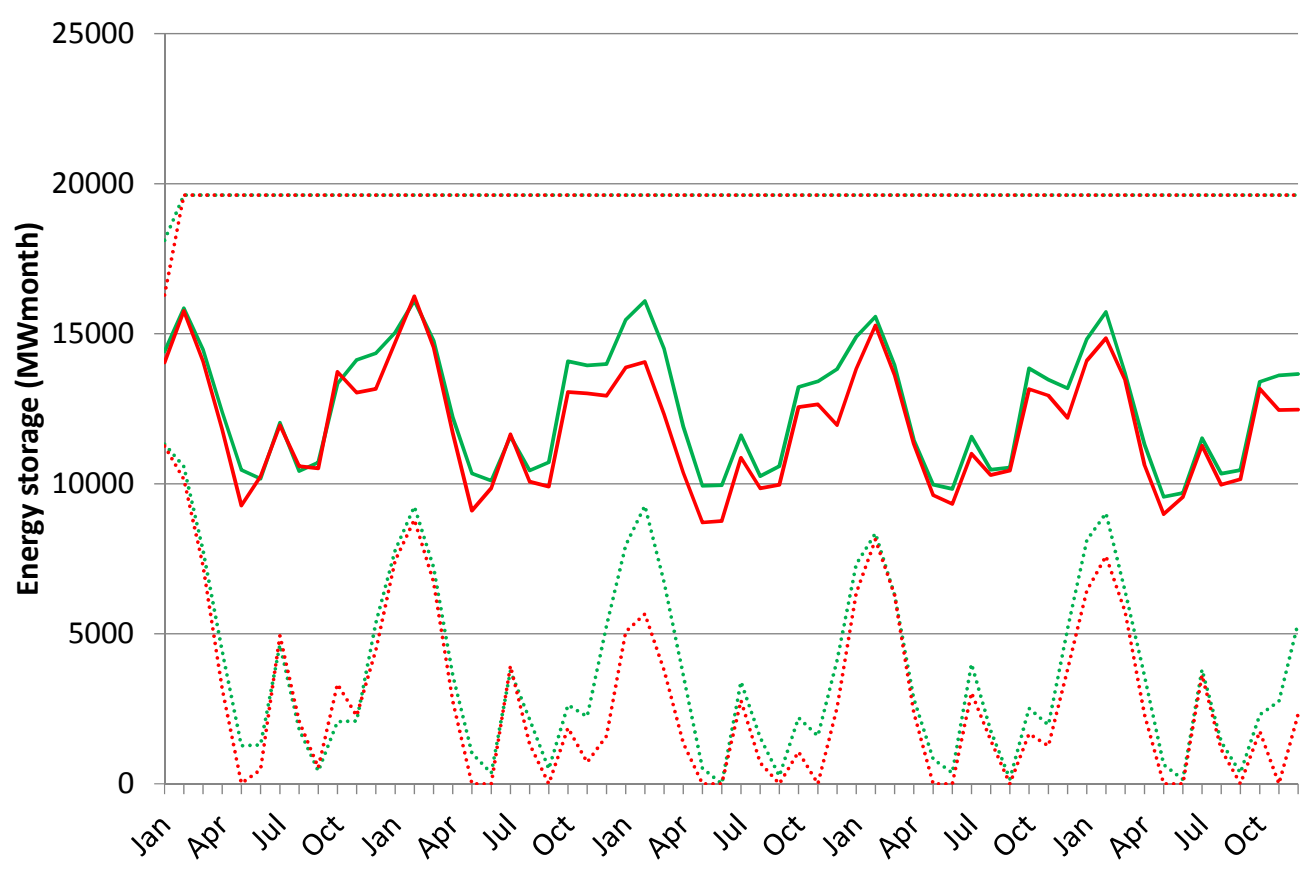

(b) South Subsystem

Fig. 5.8: Energy storage at the reservoirs 
5. CASE STUDY

59

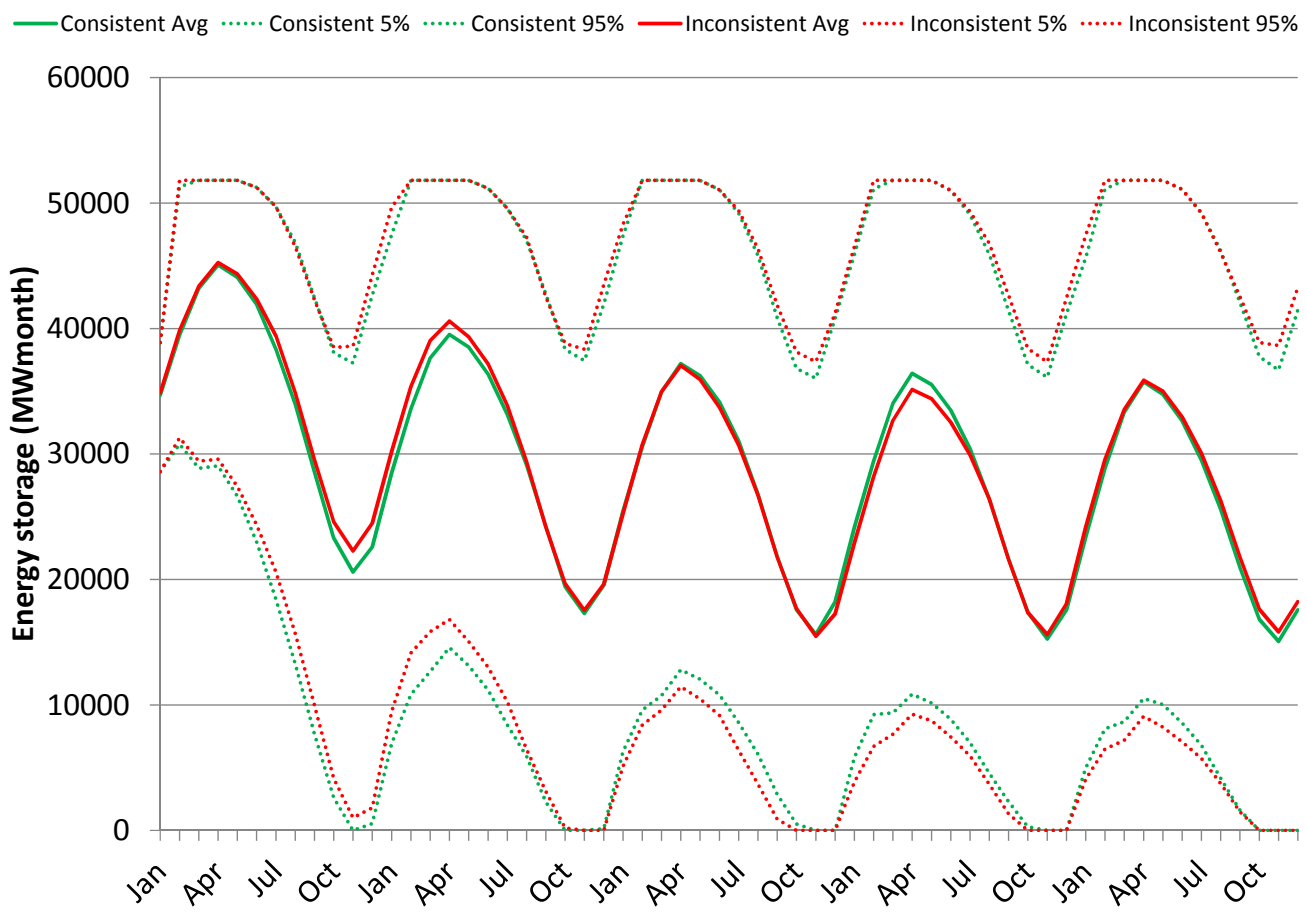

(a) Northeast Subsystem

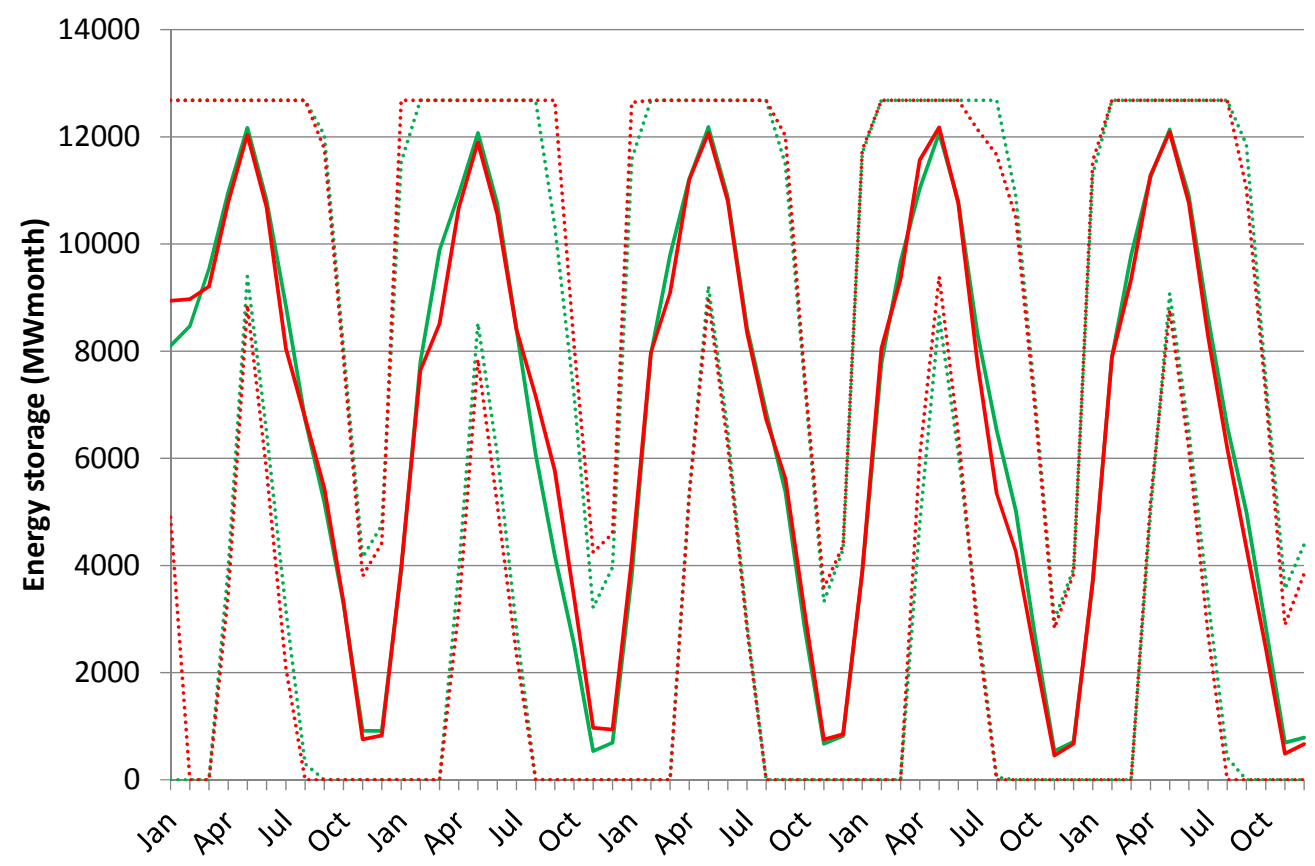

(b) North Subsystem

Fig. 5.9: Energy storage at the reservoirs (cont.) 
Section 4.2 and described in Algorithm 3.

Tab. 5.4: Elapsed time (sec)

\begin{tabular}{crrr}
\hline Algorithm & Iterations & Simulation & Total \\
\hline HD & 1,535 & 223 & 1,758 \\
DH Two-stage & 25,003 & 12,178 & 37,181 \\
DH Augmented-state & 6,699 & 1,981 & 8,680 \\
\hline
\end{tabular}

As explained in Chapter 4, the forward procedure of DH Two-stage algorithm is severely impacted due to problem structure, being the reason of time increasing both for the iteration and simulation steps, since the former also comprehend an evaluation procedure to determine stopping criterion. Based on the elapsed time obtained for this study, we notice that the incorporation of non-anticipativity constraints increases the total required time by a factor of 21 , which can be limited to less than $25 \%$ of that value by adopting the proposed augmented-state methodology. 


\section{6 \\ Conclusions}

Planning and operation of real life hydrothermal power systems regularly approximate or even neglect some restrictions when translating the problem to mathematical models. Precise representation of complex problems may be very difficult or require excessive computational effort to solve. Literature on the subject indicates that policies based on underestimated future scenarios may lead to worst operational results.

From that perspective, this work discusses the impacts on the operation of a hydrothermal power system due to an information-revelation structure simplification of the decision process. Furthermore, a solution methodology is presented in order to incorporate the decision-hazard process to a multistage problem, yet ensuring computational performance. By incorporating first-stage decision variables to the system's state, the proposed methodology ensures that the problem is non-anticipative and scenario-decomposable, therefore providing a hazard-decision solution methodology to a decision-hazard problem.

Results based on the Brazilian power system show that adopting a (consistent) decision-hazard process not only reduces the overall operational cost by diminishing the energy supply of more expensive thermal generators, but also provides reduced peaks of spot prices as well as lower variability of both spot prices and water storage on hydro reservoirs. Moreover, the proposed methodology significantly reduces the elapsed time to obtain a solution when compared to a decision-hazard model that utilizes non-anticipativity constraints.

As announced recently by the Brazilian Electricity Regulatory Agency (ANEEL), hourly prices will be adopted in the country in 2019. Adequate approximation of the daily process in the long-term operation planning will, therefore, become even more important in the near future. Increasing participation of renewable sources, already experienced presently, will also demand a satisfactory representation of the uncertainties during the planning phase. Despite the improvement presented in this work, there is still room for progress. 


\subsection{Next steps}

Computational performance may be considerably improved for the augmented-state solution approach, therefore reducing even more the difference between the hazard-decision and the decision-hazard approaches, based on the proposed methodology.

Depending on the number of thermal generators to be considered as firststage variables, the presented model may excessively increase the number of state dimensions, and consequently the required memory to treat the problem. However, reducing the impact on computer memory by taking advantage of the problem's characteristics is possible. Given that all electrical restriction are respected, energy dispatch is determined by economic reasons alone, i.e., thermal units are called to supply in ascending order of cost until fulfilling the demand. Hence, instead of treating first-stage generators individually, these units may be assembled based on bus location. In this manner, increasing of state's dimension is limited to the number of buses in the system, each of which determining the total sum of energy supplied by thermal plants located on that particular bus. Thus, constraint (4-30) is replaced by $(6-1)$.

$$
\sum_{j \in J} g_{j, t, \omega}=G_{s, t \mid t-1} \quad \forall s \leq S \quad:\left(\gamma_{s, t}\right)
$$

Where $S$ represents the number of buses of the system, $G_{s, t \mid t-1}$ is the total generation of first-stage thermal plants in bus $s$ at period $t$ determined in $t-1$, and $J$ is the set of first-stage generators formed by the partitions indexed to each of the buses of the system, i.e., $J=\cup_{s=1}^{S} J_{s}$. Thus, the problem becomes:

$$
\tilde{Q}_{t}^{(m)}\left(v_{t-1}^{(m)}, G_{t \mid t-1}^{(m)}, w_{t, \omega}\right)=\min _{\left\{\alpha_{t+1, \omega}, G_{t+1 \mid t}, y_{t, \omega}\right\}_{\omega \in \Omega_{t}}} c_{t}^{\mathrm{T}} g_{t, \omega}+\alpha_{t+1}
$$

subject to

$$
\begin{array}{ll}
A f_{t, \omega}+B g_{t, \omega}+P u_{t, \omega}=D_{t} & :\left(\tau_{t}\right) \\
v_{t, \omega}=v_{t-1}^{(m)}-H\left(u_{t, \omega}+s_{t, \omega}\right)+w_{t, \omega} & :\left(\pi_{t, \omega}^{m}\right) \\
\sum_{j \in J} g_{j, t, \omega}=G_{s, t \mid t-1}^{(m)} \quad \forall s \leq S & :\left(\gamma_{s, t}^{m}\right)
\end{array}
$$




$$
\begin{aligned}
& f_{t, \omega}=S \theta_{t, \omega} \\
& \left.\alpha_{t+1} \geq \tilde{\mathcal{Q}}_{t+1}^{(k)}\left(v^{(} k\right)_{t}, G_{t+1 \mid t}^{(k)}\right)+\tilde{\pi}_{t+1}^{(k)}{ }^{\mathrm{T}}\left(v_{t, \omega}-v_{t}^{(k)}\right)+ \\
& \sum_{s=1}^{S} \tilde{\gamma}_{s, t+1}^{(k)}{ }^{\mathrm{T}}\left(G_{s, t+1 \mid t}-G_{s, t+1 \mid t}^{(k)}\right) \quad \forall k \leq m \\
& \left(G_{t+1 \mid t}, g_{t, \omega}, u_{t, \omega}, v_{t, \omega}, s_{t, \omega}, f_{t, \omega}, \theta_{t, \omega}\right) \in \mathcal{X}_{t}
\end{aligned}
$$

And the pre-dispatch model is given by

$$
\tilde{Q}_{0}^{(m)}\left(G_{t=0}\right)=\min _{\alpha_{1}, G_{t=1 \mid 0}} \alpha_{1}
$$

subject to

$$
\begin{aligned}
& G_{\text {min }} \leq G_{t=1 \mid 0} \leq G_{\max } \\
& \alpha_{1} \geq \tilde{\mathcal{Q}}_{1}^{(k)}\left(v_{0}, G_{t=1 \mid 0}^{(k)}\right)+\sum_{s=1}^{S} \tilde{\gamma}_{s, 1}^{(k)^{\mathrm{T}}}\left(G_{s, t=1 \mid 0}-G_{s, t=1 \mid 0}^{(k)}\right) \quad \forall k \leq m
\end{aligned}
$$

This approach limits state increase to the number of buses of the system. Taking the case study presented in Chapter 5 as an example, instead of including 56 extra state dimensions to the problem, only 4 are incorporated.

Besides, the implementation of parallel computing techniques may greatly reduce the total elapsed time. 


\section{Bibliography}

[1] M. E. P. Maceira, V. Duarte, D. Penna, L. Moraes, and A. Melo, "Ten years of application of stochastic dual dynamic programming in official and agent studies in brazil-description of the newave program," 16th PSCC, Glasgow, Scotland, pp. 14-18, 2008.

[2] R. de Mello Novaes, Uma análise conceitual sobre a aplicação de modelos acaso-decisão, decisão-acaso e valor esperado no planejamento energético. Bachelor thesis, Faculdade de Engenharia, Universidade Federal de Juiz de Fora, Juiz de Fora, 2017.

[3] M. V. Pereira and L. M. Pinto, "Multi-stage stochastic optimization applied to energy planning," Mathematical programming, vol. 52, no. 1-3, pp. 359-375, 1991.

[4] R. T. Rockafellar and S. Uryasev, "Optimization of conditional value-at-risk," Journal of risk, vol. 2, pp. 21-42, 2000.

[5] A. Shapiro, W. Tekaya, J. P. da Costa, and M. P. Soares, "Risk neutral and risk averse stochastic dual dynamic programming method," European journal of operational research, vol. 224, no. 2, pp. 375-391, 2013.

[6] S. Bruno, S. Ahmed, A. Shapiro, and A. Street, "Risk neutral and risk averse approaches to multistage renewable investment planning under uncertainty," European Journal of Operational Research, vol. 250, no. 3, pp. 979-989, 2016.

[7] L. Freire, A. Street, D. A. Lima, and L. A. Barroso, "A hybrid milp and benders decomposition approach to find the nucleolus quota allocation for a renewable energy portfolio," IEEE Transactions on Power Systems, vol. 30, no. 6, pp. 3265-3275, 2015.

[8] A. B. Philpott and V. L. De Matos, "Dynamic sampling algorithms for multistage stochastic programs with risk aversion," European Journal of Operational Research, vol. 218, no. 2, pp. 470-483, 2012.

[9] M. E. P. Maceira, L. Marzano, D. D. J. Penna, A. Diniz, and T. Justino, “Application of cvar risk aversion approach in the expansion and operation planning 
and for setting the spot price in the brazilian hydrothermal interconnected system," International Journal of Electrical Power \& Energy Systems, vol. 72, pp. 126-135, 2015.

[10] M. Pereira, G. Oliveira, C. Costa, and J. Kelman, "Stochastic streamflow models for hydroelectric systems," Water Resources Research, vol. 20, no. 3, pp. 379-390, 1984.

[11] D. Jardim, M. Maceira, and D. Falcao, "Stochastic streamflow model for hydroelectric systems using clustering techniques," in Power Tech Proceedings, 2001 IEEE Porto, vol. 3, pp. 6-pp, IEEE, 2001.

[12] M. P. Soares, A. Street, and D. M. Valladão, "On the solution variability reduction of stochastic dual dynamic programming applied to energy planning," $E u$ ropean Journal of Operational Research, vol. 258, no. 2, pp. 743-760, 2017.

[13] T. N. Dos Santos and A. L. Diniz, "A dynamic piecewise linear model for dc transmission losses in optimal scheduling problems," IEEE Transactions on Power systems, vol. 26, no. 2, pp. 508-519, 2011.

[14] A. L. Diniz and M. E. P. Maceira, "A four-dimensional model of hydro generation for the short-term hydrothermal dispatch problem considering head and spillage effects," IEEE transactions on power systems, vol. 23, no. 3, pp. 1298-1308, 2008.

[15] A. Street, A. Moreira, and J. M. Arroyo, "Energy and reserve scheduling under a joint generation and transmission security criterion: An adjustable robust optimization approach," IEEE transactions on Power Systems, vol. 29, no. 1, pp. 3-14, 2014.

[16] A. Street, F. Oliveira, and J. M. Arroyo, "Contingency-constrained unit commitment with $n-k$ security criterion: A robust optimization approach," IEEE Transactions on Power Systems, vol. 26, no. 3, pp. 1581-1590, 2011.

[17] A. L. Diniz and T. M. Souza, "Short-term hydrothermal dispatch with riverlevel and routing constraints," IEEE Transactions on Power Systems, vol. 29, no. 5, pp. 2427-2435, 2014. 
[18] A. Moreira, A. Street, and J. M. Arroyo, "Energy and reserve scheduling under correlated nodal demand uncertainty: An adjustable robust optimization approach," International Journal of Electrical Power \& Energy Systems, vol. 72, pp. 91-98, 2015.

[19] F. Toledo, E. Sauma, and S. Jerardino, "Energy cost distortion due to ignoring natural gas network limitations in the scheduling of hydrothermal power systems," IEEE Transactions on Power Systems, vol. 31, no. 5, pp. 3785-3793, 2016.

[20] S. Rebennack, B. Flach, M. V. Pereira, and P. M. Pardalos, "Stochastic hydrothermal scheduling under co2 emissions constraints," IEEE Transactions on Power Systems, vol. 27, no. 1, pp. 58-68, 2012.

[21] L. Martins, A. Azevedo, and S. Soares, "Nonlinear medium-term hydrothermal scheduling with transmission constraints," IEEE Transactions on Power Systems, vol. 29, no. 4, pp. 1623-1633, 2014.

[22] B. Rudloff, A. Street, and D. M. Valladão, "Time consistency and risk averse dynamic decision models: Definition, interpretation and practical consequences," European Journal of Operational Research, vol. 234, no. 3, pp. 743-750, 2014.

[23] A. Shapiro, "On a time consistency concept in risk averse multistage stochastic programming," Operations Research Letters, vol. 37, no. 3, pp. 143-147, 2009.

[24] T. Asamov and A. Ruszczyński, "Time-consistent approximations of riskaverse multistage stochastic optimization problems," Mathematical Programming, vol. 153, no. 2, pp. 459-493, 2015.

[25] A. Brigatto, A. Street, and D. M. Valladao, "Assessing the cost of timeinconsistent operation policies in hydrothermal power systems," IEEE Transactions on Power Systems, 2017.

[26] A. Diniz, L. d. Souza, M. Maceira, S. Romero, F. Costa, C. Sagastizabal, and A. Belloni, "Estratégia de representação dc da rede elétrica no modelo de despacho da operação energética-dessem," in Proceedings of the VIII Symposium of Specialists in Electric Operational and Expansion PlanningSEPOPE, Brasilia, Brazil, 2002. 
[27] Operador Nacional do Sistema - ONS, Brasil. http://www.ons.org.br/ Paginas/resultados-da-operacao/historico-da-operacao/carga_ energia.aspx.

[28] Operador Nacional do Sistema - ONS, Brasil. http://www.ons.org. $\mathrm{br} /$ Paginas/resultados-da-operacao/historico-da-operacao/ energia_armazenada.aspx.

[29] R. J.-B. Wets, "Chapter viii stochastic programming," Handbooks in operations research and management science, vol. 1, pp. 573-629, 1989.

[30] A. S. Kligerman, Operação Ótima de Subsistemas Hidrotérmicos Interligados Utilizando Programação Dinamica Estocástica Dual. PhD thesis, Faculdade de Engenharia Elétrica e Computação - FEEC, Universidade Estadual de Campinas, Campinas, 1992.

[31] A. L. Diniz and M. E. Maceira, "Multi-lag benders decomposition for power generation planning with nonanticipativity constraints on the dispatch of $\operatorname{lng}$ thermal plants," in Stochastic Programming: Applications in Finance, Energy, Planning and Logistics, pp. 443-464, World Scientific, 2013.

[32] K. Linowsky and A. B. Philpott, "On the convergence of sampling-based decomposition algorithms for multistage stochastic programs," Journal of optimization theory and applications, vol. 125, no. 2, pp. 349-366, 2005.

[33] A. B. Philpott and Z. Guan, "On the convergence of stochastic dual dynamic programming and related methods," Operations Research Letters, vol. 36, no. 4, pp. 450-455, 2008.

[34] P. Girardeau, V. Leclere, and A. B. Philpott, "On the convergence of decomposition methods for multistage stochastic convex programs," Mathematics of Operations Research, vol. 40, no. 1, pp. 130-145, 2014.

[35] A. Shapiro, "Analysis of stochastic dual dynamic programming method," European Journal of Operational Research, vol. 209, no. 1, pp. 63-72, 2011.

[36] T. Homem-de Mello, V. L. De Matos, and E. C. Finardi, "Sampling strategies and stopping criteria for stochastic dual dynamic programming: a case study in long-term hydrothermal scheduling," Energy Systems, vol. 2, no. 1, pp. 131, 2011. 
[37] A. Street, A. Brigatto, and D. M. Valladao, "Co-optimization of energy and ancillary services for hydrothermal operation planning under a general security criterion," IEEE Transactions on Power Systems, 2017.

[38] Operador Nacional do Sistema - ONS, Brasil. http: //www . ons . org. br/pt/ paginas/sobre-o-sin/o-sistema-em-numeros.

[39] Operador Nacional do Sistema - ONS, Brasil. http://www . ons.org.br/PublishingImages/paginas/sobre_sin/mapas/ SistemadeTransmissao_Horizonte2017.jpg.

[40] Agência Nacional de Energia Eltrica ANEEL, Brasil. http://www.aneel.gov.br/ acompanhamento-da-expansao-da-oferta-de-geracao-de-energia-eletrica.

[41] Operador Nacional do Sistema - ONS, Brasil. http://www.ons.org. br/Paginas/resultados-da-operacao/historico-da-operacao/ geracao_energia.aspx.

[42] Operador Nacional do Sistema - ONS, Brasil. http://www.ons. org.br/PublishingImages/paginas/sobre_sin/mapas/Diagrama_ Esquematico_Usinas_Hidroeletricas_SIN_Ago2017.jpg.

[43] M. P. Maceira, L. A. Terry, F. S. Costa, J. M. Damázio, and A. Melo, "Chain of optimization models for setting the energy dispatch and spot price in the brazilian system," in Proceedings of the Power System Computation ConferencePSCC, vol. 2, pp. 24-28, 2002.

[44] N. V. Arvanitidits and J. Rosing, "Composite representation of a multireservoir hydroelectric power system," IEEE Transactions on Power Apparatus and Systems, no. 2, pp. 319-326, 1970.

[45] M. Maceira, V. Duarte, D. Penna, and M. Tcheou, "An approach to consider hydraulic coupled systems in the construction of equivalent reservoir model in hydrothermal operation planning," in 17th Power Systems Computation Conference, Stockholm, 2011.

[46] F. C. Schweppe, M. C. Caramanis, R. D. Tabors, and R. E. Bohn, Spot pricing of electricity. Springer Science \& Business Media, 2013. 
[47] R. C. Grinold, "Model building techniques for the correction of end effects in multistage convex programs," Operations Research, vol. 31, no. 3, pp. 407$431,1983$. 
APPENDIX

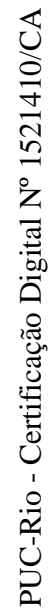




\section{A \\ Data For Case Studies From Chapter 5}

Transmission lines data:

Tab. A.1: Transmission line data for case studies from Chapter 5

\begin{tabular}{ccccc}
\hline $\begin{array}{c}\text { Transmission } \\
\text { line }\end{array}$ & From & To & $\bar{F}$ (MWavg) & $x(\mathrm{pu})$ \\
\hline 1 & $\mathrm{SE}$ & $\mathrm{S}$ & 7710 & 1 \\
2 & $\mathrm{SE}$ & $\mathrm{S}$ & 7700 & 1 \\
3 & $\mathrm{SE}$ & $\mathrm{NE}$ & 1010 & 1 \\
4 & $\mathrm{SE}$ & $\mathrm{NE}$ & 1000 & 1 \\
5 & $\mathrm{SE}$ & Imperatriz & 4010 & 1 \\
6 & $\mathrm{SE}$ & Imperatriz & 4000 & 1 \\
7 & $\mathrm{NE}$ & Imperatriz & 3970 & 1 \\
8 & $\mathrm{NE}$ & Imperatriz & 3960 & 1 \\
9 & $\mathrm{~N}$ & Imperatriz & 3159 & 1 \\
10 & $\mathrm{~N}$ & Imperatriz & 3149 & 1 \\
\hline
\end{tabular}

Thermal generators data:

Tab. A.2: Thermal generators data for case studies from Chapter 5

\begin{tabular}{cccccc}
\hline $\begin{array}{c}\text { Thermal } \\
\text { Unit }\end{array}$ & Subsystem & $c$ (R\$/MWavg) & $\bar{G}($ MWavg $)$ & $\underline{G}($ MWavg $)$ & Fuel \\
\hline 1.0 & SE & 29.13 & 640.0 & 520.0 & Nuclear \\
2.0 & $\mathrm{SE}$ & 20.12 & 1350.0 & 1080.0 & Nuclear \\
3.0 & $\mathrm{SE}$ & 88.08 & 530.0 & 0.0 & Gas \\
4.0 & $\mathrm{SE}$ & 937.0 & 36.0 & 0.0 & Oil \\
5.0 & $\mathrm{SE}$ & 300.89 & 157.0 & 0.0 & Gas \\
6.0 & $\mathrm{SE}$ & 300.62 & 59.0 & 0.0 & Gas \\
7.0 & $\mathrm{SE}$ & 511.77 & 529.0 & 0.0 & Gas \\
8.0 & $\mathrm{SE}$ & 751.48 & 44.0 & 0.0 & Diesel \\
9.0 & $\mathrm{SE}$ & 0.0 & 255.0 & 216.34 & Waste \\
10.0 & $\mathrm{SE}$ & 173.66 & 235.0 & 201.5 & Waste \\
11.0 & $\mathrm{SE}$ & 282.58 & 321.0 & 0.0 & Gas \\
12.0 & $\mathrm{SE}$ & 305.82 & 65.0 & 0.0 & Gas \\
13.0 & $\mathrm{SE}$ & 399.02 & 572.0 & 0.0 & Gas \\
14.0 & $\mathrm{SE}$ & 779.03 & 140.0 & 0.0 & Diesel \\
15.0 & $\mathrm{SE}$ & 303.29 & 226.0 & 0.0 & Gas \\
16.0 & $\mathrm{SE}$ & 653.43 & 131.0 & 0.0 & Oil
\end{tabular}




\begin{tabular}{|c|c|c|c|c|c|c|}
\hline & 17.0 & SE & 213.84 & 87.0 & 0.0 & Gas \\
\hline & 18.0 & SE & 190.44 & 204.0 & 52.57 & LNG \\
\hline & 19.0 & SE & 50.93 & 400.0 & 0.0 & Gas \\
\hline & 20.0 & SE & 59.94 & 100.0 & 0.0 & Gas \\
\hline & 21.0 & SE & 114.06 & 200.0 & 0.0 & Gas \\
\hline & 22.0 & SE & 232.56 & 127.0 & 0.0 & Gas \\
\hline & 23.0 & SE & 592.66 & 176.0 & 0.0 & Diesel \\
\hline & 24.0 & SE & 470.34 & 200.0 & 0.0 & Gas \\
\hline & 25.0 & SE & 630.47 & 25.0 & 0.0 & Diesel \\
\hline & 26.0 & SE & 310.41 & 436.0 & 0.0 & Oil \\
\hline & 27.0 & SE & 127.40 & 500.0 & 0.0 & LNG \\
\hline & 28.0 & SE & 182.55 & 134.0 & 0.0 & Gas \\
\hline & 29.0 & SE & 301.94 & 216.0 & 0.0 & Gas \\
\hline & 30.0 & SE & 678.04 & 340.0 & 0.0 & Oil \\
\hline & 31.0 & SE & 504.65 & 929.0 & 0.0 & Gas \\
\hline & 32.0 & SE & 216.31 & 770.0 & 0.0 & Gas \\
\hline & 33.0 & SE & 304.51 & 266.0 & 0.0 & Gas \\
\hline & 34.0 & SE & 1047.38 & 10.0 & 0.0 & Diesel \\
\hline & 35.0 & SE & 392.3 & 175.0 & 12.86 & Oil \\
\hline & 36.0 & SE & 297.27 & 206.0 & 0.0 & Gas \\
\hline in & 37.0 & SE & 1077.29 & 54.0 & 0.0 & Diesel \\
\hline $\bar{z}$ & 38.0 & $\mathrm{~S}$ & 710.65 & 485.0 & 0.0 & Gas \\
\hline$\overline{\widetilde{J}}$ & 39.0 & $S$ & 77.96 & 350.0 & 202.71 & Coal \\
\hline & 40.0 & $S$ & 698.14 & 249.0 & 34.49 & Diesel \\
\hline & 41.0 & $S$ & 278.12 & 4.0 & 0.0 & Biomass \\
\hline & 42.0 & S & 486.49 & 20.0 & 8.05 & Coal \\
\hline & 43.0 & $S$ & 238.56 & 100.0 & 27.8 & Coal \\
\hline$\frac{1}{2}$ & 44.0 & S & 217.89 & 132.0 & 70.21 & Coal \\
\hline & 45.0 & $S$ & 209.48 & 262.0 & 175.87 & Coal \\
\hline & 46.0 & $S$ & 178.91 & 363.0 & 253.78 & Coal \\
\hline & 47.0 & $S$ & 780.0 & 24.0 & 0.0 & Oil \\
\hline & 48.0 & S & 115.9 & 126.0 & 0.0 & Coal \\
\hline & 49.0 & S & 248.31 & 20.0 & 0.0 & Coal \\
\hline & 50.0 & $S$ & 486.2 & 640.0 & 0.0 & Gas \\
\hline & 51.0 & $\mathrm{NE}$ & 645.84 & 13.0 & 50.5 & Diesel \\
\hline & 52.0 & $\mathrm{NE}$ & 645.84 & 11.0 & 66.6 & Diesel \\
\hline & 53.0 & $\mathrm{NE}$ & 513.35 & 31.0 & 0.0 & Oil \\
\hline & 54.0 & $\mathrm{NE}$ & 645.84 & 11.0 & 182.0 & Diesel \\
\hline & 55.0 & $\mathrm{NE}$ & 943.88 & 347.0 & 0.0 & Diesel \\
\hline & 56.0 & $\mathrm{NE}$ & 599.17 & 150.0 & 0.0 & Oil \\
\hline & 57.0 & $\mathrm{NE}$ & 392.31 & 169.0 & 0.0 & Oil \\
\hline & 58.0 & $\mathrm{NE}$ & 645.84 & 13.0 & 10.8 & Diesel \\
\hline & 59.0 & $\mathrm{NE}$ & 645.84 & 15.0 & 320.1 & Diesel \\
\hline
\end{tabular}




\begin{tabular}{|c|c|c|c|c|c|c|}
\hline & 60.0 & NE & 645.84 & 13.0 & 6.8 & Diesel \\
\hline & 61.0 & $\mathrm{NE}$ & 645.84 & 15.0 & 6.2 & Diesel \\
\hline & 62.0 & $\mathrm{NE}$ & 301.36 & 138.0 & 0.0 & Gas \\
\hline & 63.0 & $\mathrm{NE}$ & 139.88 & 327.0 & 0.0 & Gas \\
\hline & 64.0 & $\mathrm{NE}$ & 446.22 & 149.0 & 0.0 & Oil \\
\hline & 65.0 & $\mathrm{NE}$ & 446.22 & 149.0 & 0.0 & Oil \\
\hline & 66.0 & $\mathrm{NE}$ & 645.84 & 15.0 & 75.8 & Diesel \\
\hline & 67.0 & $\mathrm{NE}$ & 645.84 & 15.0 & 84.7 & Diesel \\
\hline & 68.0 & $\mathrm{NE}$ & 374.8 & 168.0 & 0.0 & Oil \\
\hline & 69.0 & $\mathrm{NE}$ & 645.84 & 13.0 & 7.8 & Diesel \\
\hline & 70.0 & $\mathrm{NE}$ & 599.17 & 147.0 & 0.0 & Oil \\
\hline & 71.0 & $\mathrm{NE}$ & 645.84 & 13.0 & 110.7 & Diesel \\
\hline & 72.0 & $\mathrm{NE}$ & 139.13 & 720.0 & 0.0 & Coal \\
\hline & 73.0 & NE & 149.25 & 365.0 & 0.0 & Coal \\
\hline & 74.0 & $\mathrm{NE}$ & 863.5 & 94.0 & 0.0 & Diesel \\
\hline & 75.0 & NE & 327.22 & 201.0 & 0.0 & Oil \\
\hline & 76.0 & $\mathrm{NE}$ & 657.39 & 136.0 & 0.0 & Oil \\
\hline & 77.0 & $\mathrm{NE}$ & 757.4 & 53.0 & 0.0 & Diesel \\
\hline & 78.0 & $\mathrm{NE}$ & 757.4 & 66.0 & 0.0 & Diesel \\
\hline & 79.0 & $\mathrm{NE}$ & 384.73 & 381.0 & 0.0 & Oil \\
\hline & 80.0 & $\mathrm{NE}$ & 510.12 & 30.0 & 0.0 & Biomass \\
\hline Zz & 81.0 & NE & 279.04 & 186.0 & 0.0 & Gas \\
\hline & 82.0 & $\mathrm{NE}$ & 387.78 & 50.0 & 0.0 & Oil \\
\hline & 83.0 & $\mathrm{NE}$ & 318.53 & 223.0 & 0.0 & Gas \\
\hline & 84.0 & $\mathrm{NE}$ & 863.5 & 143.0 & 0.0 & Diesel \\
\hline & 85.0 & $\mathrm{NE}$ & 393.88 & 171.0 & 0.0 & Oil \\
\hline & 86.0 & $\mathrm{NE}$ & 393.88 & 171.0 & 0.0 & Oil \\
\hline & 87.0 & $\mathrm{NE}$ & 107.04 & 533.0 & 0.0 & Gas \\
\hline & 88.0 & $\mathrm{NE}$ & 314.63 & 368.0 & 0.0 & Gas \\
\hline & 89.0 & $\mathrm{~N}$ & 302.19 & 166.0 & 0.0 & Gas \\
\hline & 90.0 & $\mathrm{~N}$ & 0.0 & 85.0 & 85.7 & Gas \\
\hline & 91.0 & $\mathrm{~N}$ & 794.72 & 40.0 & 0.0 & Diesel \\
\hline & 92.0 & $\mathrm{~N}$ & 808.99 & 40.0 & 0.0 & Diesel \\
\hline & 93.0 & $\mathrm{~N}$ & 392.29 & 166.0 & 0.0 & Oil \\
\hline & 94.0 & $\mathrm{~N}$ & 392.29 & 166.0 & 0.0 & Oil \\
\hline & 95.0 & $\mathrm{~N}$ & 784.21 & 25.0 & 0.0 & Oil \\
\hline & 96.0 & $\mathrm{~N}$ & 0.0 & 75.0 & 83.2 & Gas \\
\hline & 97.0 & $\mathrm{~N}$ & 0.0 & 67.0 & 83.2 & Gas \\
\hline & 98.0 & $\mathrm{~N}$ & 74.91 & 519.0 & 0.0 & Gas \\
\hline & 99.0 & $\mathrm{~N}$ & 118.63 & 338.0 & 0.0 & Gas \\
\hline & 100.0 & $\mathrm{~N}$ & 118.63 & 338.0 & 0.0 & Gas \\
\hline & 101.0 & $\mathrm{~N}$ & 411.92 & 110.0 & 0.0 & Gas \\
\hline & 102.0 & $\mathrm{~N}$ & 575.0 & 150.0 & 0.0 & Oil \\
\hline
\end{tabular}




\begin{tabular}{lccccc}
103.0 & $\mathrm{~N}$ & 203.0 & 178.0 & 0.0 & Gas \\
104.0 & $\mathrm{~N}$ & 88.97 & 56.0 & 0.0 & Gas \\
105.0 & $\mathrm{~N}$ & 0.0 & 66.0 & 0.0 & Gas \\
106.0 & $\mathrm{~N}$ & 144.29 & 360.0 & 0.0 & Coal \\
107.0 & $\mathrm{~N}$ & 898.56 & 50.0 & 0.0 & Diesel \\
108.0 & $\mathrm{~N}$ & 640.96 & 58.0 & 0.0 & Diesel \\
109.0 & $\mathrm{~N}$ & 828.01 & 50.0 & 0.0 & Diesel \\
110.0 & $\mathrm{~N}$ & 0.0 & 255.0 & 233.41 & Waste \\
111.0 & $\mathrm{~N}$ & 0.0 & 93.0 & 83.2 & Gas \\
\hline
\end{tabular}

Demand data:

Tab. A.3: Demand data for case studies from Chapter 5 (MWmonth)

\begin{tabular}{ccccc}
\hline Period (month) & SE & S & NE & N \\
\hline 1 & 40117 & 11127 & 9248 & 4344 \\
2 & 41110 & 11383 & 9020 & 4365 \\
3 & 41221 & 11473 & 9257 & 4502 \\
4 & 40360 & 11114 & 9302 & 4539 \\
5 & 38621 & 10446 & 9049 & 4600 \\
6 & 38079 & 10387 & 8701 & 4578 \\
7 & 38223 & 10291 & 8680 & 4553 \\
8 & 38652 & 10128 & 8492 & 4602 \\
9 & 39095 & 10102 & 8677 & 4620 \\
10 & 39004 & 10151 & 8839 & 4583 \\
11 & 38809 & 10431 & 8862 & 4574 \\
12 & 38770 & 10469 & 8781 & 4517 \\
13 & 40117 & 11127 & 9248 & 4344 \\
14 & 41110 & 11383 & 9020 & 4365 \\
15 & 41221 & 11473 & 9257 & 4502 \\
16 & 40360 & 11114 & 9302 & 4539 \\
17 & 38621 & 10446 & 9049 & 4600 \\
18 & 38079 & 10387 & 8701 & 4578 \\
19 & 38223 & 10291 & 8680 & 4553 \\
20 & 38652 & 10128 & 8492 & 4602 \\
21 & 39095 & 10102 & 8677 & 4620 \\
22 & 39004 & 10151 & 8839 & 4583 \\
23 & 38809 & 10431 & 8862 & 4574 \\
24 & 38770 & 10469 & 8781 & 4517 \\
25 & 40117 & 11127 & 9248 & 4344 \\
26 & 41110 & 11383 & 9020 & 4365 \\
27 & 41221 & 11473 & 9257 & 4502 \\
28 & 40360 & 11114 & 9302 & 4539
\end{tabular}




\begin{tabular}{|c|c|c|c|c|c|}
\hline & 29 & 38621 & 10446 & 9049 & 4600 \\
\hline & 30 & 38079 & 10387 & 8701 & 4578 \\
\hline & 31 & 38223 & 10291 & 8680 & 4553 \\
\hline & 32 & 38652 & 10128 & 8492 & 4602 \\
\hline & 33 & 39095 & 10102 & 8677 & 4620 \\
\hline & 34 & 39004 & 10151 & 8839 & 4583 \\
\hline & 35 & 38809 & 10431 & 8862 & 4574 \\
\hline & 36 & 38770 & 10469 & 8781 & 4517 \\
\hline & 37 & 40117 & 11127 & 9248 & 4344 \\
\hline & 38 & 41110 & 11383 & 9020 & 4365 \\
\hline & 39 & 41221 & 11473 & 9257 & 4502 \\
\hline & 40 & 40360 & 11114 & 9302 & 4539 \\
\hline & 41 & 38621 & 10446 & 9049 & 4600 \\
\hline & 42 & 38079 & 10387 & 8701 & 4578 \\
\hline & 43 & 38223 & 10291 & 8680 & 4553 \\
\hline & 44 & 38652 & 10128 & 8492 & 4602 \\
\hline & 45 & 39095 & 10102 & 8677 & 4620 \\
\hline & 46 & 39004 & 10151 & 8839 & 4583 \\
\hline & 47 & 38809 & 10431 & 8862 & 4574 \\
\hline & 48 & 38770 & 10469 & 8781 & 4517 \\
\hline & 49 & 40117 & 11127 & 9248 & 4344 \\
\hline & 50 & 41110 & 11383 & 9020 & 4365 \\
\hline & 51 & 41221 & 11473 & 9257 & 4502 \\
\hline & 52 & 40360 & 11114 & 9302 & 4539 \\
\hline & 53 & 38621 & 10446 & 9049 & 4600 \\
\hline & 54 & 38079 & 10387 & 8701 & 4578 \\
\hline & 55 & 38223 & 10291 & 8680 & 4553 \\
\hline & 56 & 38652 & 10128 & 8492 & 4602 \\
\hline & 57 & 39095 & 10102 & 8677 & 4620 \\
\hline & 58 & 39004 & 10151 & 8839 & 4583 \\
\hline & 59 & 38809 & 10431 & 8862 & 4574 \\
\hline & 60 & 38770 & 10469 & 8781 & 4517 \\
\hline & 61 & 40117 & 11127 & 9248 & 4344 \\
\hline & 62 & 41110 & 11383 & 9020 & 4365 \\
\hline & 63 & 41221 & 11473 & 9257 & 4502 \\
\hline & 64 & 40360 & 11114 & 9302 & 4539 \\
\hline & 65 & 38621 & 10446 & 9049 & 4600 \\
\hline & 66 & 38079 & 10387 & 8701 & 4578 \\
\hline & 67 & 38223 & 10291 & 8680 & 4553 \\
\hline & 68 & 38652 & 10128 & 8492 & 4602 \\
\hline & 69 & 39095 & 10102 & 8677 & 4620 \\
\hline & 70 & 39004 & 10151 & 8839 & 4583 \\
\hline & 71 & 38809 & 10431 & 8862 & 4574 \\
\hline
\end{tabular}




\begin{tabular}{lllll}
72 & 38770 & 10469 & 8781 & 4517 \\
73 & 40117 & 11127 & 9248 & 4344 \\
74 & 41110 & 11383 & 9020 & 4365 \\
75 & 41221 & 11473 & 9257 & 4502 \\
76 & 40360 & 11114 & 9302 & 4539 \\
77 & 38621 & 10446 & 9049 & 4600 \\
78 & 38079 & 10387 & 8701 & 4578 \\
79 & 38223 & 10291 & 8680 & 4553 \\
80 & 38652 & 10128 & 8492 & 4602 \\
81 & 39095 & 10102 & 8677 & 4620 \\
82 & 39004 & 10151 & 8839 & 4583 \\
83 & 38809 & 10431 & 8862 & 4574 \\
84 & 38770 & 10469 & 8781 & 4517 \\
\hline
\end{tabular}

Ư 